NBER WORKING PAPER SERIES

\title{
JUMP STARTING THE EURO AREA RECOVERY: WOULD A RISE IN CORE FISCAL SPENDING HELP THE PERIPHERY?
}

\author{
Olivier Blanchard \\ Christopher J. Erceg \\ Jesper Lindé \\ Working Paper 21426 \\ http://www.nber.org/papers/w21426 \\ NATIONAL BUREAU OF ECONOMIC RESEARCH \\ 1050 Massachusetts Avenue \\ Cambridge, MA 02138 \\ July 2015
}

We thank Andrew Berg, Martin Eichenbaum, Emmanuel Farhi, Josef Hollmayr, Andrew Levin, Jonathan Parker, Ricardo Reis, Pedro Teles, Harold Uhlig, and Volker Wieland for helpful comments, as well as participants at the CEPR's ESSIM conference, the ECB Public Finance conference, the NBER Summer Institute, the EABCN conference in Cambridge (U.K.), and the 2016 NBER Macroeconomics Annual conference, and at seminars at the Federal Reserve Board, the IMF, the Bank of Portugal, the San Francisco Federal Reserve Bank, the OFCE in Paris, the JRC in Ispra, the University of Glasgow, and the Sveriges Riksbank. We especially thank Mazi Kazemi, Patrick Moran, Aaron Markiewitz, and Sher Singh for providing excellent research assistance. The views expressed in this paper are solely the responsibility of the authors and should not be interpreted as reflecting the views of the IMF, the Riksbank,the Board of Governors of the Federal Reserve System, any other person associated with the Federal Reserve System, or the National Bureau of Economic Research.

NBER working papers are circulated for discussion and comment purposes. They have not been peer-reviewed or been subject to the review by the NBER Board of Directors that accompanies official NBER publications.

(C) 2015 by Olivier Blanchard, Christopher J. Erceg, and Jesper Lindé. All rights reserved. Short sections of text, not to exceed two paragraphs, may be quoted without explicit permission provided that full credit, including $(\odot$ notice, is given to the source. 
Jump Starting the Euro Area Recovery: Would a Rise in Core Fiscal Spending Help the Periphery? Olivier Blanchard, Christopher J. Erceg, and Jesper Lindé

NBER Working Paper No. 21426

July 2015, Revised October 2016

JEL No. E62,F41,F45

\begin{abstract}
$\underline{\text { ABSTRACT }}$
We show that a fiscal expansion by the core economies of the euro area would have a large and positive impact on periphery GDP assuming that policy rates remain low for a prolonged period. Under our preferred model specification, an expansion of core government spending equal to one percent of euro area GDP would boost periphery GDP by over 1 percent in a liquidity trap lasting three years, nearly half as large as the effect on core GDP. Accordingly, under a standard ad hoc loss function involving output and inflation gaps, increasing core spending would generate substantial welfare improvements, especially in the periphery. The benefits are considerably smaller under a utility-based welfare measure, reflecting in part that higher net exports play a material role in raising periphery GDP.

Olivier Blanchard

Peterson Institute for International Economics

1750 Massachusetts Avenue, NW

Washington, DC 20036

and NBER

oblanchard@piie.com

Christopher J. Erceg

The Federal Reserve Board

Mail Stop 20

20th and C Street, N.W.

Washington, D.C. 20551

Christopher.Erceg@frb.gov

Jesper Lindé

Sveriges Riksbank

SE-103 37 Stockholm

Sweden

jesper.1.linde@gmail.com
\end{abstract}




\section{Introduction}

If the euro area were a fiscal union like the United States, there would be a strong case for fiscal expansion: the unemployment rate remains in double digits, inflation has run persistently too low, and monetary policy has limited scope to provide additional stimulus. However, the euro area is not a fiscal union, and fiscal expansion has to be carried out by member states. Given that the periphery economies most likely to benefit from domestic fiscal expansion are constrained from doing because of concerns about high public debt and fiscal solvency, any sizeable fiscal expansion has to come from the euro area's core economies.

In this paper, we analyze the effects of an expansion of fiscal spending in the euro area's core economies. Rather than limiting attention to the effects on the euro area as a whole, we focus on how the stimulative effects would be distributed between core and periphery: Would a core fiscal expansion have sizeable positive "spillovers" to periphery output and inflation, or would the stimulus mostly be limited to those core economies opting to raise public spending? The answer is clearly critical to evaluating potential welfare benefits. Even if core fiscal expansion increased euro area output and inflation, it may not be desirable if it caused core economies to overheat while imparting little positive impetus to the periphery.

The fiscal consolidations that began in 2010 in Greece, Portugal, Ireland, Portugal, and Spain offers some clues about the channels through which a prospective core fiscal expansion might play out. On the one hand, the deep fiscal cuts carried out from 2010 to 2013 had strong adverse effects on the periphery countries' domestic demand, due at least in part to the zero lower bound on monetary policy (Blanchard and Leigh, 2014). On the other hand, the large negative output gaps in those countries led to a decrease in relative price levels, and some improvement in external 
demand. In this vein, Figure 1 illustrates the positive relationship between the average output gap and price inflation for euro area economies in the aftermath of the financial crisis: the high degree of resource slack in countries such as Spain and Portugal, partly driven by massive fiscal consolidation, translated into lower average inflation than in Germany. The euro area's recent experience makes clear that the net result of fiscal consolidation, for both periphery and core countries, depends on the stance of monetary policy and the relevance of the zero lower bound, on the size of the multipliers, on the effect of output gaps on inflation and by implication on relative prices, and on the effect of relative prices on imports and exports.

The same considerations are likely to play a key role in influencing the macroeconomic effects of a rise in core government spending, and suggest the importance of both aggregate (euro-wide) and compositional channels.

From an aggregate perspective, the effects are likely to depend on how strongly monetary policy reacts to the induced rise in euro area output and inflation. Outside of a liquidity trap, the ECB would raise interest rates in real terms, which would dampen private demand in both the core and periphery; and unless periphery net exports rose enough to compensate, periphery GDP would likely fall. But in a liquidity trap, higher core spending boosts inflation in both the core and periphery, and potentially reduces real interest rates enough to provide a significant boost both to periphery and core GDP. From a compositional perspective, while the demand stimulus is likely to affect primarily core countries, the increase in inflation in core relative to periphery countries leads to an increase in core relative prices, and to some reallocation of demand toward periphery countries.

To gauge the strength of the various channels and make an assessment of the likely effects of a core fiscal expansion on core and periphery GDP, we use two variants of a New Keynesian model of a currency union. Our benchmark model is quite simple - extending Gali and Monacelli (2008) 
mainly by adding habit persistence in consumption to get more plausible dynamics - but is useful for pinpointing how the various aggregate and compositional channels shape the response of periphery output. Moreover, the simple structure facilitates showing how key features such as the Phillips Curve slope affect both the aggregate multiplier and spillovers to the periphery. However, we also use a larger-scale DSGE model - which includes price and wage rigidities, endogenous investment, and allows for non-Ricardian consumption behavior - to derive quantitative assessments in a more empirically-realistic setting. Following the general approach of Christiano, Eichenbaum, and Evans (2005) and Altig, Christiano, Eichenbaum, and Linde (2011), we estimate this model by calibrating key parameters to match the empirical responses to both a euro area monetary policy shock and government spending shock.

We find that, outside of a liquidity trap, the effects of higher core government spending on periphery GDP tend to be small and even negative (assuming that the import content of core government spending is low). The small response of periphery GDP reflects that the central bank raises real interest rates, more than offsetting the stimulus arising from a depreciation of the periphery's terms of trade. These results concur with previous research by Wieland (1996) and Kollmann et al (2014) indicating that fiscal spillovers tend to be negative under fixed exchange rates (assuming that the central bank responds according to a standard policy reaction function).

The spillovers to periphery GDP are markedly different in a liquidity trap: Periphery GDP tends to rise, reflecting the weaker interest rate response. The size of the periphery GDP response to a core spending hike increases with the expected duration of the liquidity trap, with the import content of core government spending, and with the responsiveness of inflation. In a relatively short-lived trap lasting only a few quarters, the GDP stimulus to the periphery is small (unless a sizeable fraction of core spending is imported), so that most of the expansionary effects of the fiscal stimulus is confined to the core. However, higher core spending can provide a potent source 
of stimulus to the periphery if monetary policy is expected to be constrained from raising interest rates for a prolonged period of a couple of years or more.

The larger-scale model implies that a rise in core government spending has effects on periphery GDP that are about half as large as on core GDP in a three year liquidity trap; the aggregate euro area multiplier of around 2 seems in line with both model-based analysis suggesting high multipliers in a liquidity trap, and empirical analysis (both of which are reviewed in the next section). The large spillovers to the periphery reflect a combination of factors: higher periphery net exports, lower real interest rates as periphery inflation rises, and Keynesian multiplier effects that boost domestic demand (captured by the hand-to-mouth consumers in our model). But it bears emphasizing that the sizeable spillovers don't hinge on an implausibly large inflation response; though consistent with the empirical responses of inflation to monetary and spending shocks, our model implies an extremely flat Phillips Curve relative to most existing estimates. The Keynesian multiplier effects do play an important role, which seems in line with the substantial crowding in of domestic demand in response to government spending shocks in our empirical VAR, as well as with evidence from the literature on local multipliers (Nakamura and Steinsson 2014 and Acconcia, Corsetti, and Simonelli 2014).

We also use the simple model to conduct normative analysis: one important upshot is the reminder that the output and inflation responses perhaps shouldn't be the sole criteria for judging whether fiscal adjustment is desirable. We consider two alternative welfare metrics, including an ad hoc but standard criterion based on output and inflation gap variability in each region and a utility-based criterion that is based on a population-weighted average of the utility functions of households. Under either criterion, we show that the welfare benefits of core fiscal expansion are smaller than under fiscal union. This is intuitive, and simply reflects that a core-only spending hike delivers the most stimulus to where it is "needed least" insofar as resource slack is much smaller 
than in the periphery. Under fiscal union, more of the expansion could be targeted to the periphery, allowing comparatively large welfare gains. ${ }^{1}$

However, the alternative welfare criteria differ substantially in their assessment of whether a core fiscal expansion would improve welfare in the periphery economies. The ad hoc criterion indicates that an expansion of core spending can elicit large welfare gains in both the core and periphery by shrinking output gaps and increasing inflation closer to target. By contrast, the utility-based criterion cares about whether the fiscal stimulus boosts periphery consumption enough - and in a front-loaded manner - to justify the utility cost of the increased employment. Accordingly, the utility-based measure sees less benefit from core fiscal expansion than the simple ad hoc measure because net exports play a substantive role in reducing the periphery's output gap. In addition, the consumption rise in the periphery is very drawn out, so that much of it occurs when the economy has largely recovered. Our sense is that the utility-based analysis is useful for highlighting that a focus on reducing output and inflation gaps may be too narrow in assessing the merits of fiscal expansion. However, as we argue below, the utility-based measure probably understates the benefits of reducing the output gap and unemployment in economies facing high resource slack.

This paper is organized as follows. Section 2 provides an overview of the literature on fiscal multipliers and spillovers. Section 3 presents the simple benchmark model in log-linearized form, while Section 4 reports impulse responses to a core fiscal expansion with a focus on factors determining spillovers to the periphery. Section 5 considers both the positive and normative effects of alternative fiscal expansion packages against a reasonable baseline for the euro area. Section 6 examines robustness in the larger-scale model, while Section 7 concludes.

\footnotetext{
${ }^{1}$ While our discussion here focuses on the desirability of fiscal expansion in a prolonged liquidity trap, it bears emphasizing that a core fiscal expansion could potentially be counterproductive if monetary policy had latitude to cut interest rates sufficiently. Indeed, the analysis of Gali and Monacelli (2008) suggests that it might be desirable to respond to a contraction in periphery demand by cutting core fiscal spending - thus better aligning business cycles within the $\mathrm{CU}$ - and then cutting interest rates aggressively. While the implication that core consolidation is desirable is perhaps somewhat model-specific, the more general message that core fiscal expansion would not be desirable if monetary policy could do the lifting seems very reasonable.
} 


\section{Brief Overview of the Literature}

From an aggregate perspective, the models we consider are closely related to those of an extensive literature examining fiscal policy in a liquidity trap. This literature shows that the spending multiplier is likely to be substantially larger than in normal times, e.g., Eggertsson (2011), Christiano, Eichenbaum, and Rebelo (2011) and Woodford (2011). The higher multiplier reflects that the central bank does not raise nominal policy rates even though inflation rises, so that real interest rates fall and domestic demand is crowded in. These crowding in effects can be large if inflation is responsive to resource slack. For example, Christiano, Eichenbaum, and Rebelo (2011) showed that the peak multiplier exceeds 2 in a long-lived liquidity trap under their preferred model specification.

A number of empirical papers have corroborated the implication of a large spending multiplier when monetary policy is constrained. Some of this analysis has focused on the Great Depression period given that monetary policy was arguably unreactive to fiscal stimulus during most of that time. Almunia et al. (2010) found a spending multiplier of over 2 using a panel VAR for major industrial economies that is estimated over the interwar period and uses the same identifying assumptions as in Blanchard and Perotti (2002). Gordon and Krenn (2010) estimated a spending multiplier of slightly under 2 for the United States in a narrow window preceding the U.S. entry into World War II. They argue that this is an ideal period for estimating the multiplier given that government spending rose massively (by 13 percent of U.S. GDP between 1940:Q2-1941:Q4), monetary policy was passive, resource slack still large, and tax rates weren’t (yet) adjusted up. They also document a substantial crowding in of private demand.

Blanchard and Leigh (2014) focused on the recent experience of fiscal consolidation in the euro area during the 2010-2012 period. While some analysis suggested that deep spending cuts would exert only a modest drag on output - or possibly even raise output through confidence channels (Alesina and Ardagna 2010) - Blanchard and Leigh showed that fiscal multipliers in euro 
area countries turned out to be much larger than forecast ex ante, implying that fiscal cuts in the periphery had considerably more adverse effects than anticipated. Their estimates suggest a spending multiplier of around 1.5 for the euro area.

Both the theoretical and empirical literature has attempted to identify key factors influencing the size of the aggregate spending multiplier. In addition to the inflation response, the multiplier is larger in a longer-lived liquidity trap, if the bulk of spending occurs when the zero bound constraint is still binding (see the papers by CER and Woodford mentioned above), or if the economy is in a deep recession with substantial excess capacity (Auerbach and Gorodnichenko 2012 and Gordon and Krenn 2010). Moreover, as indicated by Uhlig (2010), Erceg and Linde (2014), and Drautzberg and Uhlig (2015), the tax reaction function can be quite consequential: the spending multiplier can be significantly lower if tax rates are adjusted quickly and if distortionary tax rates account for most of the adjustment. In our analysis, we assume that fiscal stimulus can be implemented fairly quickly, and that taxes are either lump-sum (as in the simple model of Section 3), or that tax rates at least adjust very slowly. The multipliers derived from our simulations would be lower under less favorable assumptions on these dimensions.

Several recent papers have analyzed fiscal spillovers in a liquidity trap in stylized open economy models. The qualitative analysis of Farhi and Werning (2012) shows that the pattern of spillovers flips sign - from negative in normal times when the currency union monetary authority raises interest rates - to positive in a liquidity trap. Other papers, including by Cook and Devereux (2011) and Fujiwara and Ueda (2013), have focused on environments with flexible exchange rates, and have shown that a country expanding fiscal spending is likely to cause its currency to depreciate, potentially generating negative spillovers to its trading partners.

As discussed in the introduction, an empirical implication of the models we consider is that fiscal expansion in core countries should boost periphery real net exports. This implication is consistent 
with Beetsma et al (2006), who used a panel VAR framework to show that expansionary fiscal shocks in European Union economies typically increase the net exports of their trading partners (and conversely for fiscal contractions).

We also draw on the literature estimating "local multipliers" to help assess the empirical plausibility of our model(s) for the differential effects of a rise in core government spending on core versus periphery output. This literature estimates how output is affected in a region that boosts government spending (e.g., a city or state) relative to other regions, and typically finds that relative output - i.e., output in the region experiencing the spending hike - rises by considerably more than the increase in relative government spending (scaled by GDP). For example, Acconcia et al. (2014) estimated a local multiplier of 1.5-1.9 for municipalities in Italy, using as an instrument sudden cuts in municipal public spending triggered by the removal of local city councils (following evidence of mafia-related corruption); while Nakamura and Steinsson (2014) analyzed the effects of changes in defense expenditures concentrated in particular U.S. states, and estimated a local multiplier of 1.5. Although our simple model in the next section constrains the local multiplier to be less than unity, we interpret the estimates of high local multipliers as suggestive of strong Keynesian multiplier channels, and hence build these features into the larger-scale model of Section 6 .

Finally, the Phillips Curve slope plays a paramount role in influencing both the aggregate multiplier, and in determining the size of compositional effects on trade. The extensive empirical literature estimating the Phillips Curve slope - both for the industrial economies, and the euro area in particular - generally points to a low Phillips Curve slope. This includes estimates based on DSGE models (Smets and Wouters, 2003), as well as from single equation models as in Blanchard, Cerutti, and Summers (2015), with the latter highlighting a substantial fall in the Phillips Curve slope in the early 1990s. Even so, it bears emphasizing that these estimates are generally consistent with a noticeable response of inflation to a sustained rise in fiscal spending, as we will show below. 
Moreover, a number of papers suggest that the low estimated slopes partly reflect various forms of misspecification - including e.g., not taking adequate account of how TFP shocks or financial conditions influence marginal cost (Christiano, Eichenbaum, and Trabandt 2015 and Gilchrist, Schoenle, Sim, and Zakrajšek 2015) - and that the actual Phillips Curve slope is considerably higher. Thus, although our own estimates in Section 6 imply a low Phillips Curve slope, and we embed a low slope in the baseline calibration of our models, we also consider the implications of a higher slope.

\section{The Benchmark Open Economy Model}

Our benchmark model is comprised of two countries that may differ in population size. Households are infinitely-lived, derive utility from consumption and leisure, and make consumption decisions based on their permanent income. Monopolistically competitive firms are subject to Calvo-style pricing frictions, so that nominal prices adjust sluggishly. Similar to Gali and Monacelli (2008), our model assumes that financial markets are complete both domestically and internationally, and that producers set the same price in both the home and foreign market (producer currency pricing). We generalize the Gali and Monacelli model by allowing for habit persistence in consumption, and by assuming that some fraction of government consumption may be imported.

Given the symmetric structure across countries, we look at the home country: the same equations and calibration apply to the foreign country (aside from population size). Our formulation below highlights how the model can be decomposed into two parts. The first part, which determines the equilibrium for the currency union $(\mathrm{CU})$ as a whole, is completely standard. The familiar three equations - the New Keynesian IS curve, the AS curve, and the policy reaction function determine aggregate CU output, inflation, and policy rates, respectively; and per usual, a core fiscal expansion boosts $\mathrm{CU}$ output and inflation. The second part involves characterizing the difference 
between the response of periphery and core variables. These differences depend exclusively on the terms of trade and exogenous shocks, including to fiscal policy. Importantly, monetary policy only affects the core and periphery through its effects on the $\mathrm{CU}$ as a whole, but does not influence the terms of trade, or the differences between the responses of periphery and core variables. ${ }^{2}$

Our discussion below focuses on the log-linearized equations of the model; a full description of the underlying model structure is provided in Appendix A.

\subsection{The Log-Linearized Benchmark Model}

Consumption demand in each economy is determined by the consumption Euler equation condition, which for the home economy is given by:

$$
\lambda_{c t}=\lambda_{c t+1 \mid t}+i_{t}^{C U}-\pi_{c t+1 \mid t}
$$

where $i_{t}^{C U}$ is the policy rate of the central bank in the currency union $(\mathrm{CU}), \pi_{c t}$ is consumer price inflation in the home economy, and $\lambda_{c t}$ is the marginal utility of consumption:

$$
\lambda_{c t}=-\frac{1}{\widehat{\sigma}}\left(c_{t}-\varkappa c_{t-1}-\nu \nu_{t}\right)
$$

The marginal utility of consumption varies inversely with current consumption $c_{t}$, but rises with past consumption due to habit persistence. Taken together, these equations imply that consumption falls in response to higher real interest rates, with the sensitivity depending on intertemporal elasticity in substitution parameter $\widehat{\sigma}=\sigma(1-\varkappa-\nu)$. The preference shock $\nu_{t}$ boosts consumption demand at any given interest rate. ${ }^{3}$ Given that households are infinitely-lived and taxes are lump-sum, the manner in which changes in government spending are financed has no effect on consumption decisions.

\footnotetext{
2 This decomposition depends importantly on our assumption of a symmetric structure across countries, including in the calibration of structural parameters.

${ }^{3}$ While our model also allows for discount factor shocks, these shocks have been omitted from the description of the log-linearized equations. The discount factor shock boosts consumption demand, but has no effect on potential output or labor supply.
} 
Consumption demand in the $\mathrm{CU}$ as a whole is determined as a population-weighted average of the demand of the home and foreign economies (with weights $\zeta$ and $\zeta^{*}$, respectively). Imposing the aggregate resource constraints which equate $\mathrm{CU}$ consumption $c_{t}^{C U}$ to $\mathrm{CU}$ output $y_{t}^{C U}$ less government spending $g_{t}^{C U}$ (i.e., $c_{y} c_{t}^{C U}=y_{t}^{C U}-g_{y} g_{t}^{C U}$ ) and CPI inflation in each country to CU inflation $\pi_{t}^{C U}\left(\zeta \pi_{C t}+\zeta^{*} \pi_{C t}^{*}=\pi_{t}^{C U}\right)$, aggregate demand in the CU may be expressed in terms of a familiar New Keynesian IS curve:

$$
x_{t}^{C U}=\frac{1}{1+\varkappa} x_{t+1 \mid t}^{C U}+\frac{\varkappa}{1+\varkappa} x_{t-1}^{C U}-c_{y} \widehat{\sigma}\left(i_{t}^{C U}-\pi_{t+1 \mid t}^{C U}-r_{t}^{C U, p o t}\right),
$$

where $c_{y}$ denotes the consumption-output ratio in steady state, and $g_{y}$ is the government spending share. As seen from eq. (3), the CU output gap $x_{t}^{C U}$ depends both on past and future output gaps, and inversely on the difference between the real policy rate in the $\mathrm{CU} i_{t}^{C U}-\pi_{t+1 \mid t}^{C U}$ and its potential or "natural" rate of $r_{t}^{C U, p o t} 4$

On the aggregate supply side, the inflation rate of domestically-produced goods in each country is determined by a New Keynesian Phillips Curve. Thus, the home inflation rate $\pi_{D t}$ depends both on the current marginal cost of production $m c_{t}$ and future expected inflation:

$$
\pi_{D t}=\beta \pi_{D t+1 \mid t}+\kappa_{m c} m c_{t} .
$$

The subscript " $D$ " on inflation is used to distinguish the inflation rate on domestically-produced goods $\pi_{D t}$ from the consumer price inflation rate $\pi_{C t}$. Given our assumption of monopolistically competitive producers and Calvo-style staggered price contracts, the parameter $\kappa_{m c}$ determining the sensitivity of inflation to marginal cost $m c_{t}$ depends on the mean price contract duration $\frac{1}{1-\xi_{P}}$ according to $\kappa_{m c}=\frac{\left(1-\xi_{P}\right)\left(1-\beta \xi_{P}\right)}{\xi_{P}}$. Thus, longer-lived price contracts flatten the slope of the Phillips Curve. Marginal cost in turn depends on the gap between the product real wage $\mathrm{w}_{t}^{r}$ and

\footnotetext{
4 As we discuss below, government spending shocks affect output both through influencing the potential real interest rate and potential output.
} 
the marginal product of labor $m p l_{t}$ :

$$
m c_{t}=w_{t}^{r}-m p l_{t}=\left[\chi n_{t}-\lambda_{c t}+\omega_{c} \tau_{t}\right]+\alpha n_{t}-(1-\alpha) z_{t} .
$$

The effects on marginal cost associated with fluctuations in the product real wage are captured by the term in brackets. Because wages are fully flexible, the product real wage rises in response to an increase in work hours $n_{t}$ ( $\chi$ is the inverse Frisch elasticity), a fall in the marginal utility of consumption $\lambda_{c t}$ (reflecting a wealth effect), or to a depreciation of the terms of trade $\tau_{t}$. Marginal costs also rise in response to factors which reduce the marginal product of labor, including a rise in hours work (with sensitivity $\alpha$ ), or decline in technology $z_{t}$.

Aggregate CU inflation is determined as a population-weighted average of equation (4):

$$
\pi_{t}^{C U}=\beta \pi_{t+1 \mid t}^{C U}+\kappa_{m c} m c_{t}^{C U}
$$

Using the production function to substitute for hours in terms of output, CU marginal cost can be expressed solely in terms of the CU output gap and its lag (with the latter reflecting the effect of habit persistence in consumption on labor supply). Thus, the New Keynesian Phillips Curve for $\mathrm{CU}$ inflation is given by:

$$
\pi_{t}^{C U}=\beta \pi_{t+1 \mid t}^{C U}+\kappa_{m c}\left[\phi_{x} x_{t}^{C U}+\frac{1}{c_{y} \widehat{\sigma}}\left(x_{t}^{C U}-\varkappa x_{t-1}^{C U}\right)\right]
$$

where the composite parameter $\phi_{x}=\frac{\alpha+\chi}{1-a}$ captures the influence of diminishing returns and the disutility of working, and $\frac{1}{c_{y} \widehat{\sigma}}$ the wealth effect on labor supply.

The currency union central bank is assumed to adhere to a Taylor-type policy rule subject to the ZLB of the form:

$$
i_{t}^{C U}=\max \left(-i, \psi_{\pi} \pi_{t}^{C U}+\psi_{x} x_{t}^{C U}\right)
$$

Thus, outside of a liquidity trap, the policy rate $i_{t}^{C U}$ rises in response to an increase in the CU inflation rate $\pi_{t}^{C U}$ or expansion in the CU output gap $x_{t}^{C U}$. Because the policy rate is measured 
as a deviation from the steady state nominal interest rate $i$ - the sum of the steady state interest rate $r$ and inflation rate $\pi$ - the zero bound constraint becomes binding only when the policy rate falls below $-i$. The CU output gap $x_{t}^{C U}$ is the difference between currency union output $y_{t}^{C U}$ and its potential level $y_{t}^{C U, p o t}$, with both variables again simply population-weighted averages of the respective country variables.

Both the potential output measure $y_{t}^{C U, p o t}$ relevant for the CU output gap $\left(x_{t}^{C U}=y_{t}^{C U}-\right.$ $y_{t}^{C U, p o t}$ ) and the potential real rate $r_{t}^{C U, p o t}$ depend only on population-weighted averages of the underlying shocks and lags of $y_{t}^{C U, p o t}$ (due to habit persistence). For example, abstracting from habit persistence for expositional simplicity, CU potential output is given by:

$$
y_{t}^{C U, p o t}=\Theta\left(g_{y} g_{t}^{C U}+\nu\left(1-g_{y}\right) \nu_{t}^{C U}+\left(1-g_{y}\right)(1+\chi) z_{t}^{C U}\right)
$$

where $\Theta=\frac{1}{\widehat{\sigma}\left(1-g_{y}\right) \phi_{x}+1}<1$, while the potential real interest rate may be expressed as: ${ }^{5}$

$$
r_{t}^{C U, p o t}=(1-\rho)\left(\frac{(1-\Theta)}{1-g_{y}} g_{y} g_{t}^{C U}+\nu \nu_{t}^{C U}+(1+\chi) z_{t}^{C U}\right)
$$

A rise in average $\mathrm{CU}$ government spending $g_{t}^{C U}$ has the same positive effect on currency union potential output and the potential real interest rate $r_{t}^{C U, p o t}$ irrespective of how it is distributed across the member states (as does the preference shock $\nu_{t}^{C U}$ and technology shock $z_{t}^{C U}$ ). This result rests on our assumption of a symmetric structure across the home and foreign economy, aside from population size and home bias in trade.

Our formulation highlights how a core fiscal expansion can be thought of as partly operating through aggregate channels - boosting euro area inflation, the output gap, and possibly the policy rate. Given the simple equation structure implied by the IS curve (3), the Phillips Curve (7), and the CU policy rule (8), the fiscal expansion has exactly the same effects on aggregate variables

\footnotetext{
${ }^{5}$ This expression assumes that the government spending, consumption taste, and technology shocks all follow $\operatorname{AR}(1)$ processes with common persistence parameter $\rho$.
} 
(including $x_{t}^{C U}, \pi_{t}^{C U}$, and $i_{t}^{C U}$ ) as in a similarly calibrated closed economy model. Of course, in addition to the aggregate impact, we are also interested in how the effects of core fiscal stimulus would be distributed between the periphery and core. Accordingly, we next solve for the differences in the responses between the home and foreign economy. This approach allows us to solve the model in a way that sheds light on the question of why the stimulus has a differential impact on each economy.

The resource constraint implies that home output $y_{D t}$ may be expressed as a weighted average of consumption $c_{t}$, government spending $g_{t}$, and "net exports" $n x_{t}$, which are the the difference between exports $m_{t}^{*}$ and imports $m_{t}$ scaled by the trade share of GDP:

$$
y_{D t}=c_{y} c_{t}+g_{y} g_{t}+n x_{t},
$$

Net exports in turn depend on the percentage difference between exports and imports of each type of tradable good, including private consumption goods (i.e., $m_{c t}^{*}-m_{c t}$ ) and government goods/services $\left(m_{g t}^{*}-m_{g t}\right):$

$$
n x_{t}=\omega_{c y}\left(m_{c t}^{*}-m_{c t}\right)+\omega_{g y}\left(m_{g t}^{*}-m_{g t}\right)
$$

Each component is weighted by its respective GDP share (i.e. $\omega_{c y}=\omega_{C} \times \frac{C}{Y}$ and $\omega_{g y}=\omega_{G} \times \frac{G}{Y}$ ). Net exports of either type of tradeable rise if home goods become relatively cheaper - that is, the home terms of trade $\tau_{t}$ depreciates - or if foreign demand rises relative to home demand. Thus:

$$
\begin{aligned}
& m_{c t}^{*}-m_{c t}=c_{t}^{*}-c_{t}+\epsilon_{c} \tau_{t}, \\
& m_{g t}^{*}-m_{g t}=g_{t}^{*}-g_{t}+\epsilon_{g} \tau_{t} .
\end{aligned}
$$

The parameters $\epsilon_{c}$ and $\epsilon_{g}$ capture the sensitivity of each component of real net exports to the terms of trade and may differ between consumption and government goods. ${ }^{6}$

\footnotetext{
${ }^{6}$ In terms of the model parameters, we have $\epsilon_{c}=\left(\frac{\left(1+\rho_{C}\right)}{\rho_{C}}\left(2-\omega_{C}^{*}-\omega_{C}\right)-1\right)$ and $\epsilon_{g}=$ $\left(\frac{\left(1+\rho_{G}\right)}{\rho_{G}}\left(2-\omega_{G}^{*}-\omega_{G}\right)-1\right)$, where $\frac{\left(1+\rho_{C}\right)}{\rho_{C}}$ is (the absolute value of) the price elasticity of demand between domestically-produced and imported private consumption goods, and $\frac{\left(1+\rho_{G}\right)}{\rho_{G}}$ the corresponding price elasticity of demand for government goods and services.
} 
Using the home resource constraint and its analogue for the foreign economy, the difference between home and foreign GDP may be expressed:

$$
\begin{aligned}
y_{D t}-y_{D t}^{*} & =g_{y}\left(g_{t}-g_{t}^{*}\right)+c_{y}\left(c_{t}-c_{t}^{*}\right)+\left(n x_{t}-n x_{t}^{*}\right) \\
& =g_{y}\left(1-\omega_{g}-\omega_{g}^{*}\right)\left(g_{t}-g_{t}^{*}\right)+\epsilon \tau_{t}+c_{y}\left(1-\omega_{c}-\omega_{c}^{*}\right)\left(c_{t}-c_{t}^{*}\right) .
\end{aligned}
$$

This equation says that home relative output $y_{D t}-y_{D t}^{*}$ depends on three factors - home relative government spending, the terms of trade, and home relative consumption - and is very useful for considering how a rise in foreign government spending $g_{t}^{*}$ (identified with higher core spending below) affects the composition of aggegate demand across the home and foreign economy. Specifically, the "direct" effect of a rise in foreign government spending of one percentage point of baseline GDP $g_{y} g_{t}^{*}$ is to reduce home relative output by $\left(1-\omega_{g}-\omega_{g}^{*}\right)$ percent, with the smaller-than-unity response reflecting that some government spending may be imported. We call this the "direct" effect because it holds relative prices (i.e., the terms of trade) constant. The latter two terms capture the strength of the rebalancing channel, and both vary positively with the terms of trade. In particular, the term $\epsilon \tau_{t}$ captures how the home country's terms of trade depreciation - which would be expected following a rise in foreign government spending - shifts some demand toward the home country through a net exports channel. The responsiveness coefficient $\epsilon$ is a weighted average of the import price sensitivity of private consumption and government services (i.e., $\epsilon=$ $\left.c_{y}\left(\omega_{C}+\omega_{C}^{*}\right) \epsilon_{c}+g_{y}\left(\omega_{G}+\omega_{G}^{*}\right) \epsilon_{g}\right)$. Moreover, home relative consumption $c_{t}-c_{t}^{*}$ also varies positively with the terms of trade through the complete markets risk-sharing condition (16) below, and thus also contributes to rebalancing:

$$
c_{t}-c_{t}^{*}=\varkappa\left(c_{t-1}-c_{t-1}^{*}\right)+\widehat{\sigma}\left(1-\omega_{C}-\omega_{C}^{*}\right) \tau_{t}+\frac{1}{\sigma}\left(\nu_{t}-\nu_{t}^{*}\right) .
$$

It may seem surprising that home relative consumption rises in response to the foreign government spending shock. To provide more intuition for why this occurs in the benchmark model, it 
is helpful to draw on the consumption Euler equations to link the consumption differential to the long-term real interest rate differentials in each economy:

$$
c_{t}-c_{t}^{*}=\varkappa\left(c_{t-1}-c_{t-1}^{*}\right)-\widehat{\sigma}\left(1-\omega_{C}-\omega_{C}^{*}\right)\left(r_{L t}-r_{L t}^{*}\right)+\frac{1}{\sigma}\left(\nu_{t}-\nu_{t}^{*}\right) .
$$

where the long-term real interest rate differential $\left(r_{L t}-r_{L t}^{*}\right)$ may in turn be expressed either in terms of future short-term real interest rates, or in terms of expected inflation differentials:

$$
r_{L t}-r_{L t}^{*}=\mathrm{E}_{t} \sum_{j=0}^{\infty}\left(r_{t+j}-r_{t+j}^{*}\right)=-\mathrm{E}_{t} \sum_{j=1}^{\infty}\left(\pi_{D t+j}-\pi_{D t+j}^{*}\right),
$$

A foreign government spending hike initially causes foreign inflation to rise relative to home inflation, implying that the home terms of trade depreciates. But for relative prices to converge in the long-run - as they must given that the government spending shock is stationary - long-run expected inflation in the home country must exceed long-run expected inflation abroad (i.e., $\mathrm{E}_{t} \sum_{j=1}^{\infty} \pi_{D t+j}$ $>\mathrm{E}_{t} \sum_{j=1}^{\infty} \pi_{D t+j}^{*}$ in equation (18)), implying that expected long-run real interest rates fall at home relative to abroad. ${ }^{7}$ Since it is the long-run real interest rate response that matters for consumption in the benchmark model, equation (17) implies that periphery relative consumption rises relative to foreign consumption (concurring with equation (16)).

Relative price convergence plays a key role in accounting for large output spillovers to the periphery following an expansion of foreign government spending in a liquidity trap. It is important to point out that the implication that home relative consumption rises in response to higher foreign government spending is somewhat model-specific, and in particular, reflects the dependence of consumption on the long-term real interest rate in the New Keynesian model; as we will show in Section 6, home relative consumption may decline if consumption depends more on current income due to "hand-to-mouth" consumption behavior, or if it depends more on the short-term real interest rate. Thus, the key implications about spillovers that we develop in the next section should not be

\footnotetext{
${ }^{7}$ Because the price level immediately jumps in the core when government spending increases (while rising less or falling in the periphery), the rise in the price level going forward (i.e., long-run expected inflation) must be higher in the periphery.
} 
regarded as hinging on the response of relative consumption; what matters instead is that foreign government spending has a big enough effect on home inflation and real interest rates - including through the expectation that relative prices will eventually converge - that home consumption is affected significantly.

Turning to the home price-setting equation (4) and its foreign counterpart, it follows inflation differentials between the home and foreign economy depend on the difference between home and foreign marginal costs:

$$
\pi_{D t}-\pi_{D t}^{*}=\beta\left(\pi_{D t+1 \mid t}-\pi_{D t+1 \mid t}^{*}\right)+\kappa_{m c}\left(m c_{t}-m c_{t}^{*}\right) .
$$

Relative marginal costs - using equation (5) and its foreign analogue - may be expressed:

$$
m c_{t}-m c_{t}^{*}=\frac{\alpha+\chi}{1-\alpha}\left(y_{D t}-y_{D t}^{*}\right)+\tau_{t}-(1+\chi)\left(z_{t}-z_{t}^{*}\right) .
$$

Relative marginal cost depends on relative output $y_{D t}-y_{D t}^{*}$, the terms of trade, and on exogenous productivity differentials between the home and foreign economy.consumption. ${ }^{8} \mathrm{~A}$ rise in home relative demand boosts home relative marginal costs as wages rise more at home, and because of diminishing marginal returns to production; conversely, the rise in foreign government spending we focus on below causes foreign relative marginal costs to increase. As noted above, relative demand can be expressed exclusively as a function of the terms of trade and exogenous shocks (given complete markets). ${ }^{9}$

Since inflation differences between the home and foreign economy vary inversely with terms of trade growth according to $\pi_{D t}-\pi_{D t}^{*}=-\left(\tau_{t}-\tau_{t-1}\right)$ (see equation A.19 in the Appendix), the solution for the inflation differential in equation (19) implies that the terms of trade evolves

\footnotetext{
${ }^{8}$ While this expression abstracts from habit for convenience, relative marginal cost also depends on lagged output gaps.

9 There is also an additional role for the terms of trade to affect marginal costs - captured by the middle term of equation (20) - which reflects that a terms of trade depreciation, by increasing home relative consumption, raises home relative marginal costs through a wealth effect on wages.
} 
according to:

$$
\left(\tau_{t}-\tau_{t-1}\right)=\beta\left(\tau_{t+1 \mid t}-\tau_{t}\right)-\kappa_{m c}\left(m c_{t}-m c_{t}^{*}\right)
$$

From an intuitive perspective, a rise in foreign fiscal spending $g_{t}^{*}$ initially increases aggregate demand by relatively more abroad (as seen from equation 15a). This boosts relative marginal production costs abroad, which causes the home terms of trade to depreciate (from equation $21, m c_{t}^{*}>m c_{t}$, so that $\tau_{t}$ rises). The terms of trade depreciation helps rebalance some of the expansion in aggregate demand towards the home economy. As can be seen by reformulating equation (21), the home terms of trade continues to depreciate (i.e., $\Delta \tau_{t}>0$ ) as long as the terms of trade remains below its flexible price level $\tau_{t}^{\text {pot }}$ (in discounted present value):

$$
\left(\tau_{t}-\tau_{t-1}\right)=\beta\left(\tau_{t+1 \mid t}-\tau_{t}\right)+\kappa_{m c} \phi_{m c}\left(\tau_{t}^{p o t}-\tau_{t}\right)
$$

This expression abstracts from habit persistence for expositional convenience. ${ }^{10}$

Equation (15a) underscores that the terms of trade simply evolves as an autonomous difference equation. Thus, the evolution of the terms of trade does not depend on CU monetary policy, or whether the currency union is in a liquidity trap. Because relative output levels, relative inflation rates, and relative consumption levels also only depend on the terms of trade, monetary policy has no effect on these variables: it can only operate through effects that are felt uniformly across the currency union members. ${ }^{11}$

\subsection{Calibration}

We calibrate our model at quarterly frequency, and assume a symmetric calibration for each country block aside from differences in trade intensities (due to different population sizes). While many

\footnotetext{
${ }^{10}$ The parameter $\phi_{m c}$ captures the reduced form sensitivity of marginal cost to the terms of trade gap. Even with habit persistence, the terms of trade can be represented as a function only of the terms of trade gap (as a third order difference equation).

${ }^{11}$ Moreover, given that we have solved for both aggregate CU variables and corresponding cross-country differences, country-specific variables may be solved for by the relevant identifies. For example, given that aggregate CU output is defined as $y_{t}^{C U}=\zeta y_{D t}+\zeta^{*} y_{D t}^{*}$, output of the home country may be solved for as $y_{D t}=y_{t}^{C U}+(1-\zeta) y_{t}^{d}$, where $y_{t}^{d}=y_{D t}-y_{D t}^{*}$; and foreign output is given by $y_{D t}^{*}=y_{t}^{C U}-\zeta y_{t}^{d}$.
} 
aspects of our calibration are standard, two classes of parameters - including those which govern the responsiveness of inflation, and those which influence trade flows - deserve particular emphasis.

The degree to which inflation responds to marginal cost is the key determinant of both the aggregate response of $\mathrm{CU}$ inflation and output, and of the terms of trade response. Smets and Wouters (2003) reported a Phillips Curve slope of $\kappa_{m c}=0.009$ based on estimating a DSGE model using euro area data, which implies a mean price contract duration of 10 quarters $\left(\xi_{p}=0.9\right)$. The estimated slope of $\kappa_{m c}=0.0034$ that we report in Section 6 - when using the larger scale model to fit the responses of empirical VARs to euro area monetary policy and government spending shocks - implies even more sluggish price adjustment. ${ }^{12}$

The response of relative prices in the euro area also seems consistent with a very flat Phillips Curve. Although Figure 1 shows that inflation has run noticeably lower in the periphery than in the core since the financial crisis, the difference in inflation rates - and implied adjustment in the terms of trade - seems quite modest in light of the much higher level of resource slack in periphery economies. ${ }^{13}$ The upper panel of Figure 2 considers the relationship between the periphery terms of trade and (periphery) relative marginal costs more directly. While the periphery's terms of trade have deteriorated $\left(\Delta \tau_{t}>0\right)$ since 2009 (the solid line) as periphery relative marginal costs $m c_{t}-m c_{t}^{*}$ have declined (the dotted line, where relative labor shares proxy for marginal cost differentials), the sensitivity appears quite low. As seen in the bottom panel, a simple OLS regression of $\left(\tau_{t}-\tau_{t-1}\right)-\beta\left(\tau_{t+1 \mid t}-\tau_{t}\right)$ (vertical axis) against $m c_{t}-m c_{t}^{*}$ (horizontal axis) as implied by equation (21) yields a slope estimate of $\kappa_{m c}=0.006$.

Based on these considerations, we set $\kappa_{m c}=0.005$ (consistent with $\xi_{p}=0.93$ ), which implies very sluggish price adjustment. Even so, we recognize that there is considerable uncertainty

\footnotetext{
12 A low Phillips Curve slope in the same range also helps to yield plausible inflation responses in the model following a "Great Recession-sized" shock that generates a large and persistent output gap (as shown below).

${ }^{13}$ The unemployment rate in the periphery remained in the high teens (levels typically associated with an economic depression) through most of the 2012-2014 period, over twice the unemployment rate in core economies.
} 
about the Phillips Curve slope. Most of the extensive literature estimating the Phillips Curve slope for the industrial countries using pre-financial crisis data reported estimates in the range of $\kappa_{m c}=0.009-0.014$, well above our benchmark setting. ${ }^{14}$ As noted in Section 2, some recent research argues that the low estimated slopes may partly reflect various forms of model misspecification (Christiano, Eichenbaum, and Trabandt 2014 and Gilchrist, Schoenle, Sim, and Zakrajšek 2015). With this in mind, we also consider the implications of a higher Phillips Curve slope in our simulations below.

The second key group of parameters are those determining the responsiveness of trade flows as a share of domestic output, including the import share of private (consumption) spending $\omega_{C}$, of public spending $\omega_{G}$, and the trade price elasticity of each of these components $\left(\epsilon_{c}\right.$ and $\epsilon_{g}$, respectively). Ceteris paribus, a higher trade share or higher trade price elasticity amplifies the "leakage" associated with a core fiscal expansion to the periphery, and thus should push in the direction of more balanced effects across regions. Trade data from Eurostat for Spain and Italy indicate an average import/GDP ratio of those economies of about 22 percent in $2007 .{ }^{15}$ In calibrating the trade share in our two country framework, a notable complication involves how to treat periphery trade with non-EU members: periphery imports are closer to $14-15$ percent of GDP if all non-EU trade is excluded from our computation. We assume an import share of 15 percent of GDP for the periphery in our baseline and hence effectively exclude non-EU trade, but recognize that the effects of a core fiscal expansion in reality would depend on how the periphery's real exchange rate varied relative to non-EU trading partners. ${ }^{16}$ Given that periphery GDP is

\footnotetext{
${ }^{14}$ The median estimates of the Phillips Curve slope in empirical studies by e.g. Adolfson et al (2005), Altig et al. (2011), Galí and Gertler (1999), Galí, Gertler, and López-Salido (2001), Lindé (2005), and Smets and Wouters (2003, 2007) are in this range. As we discuss in Section 6, some recent estimates based on U.S. data point to a very flat slope closer to our benchmark calibration.

${ }^{15}$ This computation excludes their trade with each other (so as to effectively treat them as a single country as in the model).

${ }^{16}$ If the ECB was unconstrained by the ZLB, the ECB would tighten policy in response to higher core spending, and the euro would appreciate; however, in a deep liquidity trap, the euro (and hence periphery exchange rate) could well depreciate as real interest rates declined.
} 
about half of that of the core euro area countries, we set the country size parameters $\zeta=1 / 3$ and $\zeta^{*}=2 / 3$; accordingly, balanced trade implies a trade share of 7.5 percent of GDP for the core.

Our model requires parsing this import share of GDP into private and public spending components. We set $\omega_{G}^{*}=\omega_{G}=0$ under our benchmark, and then consider $\omega_{G}^{*}=0.2$ (implying $\omega_{G}$ $=0.4)$ as a high side alternative. Under the benchmark with $\omega_{G}=\omega_{G}^{*}=0$, the import share of private consumption is 20 percent in the periphery and 10 percent in the core (i.e., $\omega_{C}=0.2$ and $\left.\omega_{C}^{*}=0.1\right) .{ }^{17}$ The trade price elasticity for both private consumption and government spending is assumed to be slightly above unity (1.1), consistent with estimates from the macro literature on trade price elasticities.

The calibration of remaining parameters is fairly standard. The discount factor of $\beta=0.99875$ implies a steady state real interest rate of 0.5 percent (at an annualized rate). With a steady state inflation rate of 2 percent (i.e., $\pi=.005$ ), the steady state nominal interest rate is 2.5 percent (i.e., $i=.00625$ at a quarterly rate). We set the intertemporal substitution elasticity $\sigma=1$, which is consistent with log utility over consumption. ${ }^{18}$ The habit parameter $\varkappa$ is set to 0.8 . This value is on the higher side of the range of estimates in the empirical literature, but helps our model generate a fairly plausible path for the aggregate spending multiplier, even if somewhat lower than estimated by e.g., Blanchard and Perotti (2002). The Frisch elasticity of labor supply of $\frac{1}{\chi}=0.4$ and capital share of $\alpha=0.3$ are in the typical range specified in the literature. The government share of steady state output is set to 23 percent $\left(g_{y}=0.23\right)$, which is in line with the average government spending share of GDP in the euro area in recent years.

Our benchmark model assumes that the currency union central bank follows a Taylor-rule in equation (A.27) that is somewhat more aggressive on inflation than a standard Taylor rule, and

\footnotetext{
17 The sizeable disparity between the import share of consumption and that of GDP reflects that nearly a quarter of output is devoted to government spending.

18 The scale parameter on the consumption taste shock $\nu$ is set to 0.01 (this parameter is set to have a negligible impact on model dynamics).
} 
thus sets $\psi_{\pi}=2.5$, and $\psi_{x}=0.125$.

\section{Impulse Response to Higher Core Government Spending}

Figure 3 examines the effects of a positive shock to core government spending that is scaled to equal one percent of CU baseline GDP (i.e., 1.5 percent of core GDP). The government spending hike is assumed to last 10 quarters, after which spending returns to its baseline level; this spending path is captured by an $\mathrm{MA}(10)$ in our scenarios.

We begin by considering impulse responses in normal times in which monetary policy is unconstrained by the zero lower bound. These responses are shown in the left column of Figure 3. From an aggregate perspective, the higher core spending boosts CU output (the solid line in panel A), CU inflation (panel C), and induces the central bank to raise the policy rate (panel E). Output rises well above potential (not shown) because the Taylor rule implies that real interest rates increase by somewhat less than the potential real rate (recalling equation 3); the positive output gap in turn boosts inflation. The CU output multiplier is less than unity due to some crowding out of private consumption, though habit persistence dampens these crowding-out effects, and hence raises the spending multiplier relative to a specification abstracting from habit. As discussed above, these effects on the CU are identical to those that would obtain in a closed economy model.

Turning to the compositional effects across core and periphery, it is evident that the stimulus to real GDP is confined exclusively to the core. While core output (dash-dotted line in panel A) rises more than 1 percent above baseline for the duration of the spending hike - consistent with a average spending multiplier of about 0.8 - periphery output (the dashed line) contracts modestly in the short-run. The relatively large increase in core GDP causes core inflation to run above periphery inflation for some time, and the implied depreciation of the periphery's terms of trade (the dashed line in panel E) boosts periphery real net exports. However, because the rise in core 
government spending triggers a sharp rise in real interest rates, the stimulus to periphery GDP from higher real net exports is swamped by a fall in periphery consumption.

To shed more light on why the output effects of core spending hikes are strongly tilted towards the core, it is useful to recall how relative aggregate demand $y_{D t}-y_{D t}^{*}$ is affected by core government spending (from equation 15a)):

$$
y_{D t}-y_{D t}^{*}=g_{y}\left(1-\omega_{g}-\omega_{g}^{*}\right)\left(g_{t}-g_{t}^{*}\right)+\epsilon \tau_{t}+c_{y}\left(1-\omega_{c}-\omega_{c}^{*}\right)\left(c_{t}-c_{t}^{*}\right)
$$

With the import share of government spending set to zero $\left(\omega_{g}=\omega_{g}^{*}=0\right)$, a 1.5 percent of GDP rise in core government spending (i.e., $g_{y} g_{t}^{*}=.015$ ) would cause periphery relative demand $y_{D t}-y_{D t}^{*}$ to fall by a commensurate amount if the terms of trade $\tau_{t}$ remained unchanged, reflecting that in this case neither relative consumption $c_{t}-c_{t}^{*}$ nor relative trade flows (captured by the term $\epsilon \tau_{t}$ ) would adjust. Given sluggish price adjustment, the terms of trade in fact changes very little in the nearterm, which accounts for why core output in fact rises nearly 1.5 percent above periphery output (panel A) immediately following the shock. Subsequently, the gap between core and periphery output narrows as terms of trade depreciation (panel E) boosts periphery real net exports while causing core real net exports to contract, and also induces periphery consumption to rise relative to core consumption. ${ }^{19}$

Even so, the figure shows that this "rebalancing" towards the periphery isn't particularly large over the period in which the fiscal expansion remains in force. The adjustment coming from relative trade flows $\epsilon \tau_{t}$ is quite modest because sluggish price adjustment damps the movements in the terms of trade (panel $\mathrm{F}$ shows that the depreciation peaks at only 0.7 percent), and because the trade responsiveness parameter $\epsilon$ is fairly small (around 0.3) given observed trade shares and our calibration of trade price elasticities of around unity. ${ }^{20}$ Similarly, periphery consumption rises

\footnotetext{
${ }^{19}$ Our model constrains the "local currency multiplier" to be less than unity (as the 1.5 percent of GDP rise in core spending relative to periphery spending causes core output to rise by less than 1.5 percent relative to periphery output). The model of Section 6 includes hand to mouth agents that allow the local currency multiplier to be considerably larger, and closer to the empirical estimates mentioned in Section 2.

${ }^{20}$ Only about one quarter of the 1.5 percent "autonomous" shift in demand towards the core is offset by relative
} 
only slightly above core consumption. ${ }^{21}$

We next consider the effects of core fiscal expansion in a liquidity trap. The right column of Figure 3 shows the effects of the same 1.5 percent of GDP rise in core government spending in a liquidity trap lasting 12 quarters; the liquidity trap is generated from an adverse consumption taste shock that persistently depresses the potential real rate $r_{t}^{C U, p o t} \cdot{ }^{22}$ At an aggregate CU level, the highly accommodative monetary policy stance in a liquidity trap makes fiscal expansion more potent in stimulating output and inflation than under the Taylor rule which is in force in normal times. CU output expands around 1.3 percent after four quarters in a 12 quarter liquidity trap (the solid line in panel B) rather than 0.7 percent in the case of no liquidity trap (the solid line in panel A), with the larger expansion reflecting that private consumption is "crowded in" rather than out by a fall in real interest rates. These aggregate implications are consistent with an extensive literature showing that fiscal policy has amplified effects in a liquidity trap, cf. Christiano, Eichenbaum, and Rebelo (2011) and Woodford (2011). Consistent with this literature, the stimulus to CU output due to fiscal expansion quickly dissipates once government spending reverts to its initial level.

The more accommodative monetary policy stance in a liquidity trap relative to normal times imparts a commensurate degree of stimulus to each CU member, recalling from Section 2 that the gap between the output responses in the core and periphery is invariant to monetary policy. Thus, as can be seen by comparing panel B with panel A, the output responses in both the periphery and core in panel B are shifted up by the same exactly the same amount in percent terms relative to the case of no liquidity trap (e.g., about 0.5 percent after four quarters). Output still expands by considerably more in the core, but the spillovers to the periphery are now positive and sizeable. A liquidity trap, in effect, "lifts all boats" in tandem relative to normal times. Intuitively, both price changes after 10 quarters (the final quarter of the government spending hike).

${ }^{21}$ Recalling the discussion in section 3, periphery consumption rises more than core consumption because periphery expected inflation exceeds core inflation (given that core prices initially rise by more, and that relative prices must converge in the long-run).

${ }^{22}$ The taste shock is assumed to follow a first order autoregression with persistence of 0.9 . 
periphery and core GDP are boosted by the same degree because ECB policy rates do not rise in a liquidity trap - which provides equivalent stimulus to each member state - and due to the expansionary effect this more accommodative policy stance has on inflation in each member.

The larger GDP effects on both the periphery and core in a liquidity trap are due to a larger response of consumption relative to normal times. By contrast, given that real net exports depend only on the consumption gap $c_{t}-c_{t}^{*}$ and terms of trade - both of which are invariant to the stance of monetary policy - the response of real net exports turns out to be the same in a liquidity trap as in normal times. Our results showing amplified spillovers are consistent with the qualitative analysis of Farhi and Werning (2012), who also underscore how a crowding in of private consumption plays a key role in generating positive output spillovers in a liquidity trap.

Overall, changes in core government spending seem likely to exert substantial effects on periphery output in a deep liquidity trap. Under such conditions, a core government spending hike increases periphery GDP through qualitatively similar channels as would an easing of monetary policy (if the periphery had an independent monetary policy): lower real interest rates boost periphery consumption, and terms of trade depreciation stimulates net exports. However, a key difference is that a (hypothetical) monetary easing by the periphery central bank would depress nominal interest rates and raise inflation, while the core fiscal expansion we consider relies exclusively on higher inflation to reduce real interest rates. ${ }^{23}$ A more subtle difference - but which may have important implications for welfare, as we explore in Section 5 - is that the stimulus to periphery GDP is very drawn out. As seen in Figure 3, periphery output (panel B) remains elevated for several years, even after the government spending shock has died out and CU GDP returned to baseline. These longer-term expansionary effects reflect that periphery inflation must run persistently above core inflation in the medium-run (panel D) to allow relative prices to converge back to their pre-shock

\footnotetext{
${ }^{23}$ Moreover, under an independent monetary policy in the periphery, the periphery nominal and real exchange rate would depreciate immediately.
} 
level. Thus, fiscal stimulus can have longer-lived distributional effects on member states through relative price channels even if the aggregate CU output effects dissipate quickly.

\subsection{The Longer the Liquidity Trap, the Stronger the Spillover Effects}

A key question is how the effects of a core spending expansion vary with the expected duration of the liquidity trap. The upper panels of Figure 4 show the effect of the same core government spending expansion on both periphery output (left panel) and core output (right panel) for liquidity traps ranging in duration from zero quarters (normal times) to 12 quarters. The effects are derived as the average response over the first four quarters following the stimulus, and hence can essentially be read off the IRFs in Figure 3 for both the normal times case and for the 12 quarter trap. The figure indicates that an expansion of core spending is "counterproductive" to the aim of boosting periphery output even in a liquidity trap lasting up to about a year: periphery output falls slightly, while the GDP stimulus accrues wholly to the core.

Our result that the spillovers to the periphery are negative in a shorter-lived liquidity trap and that the aggregate multipliers are fairly modest - may seem surprising in light of the literature suggesting a sharp disparity between the effects of fiscal expansion between a liquidity trap and normal times. There are three important reasons for why a short-lived liquidity trap doesn't look too different from normal times in our baseline model. The first reason is that we allow for substantial habit persistence in consumption. This allays the strong "crowding out" effects on consumption that would occur in normal times when interest rates rise in response to higher government spending, while limiting the crowding in effects due to lower real interest rates in a liquidity trap.

The second reason - explored more fully below - is that inflation is much less responsive under our calibration than often assumed in the literature. 
The third reason is that government spending shock is assumed to follow an MA(10), and hence persists well beyond the duration of the shorter-lived liquidity traps considered in the figure. As emphasized by Woodford (2011) and Christiano, Eichenbaum, and Rebelo (2012), this fiscal overhang attenuates the aggregate CU multiplier relative to a "ideally-structured" fiscal intervention that dissipates before the economy exits the liquidity trap. In particular, to the extent that fiscal spending was expected to remain high even after the economy exited the liquidity trap, long-term interest rates would be pushed up, generating negative spillovers to the periphery in short-lived traps. It turns out that spillovers to the periphery would always be positive - even in a transient liquidity trap - provided that the core spending only rose during the period in which monetary policy was constrained by the ZLB. However, practical impediments would make it unlikely to achieve a rapid phase-in and phase-out within a few quarters; and moreover, even if such a nimble fiscal response was feasible, the short duration wouldn't provide much, if any, stimulus to the periphery (since inflation wouldn't rise much). ${ }^{24}$

Somewhat more broadly, our results underscore that core fiscal expansion would probably only be likely to boost periphery GDP noticeably if the central bank was expected to remain accommodative for a fairly prolonged period of a couple of years or more. We should add that some caution is warranted with respect to the quantitative estimates from this simple model, as it tends to understate spillovers relative to the policy-oriented model in Section 6; but this main conclusion is robust.

\subsection{The Steeper the Phillips Curve, the Stronger the Spillover Effects}

While slow price adjustment seems consistent with Europe's experience since the Great Recession, it is possible that the Phillips Curve slope is higher than we have assumed in our benchmark

\footnotetext{
${ }^{24}$ As Cogan et al (2010) have pointed out, only around a third of the increased U.S. federal spending on goods and services authorized by the American Reconstruction and Recovery Act was earmarked to be spent within the first two years of the ARRA's passage in February 2009.
} 
calibration. Accordingly, Figure 5 shows IRFs to the core spending shock under a calibration with a steeper Phillips Curve slope: specifically, we set $\xi_{p}=0.88$, implying a Phillips Curve slope parameter of $\kappa_{m c}=.017$, which is slightly above the median point estimates in the literature mentioned earlier.

In normal times, the faster terms of trade adjustment (panel E) generates more rebalancing towards the periphery than in the benchmark. However, monetary policy also raises interest rates (panel E) by more given the bigger increase in inflation. As a result, CU output rises by less, and periphery output still contracts (as under the benchmark calibration).

The fiscal expansion under the higher Phillips Curve slope does have dramatically different implications than in the benchmark in a persistent liquidity trap. With the higher Phillips Curve slope, the higher inflation implies much lower real interest rates, and consequently a much larger expansion of CU GDP (comparing panel B of Figure 5 with panel B of Figure 3). With the larger rebalancing effect now reinforced by the bigger real interest rate decline, periphery GDP rises over $1 \frac{1}{2}$ percent in a 12 quarter liquidity trap, over half as much as core GDP. The dashed lines in the upper panels of Figure 4 show how the effects on core and periphery GDP vary with the duration of the liquidity trap under this alternative calibration.

This calibration is useful for highlighting conditions that might give rise to very large positive fiscal spillovers, and is of particular interest given that calibrations of the Phillips Curve slope in this range are often used in the literature. Although the implied responsiveness of inflation seems somewhat of a stretch in light of the Great Recession experience, the scenario does underscore some upside risk to fiscal spillovers if inflation proves more responsive than assumed under the benchmark. 


\subsection{The Larger the Import Content of Spending, the Stronger the Spillover Effects}

Policymakers often draw attention to terms of trade adjustment as a key channel through which the periphery might benefit from a core fiscal expansion. But with sluggish price adjustment, the stimulus accruing through this channel is likely to be quite modest. Accordingly, we next consider how allowing for a sizeable component of core spending to fall on periphery imports could facilitate rebalancing the aggregate demand stimulus more evenly across the core and periphery.

In an extreme case in which the core government spending was disbursed equally across currency union members according to population size - a "no home bias" case in which $\omega_{G}^{*}=1 / 3$ and $\omega_{G}$ $=2 / 3$ - equation (23) indicates that the periphery and core would share equally in the stimulus. Figure 6 shows the effects in a less extreme case when the import share of core government spending $\omega_{G}^{*}$ is set to 0.20 (20 percent of government spending in the steady state). As this reallocation of spending has no consequences for $\mathrm{CU}$ aggregates, the effects of the core spending hike on $\mathrm{CU}$ output are identical to Figure 3 (in which $\omega_{G}^{*}=0$ ). However, the changes in the pattern of GDP response across core and periphery are striking: the rise in periphery GDP is more than half as large as the rise in core GDP even in normal times. Thus, core spending may provide considerable stimulus to the periphery even in a short-lived liquidity trap if it falls substantially on periphery imports. As seen in the bottom panels of Figure 4, the boost to both periphery (and core) GDP is even larger in a long-lived liquidity trap.

Overall, these results underscore how direct purchases may allow core fiscal spending to have much more balanced effects on core and periphery output even if terms of trade adjustment is quite sluggish. It is important to note, however, that the greater spillovers to periphery GDP reflect a larger boost to periphery real net exports than in the baseline without direct purchases; periphery consumption actually rises a bit less than under our baseline calibration. ${ }^{25}$ As we will discuss in

\footnotetext{
${ }^{25}$ Because the output expansion is more balanced across regions, there is less upward pressure on the terms of trade; and hence periphery inflation doesn't have to rise as much to bring relative prices back to their long-run equilibrium
} 
the next section, these compositional effects turn out to be consequential in evaluating the extent to which increasing the import share of government purchases affects welfare.

\section{Welfare Effects of Higher Core Government Spending}

The literature analyzing the effects of fiscal expansion in a liquidity trap has largely focused on environments which abstract from differences in economic conditions across countries or states. The implicit assumption is that each member of a common currency area - whether a country or state - faces an equally severe downturn, and would get a similar boost in government spending if a stimulus package were enacted. The situation facing policymakers in Europe is different in two important respects. First, resource slack in the periphery economies is much larger than in the core, and inflation is correspondingly more subdued. Second, assuming that fiscal stimulus would have to come mainly from the core economies, the expansionary effects on CU GDP would be likely to be concentrated in the core economies.

These asymmetries across member states - both in initial business cycle positions, and in the effects of fiscal policy - have important implications for gauging the welfare effects of fiscal expansion. In this section, we illustrate some of the considerations that would seem relevant in designing a fiscal stimulus program in this environment.

To conduct our analysis, we use two alternative measures of welfare. First, we assume a standard ad hoc loss function in which the policymaker only cares about minimizing squared output gaps and inflation gaps in both the core and periphery economies:

$$
L_{t}^{C P}=\frac{1}{4} \sum_{s=0} \beta^{s}\left\{\zeta\left[\left(\pi_{D t+s}^{P e r}-\pi\right)^{2}+\lambda_{y}\left(x_{t+s}^{P e r}\right)^{2}\right]+(1-\zeta)\left[\left(\pi_{D t+s}^{\text {Core }}-\pi\right)^{2}+\lambda_{y}\left(x_{t+s}^{\text {Core }}\right)^{2}\right]\right\}
$$

Thus, the welfare loss $L_{t}^{C P}$ is population-weighted average of the loss function for each CU member (core or periphery). Each region's loss function is simply a sum of the squared inflation gap and level. This smaller rise in periphery expected inflation translates into a smaller rise in periphery consumption. 
squared output gap, with the parameter $\lambda_{y}$ determining the relative weight on the output gap set to $1 / 3$ for each region. The inflation target $\pi$ is set to 2 percent. While this loss function is admittedly simple, it helps address the interesting question of the extent to which fiscal policy can substitute for monetary policy when the latter is constrained by the ZLB by "filling in" output and inflation gaps. ${ }^{26}$ Our second welfare measure - considered in Section 5.2 - is based on the discounted utility of households in our model.

\subsection{Welfare Results under Ad Hoc Loss Function}

\subsubsection{Fiscal Expansion in Core and Periphery (Fiscal Union)}

As a useful reference point for assessing the effects of a core-only fiscal expansion, we first consider the welfare effects of fiscal expansion under the assumption that the euro area countries were part of a fiscal union. From the perspective of the euro area as a whole, there would seem a strong rationale for fiscal expansion under current conditions: output gaps are large, inflation is below target, and monetary policy is likely to be constrained by the ZLB for a prolonged period. A fiscal union would presumably give more scope to the periphery economies to expand domestic fiscal spending than in the current environment in which concerns about debt sustainability and adverse market reactions appear to impose tight constraints. Exactly how much latitude is unclear, as it would depend on the specific features of the fiscal compact. However, it seems plausible that such a union might allow an expansion in euro area government spending that was distributed roughly equally across member states on a per capita basis. ${ }^{27}$ Accordingly, we assume that each member state boosts fiscal spending by a commensurate amount under fiscal union.

The welfare benefits of a fiscal stimulus program clearly depend on how output and inflation

\footnotetext{
${ }^{26}$ This assumption would seem most reasonable to the extent that the additional stimulus is on goods for which there was considerable scope to substitute purchases intertemporally (e.g., construction or transport equipment).

27 The large-scale expansion of U.S. fiscal spending authorized in 2009 under the ARRA was reasonably balanced across U.S. states in per capita terms (Orr and Sporn, 2012), notwithstanding that spending on some components of these programs (such as unemployment compensation) varied with regional economic conditions.
} 
gaps in the core and periphery would evolve absent any fiscal stimulus. Our baseline assumes adverse consumption demand shocks (i.e., lower $\nu_{t}$ ) cause a prolonged recession in the euro area that is especially concentrated in the periphery. ${ }^{28}$ The solid lines in Figure 7 depict this baseline. Specifically, the output gap in the core (the solid line in panel C) is about -2 percent at the end of 2015 and nearly closes within three years; whereas the output gap in the periphery (panel D) is about -5 percent initially, and slack remains sizeable even after a few years. Inflation stays well below 2 percent in both the core (panel E) and periphery (panel F), but runs particularly low in the periphery (with some deflation on average in 2015). ${ }^{29}$ Our calibration of the Taylor rule implies that the $\mathrm{CU}$ interest rate remains pinned at zero for 12 quarters (noting that the policy rate is expressed as an annualized percentage rate, or APR).

\section{Table 1: Losses under Baseline: Ad Hoc Welfare Function}

\begin{tabular}{lccc}
\hline \hline & Overall Loss $L_{t}^{C P}$ & Core & Periphery \\
\hline Discounted Loss & 21.5 & 12.5 & 39.5
\end{tabular}

Note: The overall loss $L_{t}^{C P}$ is based on eq. (24) for 2015:Q1 to 2020:Q4. The core and periphery losses are based on their respective discounted squared inflation and output gaps with $\lambda_{y}=1 / 3$.

Table 1 reports the losses under the welfare measure (24) that are derived from cumulating the discounted squared output and inflation gaps from 2015:Q1 to 2020:Q4; given that the effects of the fiscal actions we consider on output and inflation gaps are small after six years, the welfare gains reported below would change very little if the horizon were extended beyond that period. Clearly,

\footnotetext{
28 The effects of fiscal stimulus on output and inflation gaps analyzed below do not hinge on the particular type of shock(s) driving the output gap in the baseline. Other shocks, such as the productivity shocks $z_{t}$ and $z_{t}^{*}$, would yield similar results if calibrated to imply the same evolution of the core and periphery output gaps as shown in Figure 7 (i.e., both the positive effects would be similar, as well as the normative implications under the quadratic criterion). This invariance reflects the tight link between output gaps and inflation in our benchmark model, and would not obtain if there were features such as wage rigidities that implied tradeoffs. It is important to note that the welfare results under the utility-based criterion considered in Section 5.2 do depend somewhat on the nature of the shocks driving the output and inflation gaps, reflecting that welfare depends on the evolution of consumption and other variables; however, we found that experimenting with different underlying shocks had relatively little effect on our results (provided that the alternative shocks implied similar output gap and inflation responses).

${ }^{29}$ The output gaps in the baseline are broadly similar - albeit somewhat smaller - to those forecast by the OECD in its interim economic outlook that was released in March 2015 (for example, the OECD projects that the output gap in the euro area will be about 3 percent in 2015, compared with $2-1 / 2$ percent in our baseline, and almost 6 percent in the periphery, compared with 4 percent in our baseline). The large and persistent output gaps in the baseline in turn imply considerable downward pressure on inflation, notwithstanding that Phillips Curve slope is very flat under our baseline calibration; under more typical calibrations of Phillips Curve slope used in the literature, the decline in inflation would be even sharper.
} 
losses are heavily concentrated in the periphery.

Against this backdrop, we assume that a CU-wide fiscal stimulus is initiated that boosts government spending by 1 percent of baseline GDP in both the core and periphery. The stimulus begins in the same quarter as the adverse shocks and lasts 12 quarters, and thus is "well-timed" to coincide with the period in which monetary policy is constrained. We compute the model solution - both under the baseline and for the scenario with higher fiscal spending - using a nonlinear solution algorithm for solving perfect foresight models in DYNARE. ${ }^{30}$

The blue dashed lines in Figure 7 labelled "Fiscal Union: CU-Wide Stimulus" show the effects of this fiscal expansion. The joint fiscal expansion narrows the periphery output gap (panel D) substantially - as well as the gap between periphery inflation (panel F) and the 2 percent target while nearly closing the core output gap (panel C). Panel A in Table 2 reports the welfare gains from fiscal stimulus, which is measured as the difference between the welfare loss assuming no stimulus (from Table 1) and the welfare loss under the stimulus program. Aggregate welfare improves substantially, with welfare losses cut by half relative to the baseline. While both the core and periphery experience welfare improvements, the periphery experiences much larger absolute gains given the large initial output and inflation gaps in that region (which are penalized heavily under the quadratic objective).

Fiscal policy in this setting is similar to monetary policy insofar as both forms of stimulus operate with equal force on each member state, and hence can't close output (and inflation) gaps in each. Larger welfare improvements could be achieved by channeling relatively more of the fiscal stimulus to the periphery where the marginal value of additional stimulus is higher - and thus essentially using core and periphery spending as separate instruments to "fill gaps" in each

\footnotetext{
${ }^{30}$ We assume in our simulations below that the CU central bank does not counteract the core fiscal stimulus by raising rates any earlier than in the absence of stimulus. This limited form of commitment modestly amplifies the stimulus from the fiscal expansion. Upon exit, policy rates follow the Taylor rule, and thus eventually react to the higher demand caused by the fiscal expansion.
} 
member state. ${ }^{31}$ Of course, political economy considerations could well preclude such targeted spending.

Table 2: Gains From Fiscal Expansion: Ad Hoc Welfare Function

Panel A: Welfare Gains under Fiscal Union

\begin{tabular}{cccc} 
Currency & Union & Core & Periphery \\
\hline 11.2 & 7.8 & 18.1
\end{tabular}

Panel B: Welfare Gains under "Core Only" Fiscal Expansion

\begin{tabular}{cccc} 
& Currency Union & Core & Periphery \\
\hline Benchmark $\left(\omega_{G}^{*}=0\right)$ & 10.4 & 8.3 & 14.5 \\
High Import Share $\left(\omega_{G}^{*}=0.2\right)$ & 10.9 & 7.9 & 16.8 \\
\hline Note: The table reports absolute gains, computed as Loss & Baseline & - Loss $^{\text {Scenario }}$.
\end{tabular}

\subsubsection{Fiscal Expansion only in Core}

We next assess how a fiscal expansion that was concentrated exclusively in the core would affect welfare in both the core and periphery; for comparability with the previous analysis, we continue to assume that the core spending hike equals 1 percent of CU GDP. As seen by the red dotted lines in Figure 7 labeled "Core Only Stimulus," the core spending hike provides a much larger boost to core GDP and inflation than to the periphery: the core output gap turns noticeably positive, while the periphery output gap only narrows modestly.

The first row of Panel B in Table 2 reports the welfare gains under the core-only fiscal expansion under our benchmark calibration in which the import content of government spending is zero $\left(\omega_{G}^{*}=0\right)$. The core fiscal expansion improves welfare by less than under the fiscal union case

\footnotetext{
31 As is clear from previous work by Gali and Monacelli (2008), it would not be optimal to close output or inflation gaps in each member state if there were some costs of expanding government spending (at least beyond a certain level). First, it would be essential to balance any direct fiscal costs against the benefits of reducing output (and inflation) gaps. Second, the optimal policy would also take account of how current increases in government spending affected the terms of trade and hence future output (and inflation) gaps. In particular, higher periphery government spending would boost periphery relative prices and thus tend to hurt periphery net exports in the future. Because the optimal policy would take account of both the direct fiscal costs and the loss in future competitiveness, it would not be optimal to close the periphery output gap completely (and similarly for the core).
} 
(reported in the upper panel), especially for the periphery. This is because the core expansion boosts aggregate demand relatively more in exactly the region (the core) in which it is "least needed" according to the ad hoc welfare criterion. The disparity in the welfare results between the core-only and fiscal union cases would be even larger if the size of the fiscal expansion under each case were chosen optimally to maximize the quadratic welfare criterion (24): this reflects that the optimal expansion turns out to be considerably larger under fiscal union because fiscal union allows more of the fiscal stimulus to be channeled to the region where its marginal value is comparatively high. $^{32}$

Even so, it is remarkable that the core-only fiscal expansion does achieve a good portion of the welfare gains that would accrue under fiscal union. Because output and inflation gaps are very large in the periphery - and output spillovers to the periphery sizeable in a long-lived liquidity trap - the periphery derives substantial benefits from core fiscal expansion. Moreover, even the core benefits from a modest-sized expansion that can help pare its own output and inflation gap.

An expansion of government spending in the core would raise welfare even more if some of the increase in core government spending was on imported periphery goods. As we have shown in Section 4.3, such an approach balances the stimulus to output and inflation more evenly across the core and periphery, and thus appears more akin to fiscal union than the case in which core spending falls exclusively on domestically-produced goods. For a calibration with a high core import share of 20 percent $\left(\omega_{G}^{*}=0.2\right)$, the effects of a core-only fiscal expansion on output and inflation gaps in each region are very similar to that achieved under fiscal union (and hence not shown in Figure 7 for expositional reasons). By implication, Panel B in Table 2 shows that the welfare gains to the currency union approach those achieved under fiscal union, with both the core and periphery

\footnotetext{
${ }^{32}$ The optimal spending hike under fiscal union is 2.5 percent of CU GDP, while the optimal hike for the core-only case is 3.1 percent of core GDP, which is equal to 2.1 percent of CU GDP. Under an optimally-sized fiscal expansion, the welfare gain to the $\mathrm{CU}$ is 18.0 under fiscal union, compared with 14.9 under the core-only expansion.
} 
experiencing nearly commensurate welfare gains. ${ }^{33}$

\subsection{Welfare Results under Utility-Based Criterion}

Our previous welfare results indicate that an expansion of core government spending may improve periphery welfare considerably by shrinking the periphery's sizeable output and inflation gaps; and that comparatively large welfare improvements - for both core and periphery - may be achieved to the extent that a larger share of core government spending falls on periphery imports.

We next consider the robustness of these normative results to an alternative welfare measure based on the discounted conditional expected utility of the representative household in each member state in our model:

$$
\mathbb{E}_{t} \sum_{j=0}^{\infty} \beta^{j}\left\{\ln \left(C_{t+j}-\varkappa C_{t+j-1}-C \nu_{t+j}\right)-\chi_{0} \frac{\left(N_{t+j}\right)^{1+\chi}}{1+\chi}+\frac{\vartheta_{G}}{1-\frac{1}{\sigma_{G}}}\left(G_{t+j}-\varkappa_{G} G_{t+j-1}\right)^{1-\frac{1}{\sigma_{G}}}\right\} .
$$

Household utility depends positively on public and private consumption, and inversely on hours worked. Welfare in the currency union on the "utility-based" metric is simply a population-weighted average of the utility functionals of periphery and core households. ${ }^{34}$

\subsubsection{Fiscal Expansion in Core and Periphery (Fiscal Union)}

Panel A of Table 3 reports welfare gains under fiscal union using the utility-based objective (25).

Because we continue to assume that government spending in each $\mathrm{CU}$ member would expand by 1 percent of GDP under fiscal union, the impulse responses are the same as in Figure 7 (the dashed lines labelled "Fiscal Union"). The utility gains in the table are summarized in terms of the "con-

\footnotetext{
${ }^{33}$ If a sizeable share of the rise in core government spending fell on periphery imports, then a rise in core government spending would boost periphery GDP and welfare even in a short-lived liquidity trap, at least under this ad hoc welfare metric.

${ }^{34}$ To perform this welfare analysis, we assume that households regard government spending on goods and services as somewhat more substitutable through time than private consumption, and that habit persistence is somewhat lower (specifically, we set $\sigma_{G}=2$, so that the elasticity of substitution is 2 , and the habit persistence parameter $\varkappa_{G}$ $=0.4$ ). Finally, we set $\vartheta_{G}$ to account for a steady steady share of government consumption to output of .23, and $\chi_{0}$ so that $N$ (hours worked per capita) equals unity in the steady state.
} 
sumption equivalent compensation" (CEV henceforth), which is the permanent percent increase in household private consumption - relative to the baseline with no fiscal expansion - that is required to make households equally well off as under the government spending expansion. Following the usual approach in the literature, household welfare depends on how the fiscal expansion affects the entire infinite discounted sum of period utility. The aggregate CU CEV is a population-weighted average over the core and periphery.

Table 3: Welfare Gains From Fiscal Expansion: Utility-Based

Panel A: Welfare Gains under Fiscal Union

\begin{tabular}{cccc} 
Aggregate CU & Core & Periphery \\
\hline .015 & .008 & .028
\end{tabular}

Panel B: Welfare Gains under "Core Only" Fiscal Expansion

\begin{tabular}{cccc} 
& Aggregate CU & Core & Periphery \\
\hline Benchmark $\left(\omega_{G}^{*}=0\right)$ & .010 & .013 & .002 \\
High Import Share $\left(\omega_{G}^{*}=0.2\right)$ & .012 & .027 & -.018 \\
\hline
\end{tabular}

Note: The table report consumption equivalent compensation ( $C E V$ henceforth), i.e., the percent increase in households' consumption that makes them - in expectation-equally well-off under no fiscal stimulus as when core government spending expands. Aggregate CEV is calculated as the weighted sum of CEV in the core and periphery.

As under the ad hoc loss criterion above, the equal-sized fiscal expansion in each CU member is strongly welfare-improving. Fiscal expansion is beneficial because it boosts utility directly through increasing government services, and indirectly through inducing an expansion of private consumption, with the latter reflecting that the higher inflation induced by the fiscal expansion reduces real interest rates. Crucially, this increase in utility from public and private goods comes at a low cost in terms of foregone leisure because labor is underutilized and inflation suboptimally low. The low level of inflation is undesirable because it implies substantial inefficiency in goods production in our modeling framework with staggered price setting (Rotemberg and Woodford, 1997), and hence acts like a tax on production; accordingly, a key benefit of fiscal expansion is that it boosts productivity by pushing inflation closer to target (assumed to be 2 percent). Aside 
from the implication - clear from Panel A in Table 3 - that the periphery benefits more from fiscal expansion due to its relatively large degree of slack, the logic favoring fiscal expansion under fiscal union closely parallels that provided by Woodford (2011) for a closed economy. In particular, because the fiscal expansion is the same in each CU member, it has no effect on the terms of trade or net exports; accordingly, all of induced expansion in employment goes to increasing either public or private consumption.

\subsubsection{Fiscal Expansion only in Core}

The utility-based metric in effect poses a much more stringent test than the simple ad hoc loss function (24) for assessing whether increases in core government spending improves periphery welfare: assuming as we do that the periphery gets no direct utility benefits from the higher core government spending (e.g., from better roads in France), periphery welfare only improves if the core spending hike boosts periphery consumption enough to offset the cost of working additional hours. Thus, the composition of the rise in periphery GDP matters a great deal for welfare, as well as the timing of the rise in consumption. Even if the periphery output gap is large and the output spillovers to the periphery fairly big- conditions that lead to substantial periphery welfare improvements under the simple quadratic loss function - periphery welfare may fall under the utility-based criterion if the rise in periphery GDP is driven by net exports, or if the stimulus persists too long.

As seen in Panel B in Table 3 (above), the expansion of core spending in the case in which the import content is zero $\left(\omega_{G}^{*}=0\right)$ yields an improvement in core welfare. Core welfare improves because the core's sizeable resource slack makes it less costly - and hence more desirable - to produce more government services. The effects on periphery welfare are more complicated. Periphery discounted welfare improves, though by much less than core welfare. This reflects that the core fiscal expansion boosts the period utility of periphery households in the near-term, but has slightly 
negative effects on their period utility at horizons much beyond a year.

Figure 8 is helpful for understanding these results, as it shows the "partial effects" of a rise in core government spending on key components of household welfare. ${ }^{35}$ Focusing first on our benchmark case with $\omega_{G}^{*}=0$ - shown by the red dotted lines - it is evident that periphery consumption (panel B), real net exports (panel F), and employment (panel D) each respond positively to the core spending shock. As might be expected in a deep recession, the benefits of the rise in periphery (private) consumption outweigh the cost in terms of labor effort at least in the near-term, which accounts for why the period utility of the representative periphery household (panel H) improves for over a year. Some of the improvement in periphery household utility reflects that the core spending hike boosts periphery inflation from a suboptimally low level, and this reduced inflation tax distortion means that less labor is required to produce any given quantity of output.

It may seem surprising that the core fiscal expansion doesn't provide an even more sustained boost to periphery welfare: after all, the periphery responses look very similar qualitatively to the usual effects of a favorable monetary shock under an independent monetary policy, insofar as lower periphery real interest rates crowd in consumption, and a depreciation of the periphery's terms of trade boosts real net exports. Monetary stimulus of this type might be expected to be very beneficial given the periphery's poor initial conditions. However, to achieve welfare benefits under the metric (25), it is critical that the policy action boost consumption in the near-term when the gap between the marginal utility of consumption and disutility of work is especially large. From the prism of the utility-based welfare metric, there are two key problems with how the core fiscal expansion affects the periphery. First, a sizeable share of the expansion in periphery output about $1 / 4$ under our benchmark calibration - is due to higher real net exports rather than increased periphery consumption; in effect, this diversion of employment towards net exports operates like a

\footnotetext{
35 Thus, the figure shows the deviation between the responses that include a rise in core government spending (layered onto the baseline) and the baseline.
} 
tax, because it means that the rise in periphery employment is associated with a smaller near-term consumption boost. Second, the stimulus to periphery consumption is very spread out over time, as evident in panel B (and discussed previously in Section 4.3). The protracted consumption response reflects that periphery inflation remains elevated for a long time - which holds down periphery real interest rates - to allow the terms of trade to converge back to its pre-shock level. This longer-term boost to periphery consumption, coming as it does after periphery consumption would have largely recovered even absent fiscal stimulus, simply isn't worth the labor cost.

These considerations also help explain why an expansion of core spending causes periphery welfare to deteriorate considerably - as reported in Panel B in Table 3 - in the case in which core imports are sizeable $\left(\omega_{G}^{*}=0.2\right)$. These results differ dramatically from the implications of the ad hoc loss function in which the higher import content was a major plus for welfare in both CU members. As we have seen - and is also shown by the blue dashed lines in Figure 8 - the periphery GDP expansion under the higher import share calibration is more heavily driven by net exports, which the utility-based welfare measure views as undesirable.

As might be expected, a core government spending hike yields a larger improvement in periphery household welfare if initial conditions are noticeably worse than assumed in Figures 7 and 8 . To illustrate this, Table 4 reports the effects of the same core government spending expansion against an alternative baseline in which output gaps in each member are much larger (slightly below minus 8 percent in the periphery, and close to minus 3 percent in the core), and inflation falls well below zero in the currency union as a whole. Periphery period utility - as well as CU welfare - improves very persistently under these conditions, leading to an improvement in the discounted welfare measure. The output spillovers to the periphery are not only larger than under the initial conditions underlying Figures 7 and 8, but fueled by a bigger consumption rise; moreover, the welfare benefits of boosting both consumption and inflation are larger given the poorer initial 
conditions.

Table 4: Welfare Gains of Core Fiscal Expansion

under More Adverse Baseline: Utility-Based

\begin{tabular}{cccc}
\hline \hline & Aggregate CU & Core & Periphery \\
\hline Benchmark $\left(\omega_{G}^{*}=0\right)$ & 0.021 & .027 & .010 \\
High Import Share $\left(\omega_{G}^{*}=0.2\right)$ & 0.024 & .040 & -0.007 \\
\hline
\end{tabular}

Note: The table reports consumption equivalent compensation ( $C E V$ henceforth), i.e., the percent increase in households' consumption that makes them-in expectation-equally well-off under no fiscal stimulus as when core government spending expands. Aggregate CEV is calculated as the weighted sum of CEV in the core and periphery.

Taking stock of our results, each of the alternative welfare measures we have considered - ad hoc and utility-based - suggests that a suitably-designed fiscal stimulus program in the core can improve near-term welfare in both the periphery and core. The welfare improvements under each measure are clearly larger and more persistent the worse the baseline and longer monetary policy is likely to be constrained from raising interest rates. Welfare improvements would also be larger if spillovers to periphery consumption were bigger than in our baseline (as would occur if e.g., prices were more flexible than in our benchmark). However, there is clearly some tension between how the welfare measures score policy actions which reduce the periphery output gap significantly, but don't provide much short-run stimulus to consumption. This tension can have important implications for the design of a core stimulus program, and in particular, for assessing the desirability of a higher import content of core government purchases.

Our sense is that the utility-based analysis is useful for highlighting how the welfare effects of fiscal expansion depend partly on how the stimulus affects the composition of demand - between consumption and net exports - and that fiscal policy may have long-lived effects arising through relative price channels that may possibly reduce welfare. Even so, the utility-based welfare metric probably understates some of the benefits of reducing the output gap and unemployment in economies plagued by high resource slack. Indeed, our model embeds two key assumptions - of 
perfect consumption risk-sharing, and that all variation in labor effort occurs at the intensive margin - that tend to minimize the costs of a large output gap, and correspondingly, to understate the benefits of fiscal expansion. While these assumptions are useful for analytical tractability, household consumption in reality depends heavily on each household's employment status. These considerations suggest that policies that could markedly reduce the periphery's output gap - and as a result, reduce both unemployment and consumption dispersion across households - would probably enhance periphery welfare. All in all, our sense is that the welfare benefits of fiscal expansion probably lie between the two measures, but tilt more in the direction suggested by the simple ad hoc loss function.

\section{The Effects of a Core Spending Expansion in a Larger Scale Model}

The benchmark model is useful for highlighting many of the key factors likely to shape how a core fiscal expansion would affect the periphery. However, the benchmark model likely understates both the aggregate effects of core fiscal expansion and spillovers to the periphery due to the exclusion of Keynesian multiplier and accelerator effects on household and business spending. A consequence is that the aggregate government spending multiplier is relatively modest even in a persisent liquidity trap (unless inflation rises more than under our baseline calibration).

Accordingly, we next reconsider the effects of a core government spending expansion in a largerscale two country model with endogenous investment that closely follows Erceg and Linde (2013). Abstracting from open economy features, the specification of each country block builds heavily on the estimated models of Christiano, Eichenbaum and Evans (CEE, 2005) and Smets and Wouters (2003, 2007). Thus, the model includes both sticky nominal wages and prices, allowing for some intrinsic persistence in both components; habit persistence in consumption; and embeds a $Q$-theory investment specification modified so that changing the level of investment (rather than the capital 
stock) is costly. However, our model departs from this earlier literature by assuming that some fraction of households are "Keynesian," and simply consume their current after-tax income in a hand-to-mouth fashion; this contrasts with our benchmark model which assumes that all households make consumption decisions based on their permanent income. Galí, López-Salido and Vallés (2007) show that the inclusion of non-Ricardian households helps account for structural VAR evidence indicating that private consumption rises in response to higher government spending. Although the inclusion of hand-to-mouth agents increases the spending multiplier even in normal times, we will show that the amplification effects are considerably larger in a liquidity trap, and in particular, can help generate sizeable spillovers to the periphery even if the Phillips Curve is very flat.

On the open economy dimension, the model assumes producer currency pricing as in the benchmark. Financial markets are assumed to be incomplete, meaning that there is a single "internationally traded" bond available to core and periphery households. However, given that the trade price elasticity is calibrated to be close to unity, the implications of incomplete markets are similar to those of complete markets; as we have discussed above, even complete markets may allow for sizeable country-specific fluctuations in consumption given that households have different preferences over goods (see Cole and Obstfeld, 1991, for a more detailed discussion).

Monetary policy is assumed to follow a Taylor-style rule, and government spending to evolve exogenously. To satisfy intertemporal fiscal balance, the distortionary tax rate on labor income is assumed to adjust to both government debt and the change in government debt. We assume that tax rates adjust inertially, so that a rise in government spending would mainly be deficit-financed (at least under normal conditions). A detailed description of the model is provided in Appendix B. 


\subsection{Empirical Impulse Responses to Monetary and Fiscal Shocks in the Euro Area}

We next use a structural vector autoregression estimated on euro area data over the 1970:1-2008:3 period to help gauge the dynamic effects of both a monetary policy shock and a shock to euro area government spending. We will use the empirical impulse responses to each of these shocks both to estimate key parameters of our model - following the approach of CEE (2005) and Altig, Christiano, Eichenbaum, and Linde (ACEL, 2011) - and to assess the model's empirical fit. ${ }^{36}$

Specifically, we estimate a VAR where the vector $\Theta_{t}$ of endogenous variables is comprised of government spending on goods and services $\left(g_{t}\right)$, real GDP $\left(\mathrm{y}_{t}\right)$, real private consumption $\left(c_{t}\right)$, real gross investment $\left(i n v_{t}\right)$, the GDP deflator inflation rate $\left(\pi_{D t}\right)$, the nominal wage $\left(w_{t}\right)$, and the short-term interest rate $\left(i_{t}\right)$, which we interpret as the policy rate. Following the influential analysis of Angeloni et al. (2003), which estimated monetary transmission in euro area countries, we also include commodity prices, U.S. output and the federal funds rate as exogenous variables (collected in the vector $\Theta_{t}^{*}$ ). We assume that the endogenous variables collected in $\Theta_{t}$ can be represented in reduced form as following a VAR of order $p$ :

$$
\begin{aligned}
\Theta_{t} & =\alpha+B^{*}(L) \Theta_{t}^{*}+B(L) \Theta_{t-1}+u_{t}, \\
E u_{t} u_{t}^{\prime} & =V
\end{aligned}
$$

where $B(L)$ is a $p^{t h}$-ordered polynomial in the lag operator, $L$. The structural economic innovations $\varepsilon_{t}$ are related to the reduced form innovations $u_{t}$ by the relation:

$$
u_{t}=C \varepsilon_{t}, E \varepsilon_{t} \varepsilon_{t}^{\prime}=I
$$

where $C$ is a square matrix and $I$ is the identity matrix.

We identify the monetary and fiscal spending innovations through imposing timing restrictions on the VAR. Following Christiano, Eichenbaum, and Evans (1999), we identify the monetary

\footnotetext{
${ }^{36}$ Given the complications posed by the zero lower bound constraint and possible changes in the transmission of monetary and fiscal shocks following the global financial crisis, we limit the sample for our VAR analysis to the pre-crisis period.
} 
policy innovation by assuming that it has no contemporaneous effect on aggregate quantities and prices (i.e., all other variables are ordered before the short-term interest rate in the VAR). As in Blanchard and Perotti (2002), we identify a government spending shock by assuming that government spending does not react contemporaneously to the remaining variables in the VAR, including output. This assumption seems reasonable over the pre-crisis period in light of our quarterly estimation frequency, though clearly would be problematic after the onset of the financial crisis (given that euro area governments quickly ramped up discretionary public spending in response to current and prospective output declines). These timing restrictions are implemented by a standard Cholesky factorization of the matrix $C$ which orders government spending first, and the policy rate last, in the VAR.

The solid lines in Figure 9 shows the impulse responses of each variable to a one standard deviation rise in the euro area policy rate, while 95 percent standard error bands (derived from Monte Carlo simulations) are shaded. A monetary policy innovation of about 40 basis points causes output to contract gradually, with the size of the decline reaching about 0.2 percent after two years. Private investment falls by more than GDP - presumably reflecting the high interest sensitivity of many components of investment spending - while consumption falls roughly as much as GDP. The policy tightening causes price inflation to fall about 0.1 percentage points after some delay. The initial jump in inflation is consistent with a short-lived "price-level" puzzle typically found in VAR studies of the effects of monetary shocks, see e.g., CEE (2005).

The responses to the euro area government spending shock are shown by the solid lines in Figure 10. To facilitate interpretation and comparison with other estimates, we scale the shock to equal one percent of euro area GDP, which corresponds to a rise in government spending of nearly $4 \frac{1}{2}$ percent. ${ }^{37}$ The government spending shock boosts output persistently, and induces a substantial

\footnotetext{
37 The innovation to government spending is less than a tenth as large, about 0.4 percent.
} 
crowding in of both private consumption and total gross investment at a horizon stretching out almost two years. The actual output multiplier is about $1 \frac{1}{2}$ at impact, and even somewhat higher over the next year. Thus, government spending increases appear to have large and persistent effects on real activity, nothwithstanding a sizeable rise in the policy rate. After some delay, inflation also appears to rise somewhat, though confidence intervals are wide.

The response of output to the monetary policy shock seems well in line with the evidence provided by Angeloni et al. (2003) in a similar VAR framework (as noted above), though the latter was estimated over an earlier 1965-2001 sample period. Moreover, the output responses are remarkably similar quantitatively to typical estimates of the output response to a monetary policy innovation in the United States: ACEL's VAR, for example, implies that a 40 basis point rise in the U.S. policy rate would cause U.S. output to fall 0.2-0.3 percent after about 6 quarters, and Boivin, Kiley, and Mishkin (2011) report similar results.

In some contrast, our implied estimate of the euro area government spending multiplier is substantially higher than derived by Perotti (2007) for Germany in a similar VAR-based framework, or that Guajardo, Leigh, and Pescatori (2011) found for a cross-section of OECD countries - many of them European - based on a narrative approach to identifying fiscal shocks in the spirit of Romer and Romer (2010). Similarly, the U.S. government spending multiplier is usually estimated to be around unity - as in Blanchard and Perotti (2002) - or somewhat below, at least in normal times in which policy rates can adjust freely. Thus, while the high government spending multiplier we estimate in the euro area suggest the importance of Keynesian-style multiplier effects on private demand, some caution is probably warranted in light of the relatively modest variation in euro area government spending over the past several decades, and given that evidence for other countries and derived by alternative methods - points to somewhat lower multipliers in normal times. ${ }^{38}$

\footnotetext{
38 The estimated impulse responses do not seem particularly sensitive to shortening the sample period (i.e., starting in the early 1980s), nor to adopting a more parsimonious specification of the VAR.
} 


\subsection{Matching Model Responses to Empirical Responses}

We follow the basic approach of CEE (2005) and ACEL (2011) to estimate a subset of model parameters so that the model-implied impulse responses - to both a monetary shock, and in our case, to a government spending shock - match their empirical counterparts in Figures 9 and 10 as closely as possible. We estimate an aggregate version of the model under the assumption that parameters are equal in both the core and periphery and then compare these aggregate implications to the data. Our model is formulated so that it imposes the same timing restrictions as the empirical VAR (specifically, that the monetary shock has no contemporanous effects on other variables).

The vector of parameters $\Omega$ that we estimate play a key role in determining the interest sensitivity of domestic demand and the slopes of the price and wage Phillips Curve. In particular, we estimate the vector $\Omega=\left\{\varkappa, \phi_{I}, \xi_{P}, \xi_{W} ; \rho_{G}, \sigma_{G}, \sigma_{M}\right\}$ where the parameters before the semicolon are the external habit persistence parameter $\varkappa$, the parameter determining the costs of varying investment $\phi_{I}$, the price contract duration parameter $\xi_{P}$, and the wage contract duration parameter $\xi_{W}$. The parameters following the semicolon characterize the persistence of the $\mathrm{AR}(1)$ process determining government spending (of $\rho_{G}$ ) and its standard deviation $\sigma_{G}$. The monetary innovation is assumed to be i.i.d, but exerts persistent effects given some structural persistence in the monetary policy reaction function.

This parameter vector is estimated conditional on calibrating all other model parameters as described in Appendix B. However, a couple of features of the calibration merit some discussion. First, although we simply calibrate the share of Keynesian households, we set the population share to 0.65 - and thus pin it towards the upper side of plausible empirical estimates - to help better match the crowding in of private consumption evident in the response to a government spending shock. This choice implies that Keynesian households account for about $1 / 3$ of aggregate 
consumption in the steady state. ${ }^{39}$ Second, we set the parameters of the monetary policy rule according to a Taylor-style reaction function with a coefficient of 2.5 on inflation, but allow for a modest coefficient of 0.7 on the lagged interest rate in line with most empirical estimates. As we found little evidence of a response of the policy rate to the output gap (or output growth rate), we set these coefficients to zero when matching the empirical responses. Finally, the import content of government spending in each country is assumed to be the same as for private consumption spending - 13 percent for the periphery, and hence 6.5 percent for the core.

The model impulse responses depend on the parameter vector $\Omega$ in addition to the parameters we have calibrated. We stack the first $\mathrm{T}$ model impulse responses to the monetary shock and the first $\mathrm{T}$ responses to the government spending shock into a $2 T x 1$ vector $\Psi(\Omega)$, and denote the corresponding estimates derived from the SVAR above by $\hat{\Psi}$. Our estimator of $\Omega$ is obtained as the solution to:

$$
\widehat{\Omega}=\arg \min _{\Omega}(\hat{\Psi}-\Psi(\Omega))^{\prime} \digamma^{-1}(\hat{\Psi}-\Psi(\Omega))
$$

where $\digamma$ is a diagonal matrix based on the 95 percent confidence intervals for the impulse responses shown in Figures 9 and 10. Thus, impulse responses that are measured with greater precision get more weight in determining the estimate of $\Omega$. We set $T=20$, so that impulse responses are matched for 20 quarters.

Table 5 reports the estimated parameters and standard errors (below), with the latter computed for $\widehat{\Omega}$ using the delta-function method. Our estimates of habit persistence in consumption $\varkappa$ $=0.877$ and costs of adjusting investment $\phi_{I}=1.94$ indicate an important role for real rigidities in accounting for the empirical impulse responses. The estimate of habit is somewhat above typical estimates of the literature. The Calvo price contract duration parameter of $\xi_{P}=.944$ implies a very low Phillips Curve slope - when expressed in terms of marginal cost - of only .0034; as indicated

\footnotetext{
${ }^{39}$ Because Keynesian households are assumed to own no capital in our model (and hence have much lower steady state income than forward-looking households), their share of aggregate consumption is much lower than their population share.
} 
in Section 3 and as we will discuss further below, this specification is very consequential. Wage dynamics in the model depend on both the estimated wage contract duration paramer $\xi_{W}=0.871$ and on parameters which affect strategic complementarities in wage-setting (the latter include the Frisch elasticity of labor supply, and the degree of substitutibility between labor types). From a reduced form perspective that is relevant for the model simulations below, nominal wage inflation is somewhat less sensitive to the wage markup than price inflation is to the price markup.

\section{Table 5: Estimated Parameters and Standard Errors}

\begin{tabular}{cccccccc}
\hline \hline & $\varkappa$ & $\phi_{I}$ & $\xi_{P}$ & $\xi_{W}$ & $\rho_{G}$ & $\sigma_{G}$ & $\sigma_{M}$ \\
\hline Parameter Estimate & .877 & 1.94 & .944 & .871 & .914 & .0640 & .0989 \\
Standard Error & .0494 & .580 & .0121 & .0660 & .0253 & .00518 & .00735 \\
\hline
\end{tabular}

The solid lines in Figures 9 and 10 show the euro area aggregate responses of the model to both the monetary shock and a government spending shock, and provide insight both into the ability of the model to fit the data along these dimensions, and into key factors determining our parameter estimates. We begin with the responses to the monetary shock. As emphasized by CEE (2005), empirical responses to a monetary shock are very informative for gauging the interest sensitivity of domestic demand and its components, and also the slope of the price and wage Phillips Curves: consistent with their analysis, our estimates of the structural parameters in Table 5 would change little if we only fit the monetary shock (and thus can be regarded as largely "pinned down" by the monetary shock).

As seen in Figure 9, the model does very well in tracking how a monetary policy tightening causes euro area output to fall, and also performs well in accounting for the comparatively larger contraction in investment relative to consumption. The small decline in inflation in the empirical VAR is best fit with a very flat Phillips Curve, which helps account for the high estimated value of the contract duration parameter $\xi_{P}$ in Table $5 .{ }^{40}$ More broadly, a low implied responsiveness

\footnotetext{
${ }^{40}$ While the implied contract duration is extremely long, it is important to mention that our model does not embed
} 
of inflation to resource slack seems consistent with the general resilience of euro area inflation in the aftermath of the financial crisis. Even so, because the estimation procedure tries to make the model fit the initial rise in inflation in the empirical VAR - a "puzzle" the model cannot account for - the model impulse response understates the subsequent decline in inflation. Thus, it seems plausible that the Phillips Curve slope may be at least somewhat higher than our estimate in Table $5 .^{41}$

Turning to Figure 10, the model also does well in fitting the empirical responses to a rise in government spending. Notably, the model implies an initial rise in output of a little less than $1 \frac{1}{2}$ percent, and of private consumption of almost $\frac{1}{2}$ percent, both of which are very close to the empirical responses, though it does imply somewhat less persistent responses thereafter. ${ }^{42}$ However, the model implies only a small and transient rise in investment, in contrast to the larger and more sustained response we estimate. Thus, even with a large share of rule-of-thumb households, it appears that our model may understate some of the Keynesian channels that would appear to drive the empirical responses, though the model clearly moves in the right direction relative to the simple model of Section 2.

\subsection{Core Government Spending Hike in Normal Times}

We next consider the effects of a rise in core government spending in normal times that is scaled to equal one percent of CU GDP. Given that the core and periphery are calibrated symmetrically, this rise in core government spending has exactly the same aggregate CU effects as would an equal-sized rise in both core and periphery spending. We assume core government spending is increased in a

firm-specific capital or other real rigidities that could help it account for the low reduced form slope with a much shorter implied contract duration (corresponding to a significantly lower value of $\xi_{P}$ ).

${ }^{41}$ On the other hand, some recent evidence based on U.S. data also finds a very low Phillips Curve slope. Brave et al. (2012) estimated the Chicago Federal Reserve's DSGE model of the United States over the 1989:1-2011:4 period, and found a Phillips Curve slope of only 0.002. Lindé, Smets, and Wouters (2016) estimated a Phillips Curve slope of 0.005 (identical to our estimate for the euro area), and the estimate of Del Negro, Giannoni and Schorfheide (2015) is similar.

${ }^{42}$ The lower right panel of Figure 10 shows the response of consumption in the first few quarters following the government spending hike - and omits confidence intervals - in order to highlight the initial consumption rise. 
uniform fashion for 12 quarters, and then immediately cut back to zero (i.e., spending follows an MA(12) process with unit coefficients).

As seen in Figure 11, the responses to a core spending hike in normal times are similar qualitatively to the benchmark model. CU output rises a little less than $1 \frac{1}{2}$ percent initially (panel A), then then dies out as policy rates increase (panel F). The stimulus to GDP is heavily concentrated in the core (panel C). Periphery real net exports are boosted by some direct purchases of core goods/services from the core government, and from terms of trade depreciation (panel G) as the higher core government spending puts upward pressure on the relative price of core goods. However, periphery GDP (panel D) is basically flat as this stimulus to net exports is offset by a fall in domestic demand (panel E shows consumption) that is induced by higher real interest rates. Periphery GDP would contract noticeably if the policy reaction function put even a modest weight on stabilizing the output gap (e.g., of 0.5 as under the standard Taylor rule).

The Keynesian features in this larger model - while amplifying the CU multiplier modestly also drive a greater wedge between the response of core and periphery output. Notwithstanding the leakage from lower core net exports, core GDP rises about $1 \frac{3}{4}$ percent relative to periphery GDP in the first year following the shock. This is considerably larger than the GDP difference implied by the simple model results discussed in Section 4 (in which periphery private domestic demand actually rises relative to that in the core). The bigger wedge between core and periphery output responses in Figure 11 seems more in line with the literature on local multipliers, though the local multiplier implied by our model is still only around $1 \frac{1}{4}$, which is somewhat lower than typical empirical estimates in the range of $1 \frac{1}{2}$ to $2 .{ }^{43}$ Overall, both the estimates from the empirical VAR in Figure 10 and the local multiplier literature suggest sizeable Keynesian multiplier effects that, if anything, may be somewhat larger than captured by our model. ${ }^{44}$

\footnotetext{
${ }^{43}$ Recall from Section 2 that this literature aims to estimate how a differential rise in government spending in one region 'A' vs. another region 'B' affects relative output levels.

${ }_{44}$ Nakamura and Steinsson (2014) also emphasize that a simple model that embeds separable preferences as in
} 
Given our interest in spillovers, the local multiplier is important insofar as factors which raise the local multiplier tend to generate larger negative spillovers to the periphery in normal times, at least if monetary policy is sufficiently reactive to inflation (and/or the output gap). Intuitively, stronger Keynesian multiplier effects would imply more stimulus to the core if monetary policy didn't react. Hence, the central bank must raise interest rates more sharply to keep CU output close to potential and inflation from rising above target, which in turn causes a deeper contraction in the periphery. Thus, conditions which imply a relatively larger aggregate CU multiplier in normal times - reflecting a bigger effect on the natural real interest rate $r^{*}$ - actually tend to generate bigger negative spillovers to the periphery. Stronger multiplier (and accelerator) channels and the consequent boost in $r^{*}$ have profoundly different effects in a deep liquidity trap, as we next consider; but it is important to keep in mind the risk that a core fiscal expansion could hurt periphery GDP if the CU faced less extreme economic conditions (such as a short-lived liquidity trap followed by a fast hike in policy rates).

\subsection{Core Government Spending Hike in Liquidity Trap}

We next consider the same expansion of core fiscal spending in a deep liquidity trap that would last 12 quarters absent core fiscal stimulus. Our baseline assumes that the adverse aggregate demand shock generating the liquidity trap is much larger in the periphery (as in Figure 7 in the case of the simple model). In this section, we assume that the monetary policy reaction function is very aggressive in responding to both the inflation and output gap, implying that monetary policy remains accommodative even following this sizeable and persistent fiscal expansion. ${ }^{45}$

Section 2 generates far too low a local multiplier, and propose non-separable preferences as a mechanism for generating a larger local multiplier (in contrast with our focus on Keynesian multiplier and accelerator channels).

${ }_{45}$ Specifically, we assume that the the ECB reaction function puts a substantial weight on the output gap of unity. This choice helps account for a protracted liquidity trap in the baseline, and also implies monetary policy "forbearance" in not reacting to the large fiscal stimulus program we consider. More broadly, it seems reasonable to characterize ECB monetary policy as putting a fairly large weight on the output gap as well as the inflation gap in the period following the intensification of the euro area debt crisis in 2011. In particular, the ECB put more emphasis on the output gap in its communication about monetary policy, and left policy rates low in 2012-2013 even though inflation ran only modestly below 2 percent. 
Aggregate CU output (solid line in panel A) rises much more in a protracted liquidity trap, and periphery GDP (panel D) also rises substantially. The rise in periphery GDP partly arises from the same channels as emphasized in Section 2. In particular, net exports rise in response to the rise in core domestic demand and to terms of trade depreciation. Moreover, periphery real interest rates fall persistently, reflecting the expectation that periphery prices will eventually rise enough to bring the terms of trade back to its pre-shock level. However, Keynesian effects arising from the hand-to-mouth consumers play a substantial role in amplifying this stimulus, and in contributing to periphery GDP expansion. Of course, these Keynesian effects also increase the response of core GDP.

All told, periphery GDP rises rises more than $1 \frac{1}{4}$ percent after two years, which is almost half the expansion in core GDP. Thus, as in the benchmark model of Section 2, the output stimulus due to core fiscal expansion becomes more balanced in a prolonged liquidity trap. The implied $\mathrm{CU}$ multiplier of over 2 is in the range of estimates of the spending multiplier in a deep recession surveyed in Section 2 .

While we view our estimates - including of the aggregate government spending multiplier, and spillovers to the periphery - as quite plausible, there is clearly some uncertainty about key transmission channels. Several observations seem worthwhile in this regard. First, the model may understate the importance of multiplier/accelerator effects: as we noted, the model implies an aggregate CU government spending multiplier lower than our empirical VAR, and a "local multiplier" modestly below empirical estimates. To allow for larger Keynesian effects, we have explored extending the model to include a financial accelerator in each country block following Christiano, Motto, and Rostagna's variant (CMR, 2005) of the Bernanke, Gertler, and Gilchrist (BGG, 1999) framework. In a liquidity trap, we found that both the aggregate government spending multiplier and spillovers are enhanced by financial frictions, reflecting that the boost in nominal 
demand from higher core spending improves private sector balance sheets and lowers credit spreads.

Second, the model may not adequately capture how inflation and inflation expectations evolve. As we have noted, the very flat Phillips Curve slope we have imposed seems consistent with both VAR-based estimates, and with the resilience of inflation during the financial crisis and its aftermath. But poor credit conditions and other adverse supply-side developments may have helped account for why inflation didn't fall much in spite of an enormous fall in output below trend (see Christiano, Eichenbaum, and Trabandt 2014 and Gilchrist, Schoenle, Sim, and Zakrajšek 2015), so that the Phillips Curve slope could well be higher; in this case, the multiplier and spillovers would also be larger. On the other hand, our Calvo contract specification implies an immediate jump in both inflation and inflation expectations. But it is quite plausible that inflation and inflation expectations would show a more gradual rise, perhaps more in line with the implications of Mankiw and Reis' (2002) sticky information model of price formation; or alternatively, inflation expectations could rise more gradually if expectations formation was partially adaptive. Ceteris paribus, a more gradual rise in expected inflation would tend to reduce both the aggregate multiplier and spillovers to the periphery.

Finally, it bears emphasizing that the model's implications of large spillovers depend on our assumptions that neither monetary nor fiscal policy acts to offset the stimulus. Clearly, the stimulus to the core and periphery would be much smaller if monetary policy began hiking rates more quickly as resource slack and the inflation gap closed. On the fiscal side, both the aggregate multiplier and associated spillovers would be lower if the fiscal reaction function implied a more aggressive reaction to government debt (Drautzberg and Uhlig 2015). 


\section{Conclusions}

Our paper has considered the implications for the euro area of a fiscal expansion in the core economies, with particular focus on how the periphery would be affected. We have shown that not only does the fiscal multiplier for the euro area as a whole become much larger in a prolonged liquidity trap, but also that the stimulative effects become relatively more balanced between the core and periphery (though still tilted in favor of the core). Periphery GDP expands as domestic demand is "crowded in" by lower real interest rates, and as net exports are boosted by terms of trade depreciation and an expansion of domestic demand in the core economies. Accordingly, fiscal policy seems a potent tool to improve welfare throughout the euro area, at least to the extent that welfare can be proxied by inflation and output gaps.

While an extensive literature has focused on the potential benefits of fiscal policy in a liquidity trap, most of this analysis has abstracted from differences in business cycle positions across member states. Our analysis suggests that fiscal spending is likely to be much more effective in boosting welfare to the extent that it can be targeted to countries or states facing relatively adverse business cycle conditions. Thus, a euro area fiscal compact that would allow more distressed countries greater latitude to engage in deficit-financed spending could yield substantial benefits. Of course, there are many challenges of designing a fiscal union, including of how to limit the moral hazard risks that such insurance might pose to other members of the compact.

From a methodological perspective, our modeling framework has abstracted from a number of features that would seem useful extensions for future research. First, our analysis is conducted under the assumption of perfect foresight, implying that the public is convinced that the economy will eventually recover absent fiscal action. The benefit of fiscal expansion would likely be greater in a stochastic environment in which fiscal expansion could help mitigate downside tail risks that likely are substantial in a prolonged liquidity trap. Second, our simple benchmark model assumes 
a representative agent structure with perfect risk sharing. The benefits of fiscal expansion especially using a utility-based welfare criterion - would presumably be greater in a heterogenous agent framework in which risk-sharing was much less pervasive, and each household's consumption more dependent on its particular employment opportunities. ${ }^{46}$ Finally, it would be desirable to extend our modeling framework to allow sovereign borrowing spreads to respond endogenously to changes in fiscal policy.

\footnotetext{
${ }^{46}$ On the other hand, McKay, Nakamura, and Steinsson (2015) argue that taking account of borrowing constraints and uninsurable income risk may imply a somewhat lower interest elasticity of demand than implied by models which assume that financial markets are complete at the national level. A lower interest elasticity would damp the fiscal multiplier in a liquidity trap.
} 


\section{References}

Acconcia, Antonio, Giancarlo Corsetti, and Saverio Simonelli. 2014. "Mafia and Public Spending: Evidence on the Fiscal Multiplier from a Quasi-experiment." American Economic Review, 104(7): 2185-2209

Adolfson, Malin, Stefan Laséen, Jesper Lindé and Mattias Villani (2005). "The Role of Sticky Prices in an Open Economy DSGE Model: A Bayesian Investigation." Journal of the European Economic Association Papers and Proceedings, 3(2-3), 444-457.

Alesina, Alberto and Silvia Ardagna (2010). "Large Changes in Fiscal Policy: Taxes vs. Spending." In Tax Policy in the Economy, edited by Jeffrey Brown, NBER: University of Chicago Press, 35-68.

Almunia, Miguel, Augustin Bénétrix, Barry Eichengreen, Kevin O'Rourke, Gisela Rua, Silvana Tenreyro, and Fabrizio Perri. "From Great Depression to Great Credit Crisis: Similarities, Differences, and Lessons," in Economic Policy 62 (eds G. De Ménil, R. Portes and H.-W. Sinn), John Wiley \& Sons, Ltd, Chichester, UK.

Altig, David, Lawrence J. Christiano, Martin Eichenbaum, and Jesper Lindé (2011). "Firm-Specific Capital, Nominal Rigidities and the Business Cycle." Review of Economic Dynamics, 14(2), $225-247$.

Anderson, Gary and George Moore (1985), "A Linear Algebraic Procedure for Solving Linear Perfect Foresight Models," Economics Letters 17(3), 247-252.

Angeloni, Ignazio, Anil K Kashyap, Benoit Mojon, and Daniele Terlizzese (2003). "The Output Composition Puzzle: A Difference in the Monetary Transmission Mechanism in the Euro Area and U.S.” Journal of Money, Credit, and Banking 35, 1265-1306. 
Auerbach, Alan J. and Yuriy Gorodnichenko (2012). "Measuring the Output Responses to Fiscal Policy," American Economic Journal: Economic Policy, 4(2), 1-27.

Bernanke, Ben, Gertler, Mark and Simon Gilchrist (1999). "The Financial Accelerator in a Quantitative Business Cycle Framework." In Handbook of Macroeconomics, edited by John B. Taylor and Michael Woodford, North-Holland Elsevier Science

Beetsma, Roel, and Massimo Giuliodori, and Franc Klaassen. "Trade Spill-Overs of Fiscal Policy in the European Union: A Panel Analysis," Economic Policy, vol. 21 (48), 639-687.

Bilbiie, Florin O., Monacelli, Tomasso, and Roberto Perotti (2015). "Is Government Spending at the Zero Lower Bound Desirable?," NBER Working Paper 20687.

Blanchard, Olivier, Eugenio Cerutti, and Lawrence Summers (2015). "Inflation and Activity - Two Explorations and their Monetary Policy Implications," IMF Working paper 15-230 (November).

Blanchard, Olivier and Charles Kahn (1980), "The Solution of Linear Difference Models under Rational Expectations," Econometrica 48, 1305-1311.

Blanchard, Olivier and Daniel Leigh (2014). "Learning about Fiscal Multipliers from Growth Forecast Errors," IMF Economic Review 62(2), 179-212.

Blanchard, Olivier and Roberto Perotti (2002). "An Empirical Characterization of The Dynamic Effects of Changes in Government Spending and Taxes on Output," The Quarterly Journal of Economics, 117(4), 1329-1368.

Brave, Scott, Jeffrey Campbell, Jonas Fisher, and Alejandro Justiniano (2012). "The Chicago Fed DSGE Model," Federal Reserve Bank of Chicago Working paper 2012-02 (August). 
Christiano, Lawrence J., Martin Eichenbaum, and Charles Evans (2005). "Nominal Rigidities and the Dynamic Effects of a Shock to Monetary Policy," Journal of Political Economy, 113(1), $1-45$.

Christiano, Lawrence J., Martin Eichenbaum, and Sergio Rebelo (2011). "When is the Government Spending Multiplier Large?," Journal of Political Economy, 119(1), 78-121.

Christiano, Lawrence J., Martin Eichenbaum, and Mathias Trabandt (2015). "Understanding the Great Recession," American Economic Journal: Macroeconomics, 7(1), 110-167.

Christiano, Lawrence, Motto, Roberto and Massimo Rostagno (2008), "Shocks, Structures or Monetary Policies? The Euro Area and the US After 2001," Journal of Economic Dynamics and Control 32(8), 2476-2506.

Christiano, Lawrence, Trabandt, Mathias and Karl Walentin (2007), "Introducing Financial Frictions and Unemployment into a Small Open Economy Model," Sveriges Riksbank Working Paper Series No. 214.

Clarida, Richard, Jordi Galí and Mark Gertler (2001), "Optimal Monetary Policy in Open Versus Closed Economics: An Integrated Approach," American Economic Review Papers and Proceedings 91, 248-252.

Coenen, Günter, Christopher J. Erceg, Charles Freedman, Davide Furceri, Michael Kumhof, René Lalonde, Douglas Laxton, Jesper Lindé, Annabelle Mourougane, Dirk Muir, Susanna Mursula, Carlos de Resende, John Roberts, Werner Roeger, Stephen Snudden, Mathias Trabandt, and Jan in't Veld (2012). "Effects of Fiscal Stimulus in Structural Models," American Economic Journal: Macroeconomics 4(1), 22-68.

Cogan, John F., Tobias Cwik, John B. Taylor, and Volker Wieland (2010). "New Keynesian 
versus Old Keynesian Government Spending Multipliers," Journal of Economic Dynamics and Control 34, 281-295.

Cole, Harold and Maurice Obstfeld (1991). "Commodity Trade and International Risk Sharing: How Much Do Financial Markets Matter?," Journal of Monetary Economics, 28(1), 3-24.

Cook, David and Michael B. Devereux (2011). "Optimal Fiscal Policy in a World Liquidity Trap," European Economic Review, 55(2), 443-462.

Del Negro, Marco, Marc P. Giannoni, and Frank Schorfheide (2015), "Inflation in the Great Recession and New Keynesian Models," American Economic Journal: Macroeconomics 7(1), 168-196.

Thorsten Drautzburg \& Harald Uhlig, 2015. "Fiscal Stimulus and Distortionary Taxation," Review of Economic Dynamics 18(4), 894-920.

Eggertsson, Gauti and Michael Woodford (2003). "The Zero Interest-Rate Bound and Optimal Monetary Policy." Brookings Papers on Economic Activity 1, 139-211.

Eggertsson, Gauti (2011). "What Fiscal Policy is Effective at Zero Interest Rates?" NBER Macroeconomics Annual 2010, Volume 25, NBER Books, National Bureau of Economic Research, $59-112$.

Erceg, Christopher, Luca Guerrieri, and Christopher Gust (2006). "SIGMA: A New Open Economy Model for Policy Analysis," Journal of International Central Banking 2(1), 1-50.

Erceg, Christopher and Jesper Lindé (2013). "Fiscal Consolidation in a Currency Union: Spending Cuts vs. Tax Hikes," Journal of Economic Dynamics and Control 37, 422-445.

Erceg, Christopher and Jesper Lindé (2014). "Is there a Fiscal Free Lunch in a Liquidity Trap?," Journal of the European Economic Association 12(1), 73-107. 
Fujiwari, Ippei and Kozo Ueda (2013) "The Fiscal Multiplier and Spillover in a Global Liquidity Trap," Journal of Economic Dynamics and Control 37, 1264-1283.

Farhi, Emmanuel and Ivan Werning (2012) "Fiscal Multipliers: Liquidity Traps and Currency Unions." Manuscript, Harvard University.

Galí, Jordi, David López-Salido, and Javier Vallés (2007). "Understanding the Effects of Government Spending on Consumption," Journal of the European Economic Association 5(1), $227-270$.

Galí, Jordi and Tommaso Monacelli (2008), "Optimal Monetary and Fiscal Policy in a Currency Union," Journal of International Economics, 76, 116-132.

Gilchrist, Simon, Raphael Schoenle, Jae Sim, and Egon Zakrajšek (2015). "Inflation Dynamics During the Financial Crisis," Finance and Economic Discussion Series paper 2015-012, Board of Governors of the Federal Reserve System (March).

Gordon, Robert, and Robert Krenn (2010). "The End of the Great Depression 1939-41: Policy Contributions and Fiscal Multipliers," NBER Working paper 16380.

Greenwood, Jeremy, Zvi Hercowitz and Gregory W. Huffman (1998), "Investment, Capacity Utilization, and the Real Business Cycle," American Economic Review 78(3), 402-417

Guajardo, Jaime, Daniel Leigh, and Andrea Pescatori (2014). "Expansionary Austerity: International Evidence" Journal of the European Economic Association 12(4), 949-968.

Hebden, James, Lindé, Jesper and Lars E.O. Svensson (2009), "Optimal Monetary Policy in the Hybrid New Keynesian Model under the Zero Lower Bound Constraint," mimeo, Federal Reserve Board and Sveriges Riksbank. 
Jung, Taehun, Yuki Teranishi, and Tsotumu Watanabe (2005). "Optimal Monetary Policy at the Zero-Interest-Rate Bound," Journal of Money, Credit, and Banking 37(5), 813-835.

Kollmann, Robert, Marco Ratto, Werner Roeger, and Lukas Vogel (2015). "What drives the German current account? And how does it affect other EU member states?," Economic Policy 30, 47-93.

Lindé, Jesper (2005). "Estimating New Keynesian Phillips Curves: A Full Information Maximum Likelihood Approach," Journal of Monetary Economics 52(6), 1135-1149.

Lindé, Jesper, Frank Smets, and Raf Wouters (2016). "Challenges for Central Banks' Macro Models," Riksbank Research Paper Series paper 147 (May).

Lucas, Robert E., Jr., (1987). Models of Business Cycles, Basil Blackwell, New York.

Mankiw, N. Gregory and Ricardo Reis (2002). "Sticky Information versus Sticky Prices: A Proposal to Replace the New Keynesian Phillips Curve," Quarterly Journal of Economics 117(4), 1295-1328.

McKay, Alisdair, Emi Nakumura, and Jon Steinsson (2015). "The Power of Forward Guidance Revisited," Manuscript, Columbia University.

Orr, James and John Sporn.(2012) "The American Recovery and Reinvestment Acto of 2009: A Review of Stimulus Spending in New York and New Jersey," Current Issues in Economics and Finance 18(6), 1-12.

Nakamura, Emi, and Jón Steinsson (2014). "Fiscal Stimulus in a Monetary Union: Evidence from US Regions," American Economic Review 104(3): 753-92.

Perotti, Roberto (2007). "In Search of the Transmission Mechanism of Fiscal Policy," NBER Macroeconomics Annual 22, 169-226. 
Ramey, Valerie A. (2011). "Identifying Government Spending Shocks: It's All in the Timing," Quarterly Journal of Economics, 126(1), 1-50.

Romer, Christina and David Romer (2010). "The Macroeconomic Effects of Tax Changes: Estimates Based on New Measures of Fiscal Shocks," American Economic Review 100(3): 763801.

Rotemberg, Julio and Michael Woodford (1997). "An Optimization-Based Econometric Framework for the Evaluation of Monetary Policy." In NBER Macroeconomics Annual volume 12, edited by Ben S. Bernanke and Julio Rotemberg, MIT Press.

Smets, Frank and Raf Wouters (2003). "An Estimated Stochastic Dynamic General Equilibrium Model of the Euro Area," Journal of the European Economic Association 1(5), 1123-1175.

Smets, Frank and Raf Wouters (2007). "Shocks and Frictions in US Business Cycles: A Bayesian DSGE Approach," American Economic Review 97(3), 586-606.

Wieland, Volker (1996). "Monetary Policy Targets and the Stabilization Objective: A Source of Tension within the EMS," Journal of International Money and Finance 15(1), 95-116.

Uhlig, Harald (2010). "Some Fiscal Calculus." American Economic Review Papers and Proceedings 100(2), 30-34.

Woodford, Michael (2003). Interest and Prices. Princeton University Press.

Woodford, Michael (2011). "Simple Analytics of the Government Expenditure Multiplier," American Economic Journal: Macroeconomics 3(1), 1-35. 
Figure 1: Average Output Gaps and Inflation Rates in Euro Area: 2010-2014

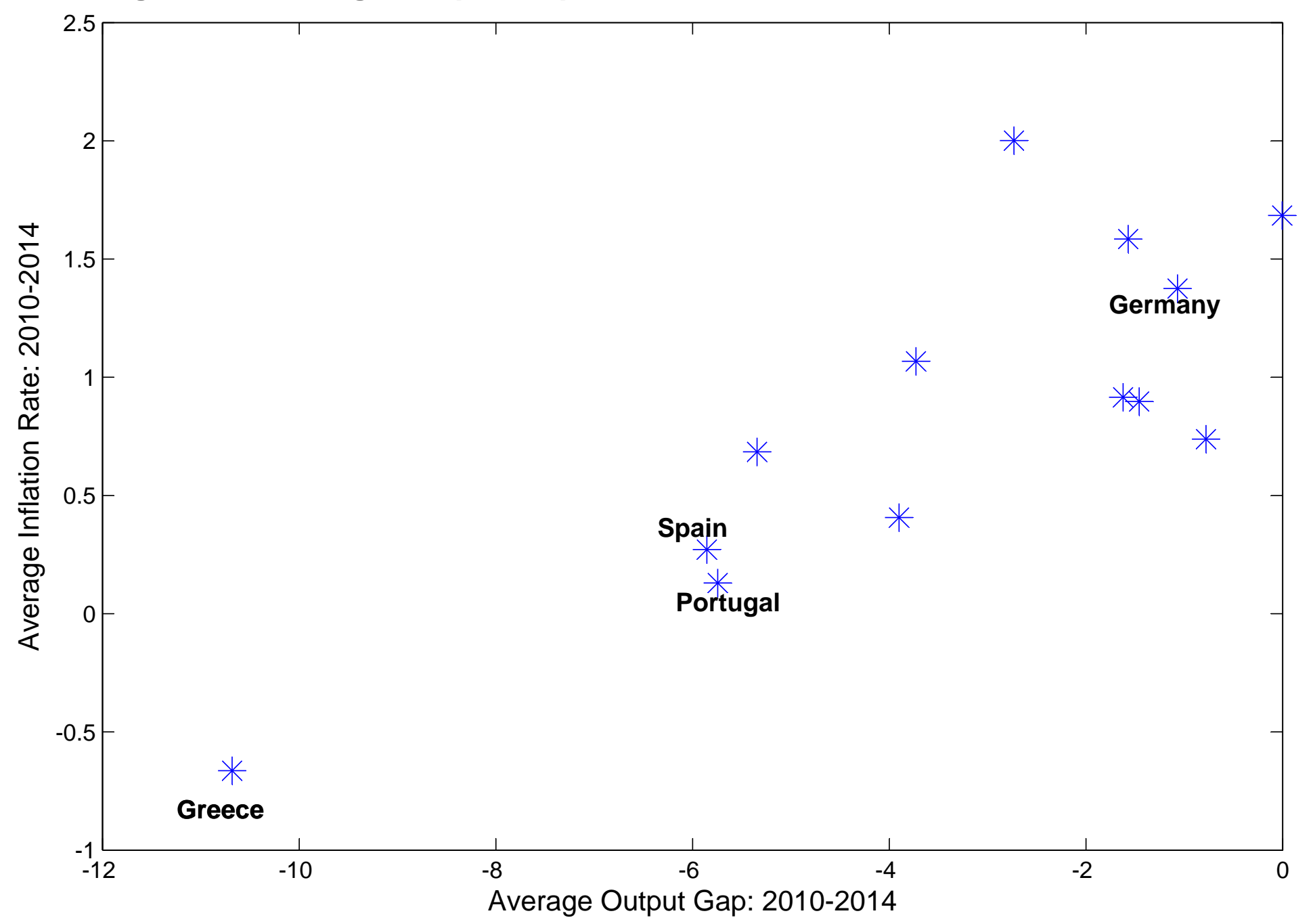


Figure 2: Calibrating the Speed of Price Adjustment

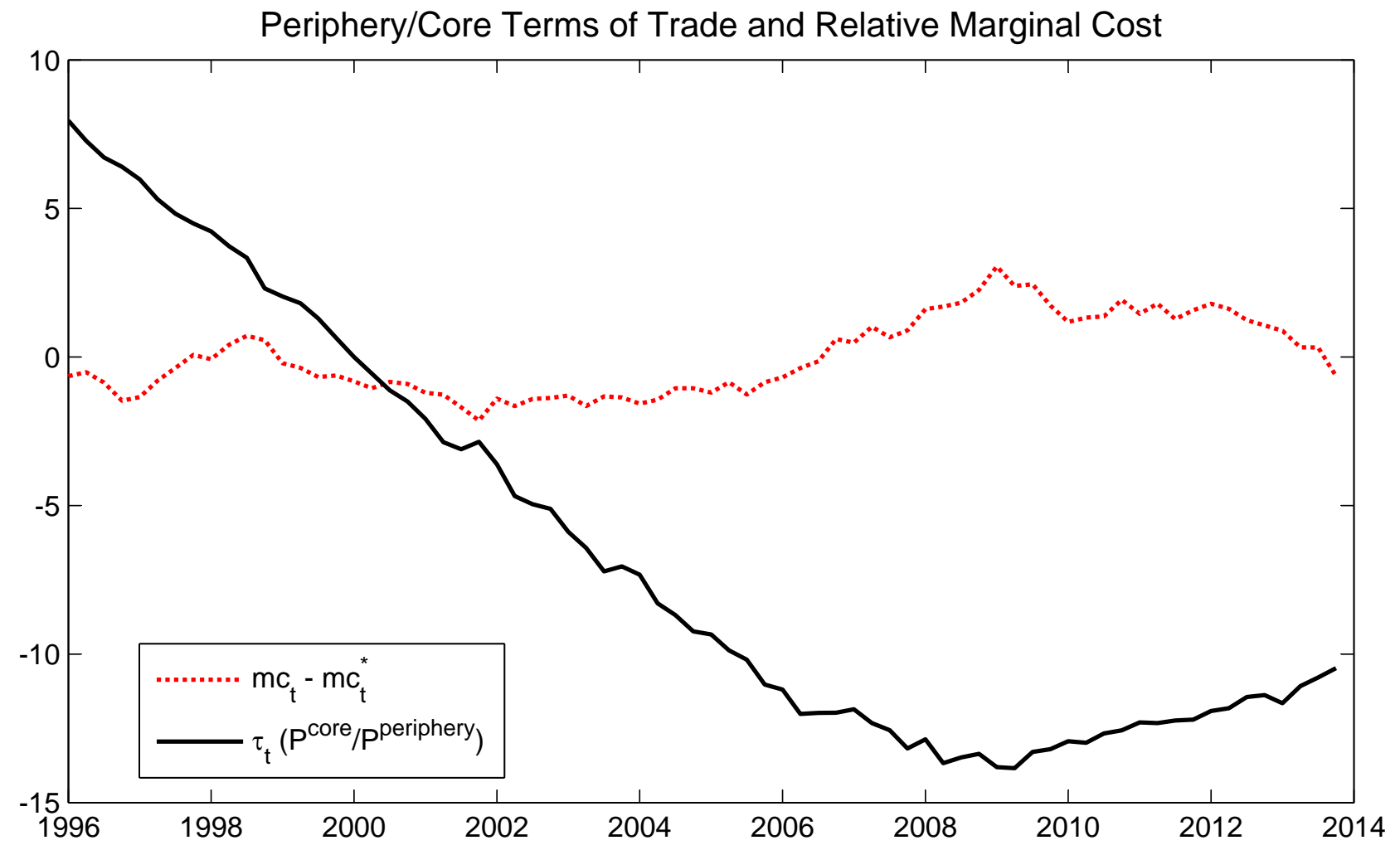

Quasi First Difference of Terms of Trade Vs. Difference of Marginal Cost: 1996Q1 - 2013Q4

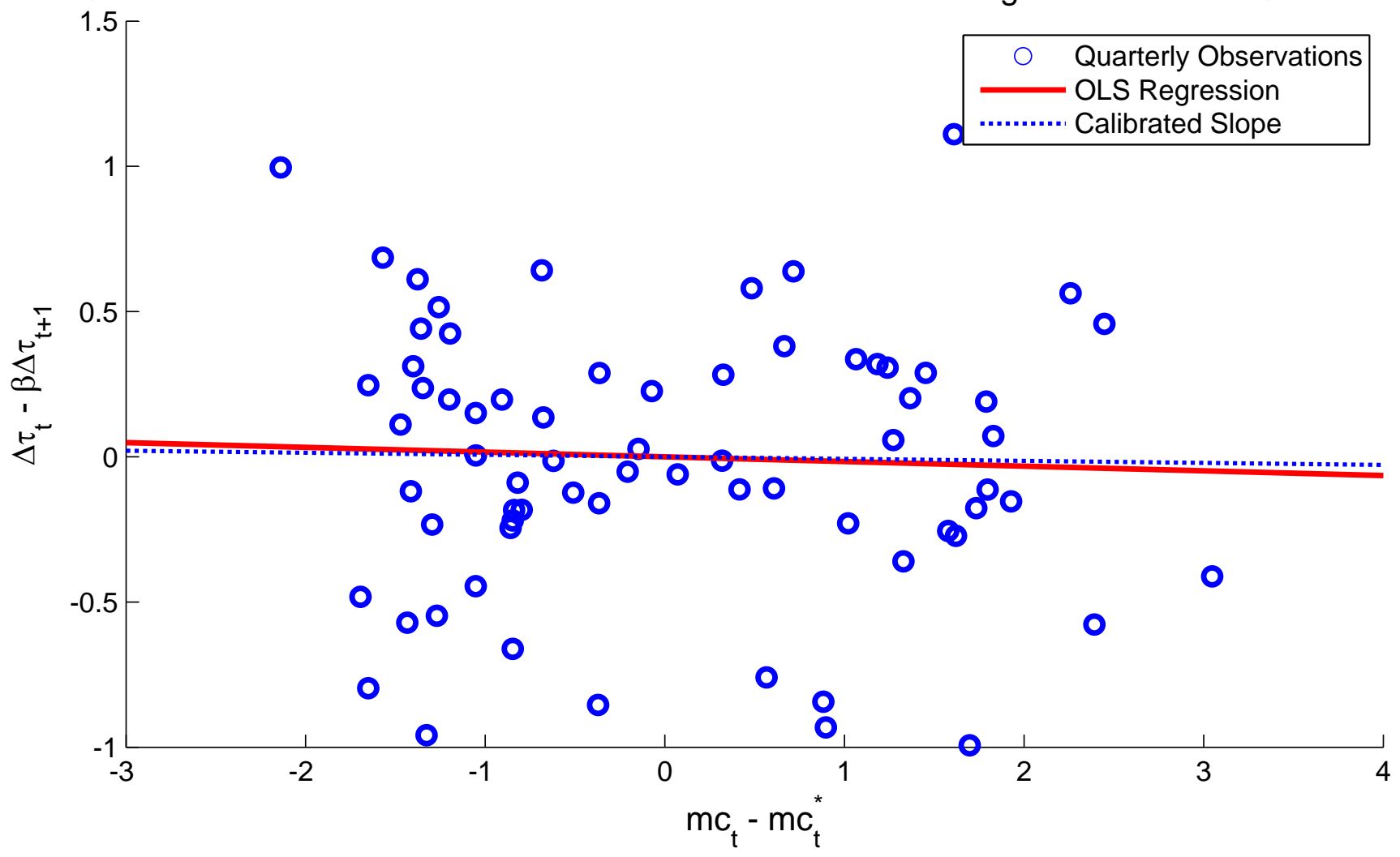


Figure 3: Rise in Core Government Spending

No Liquidity Trap

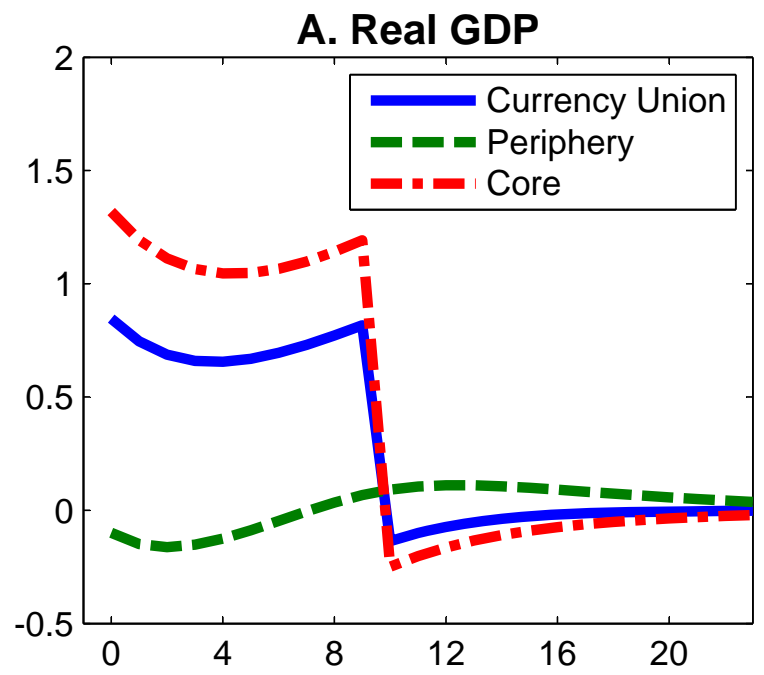

C. Inflation

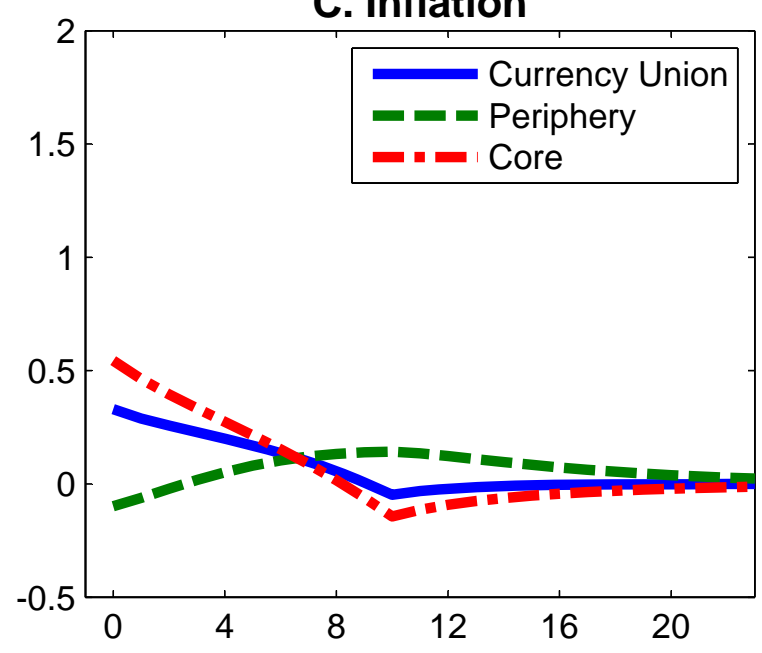

E. Policy Rate and Terms of Trade

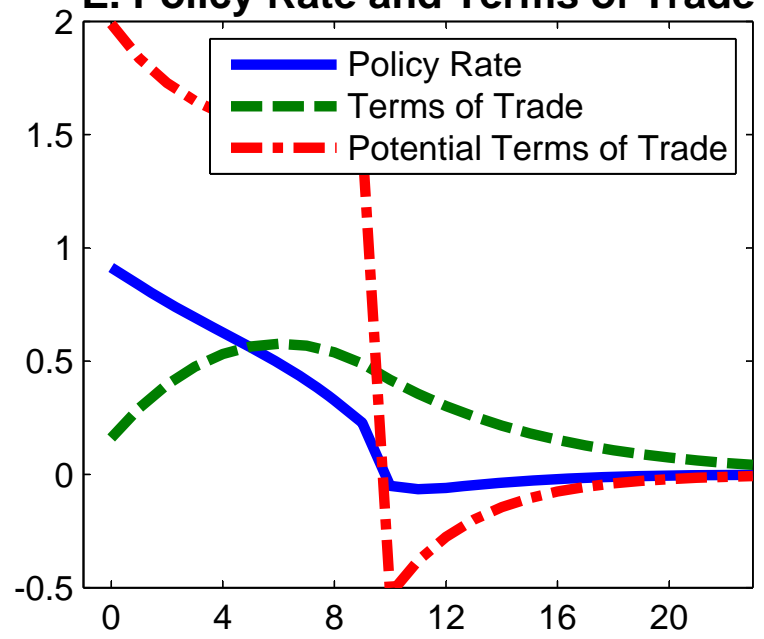

12 Quarter Liquidity Trap

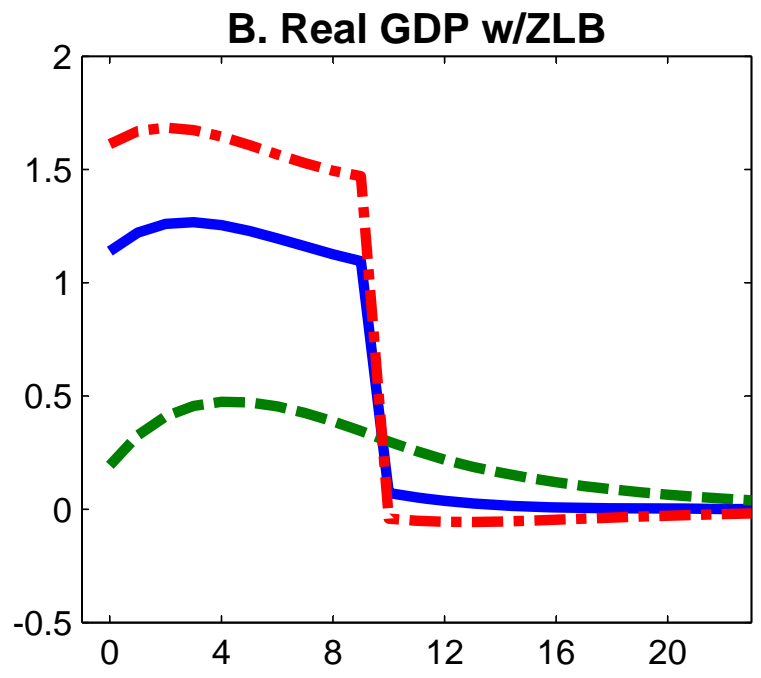

D. Inflation w/ZLB

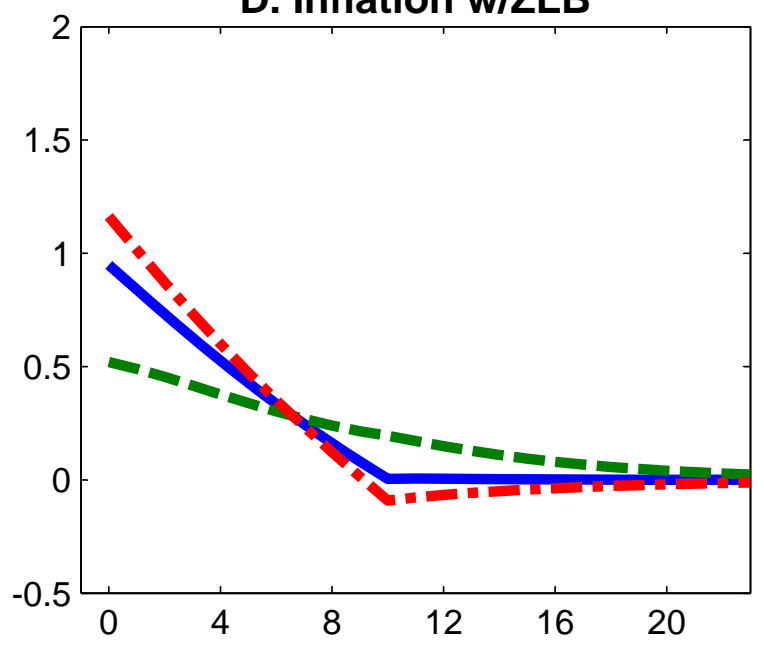

F. Policy Rate and Terms of Trade w/ZLB

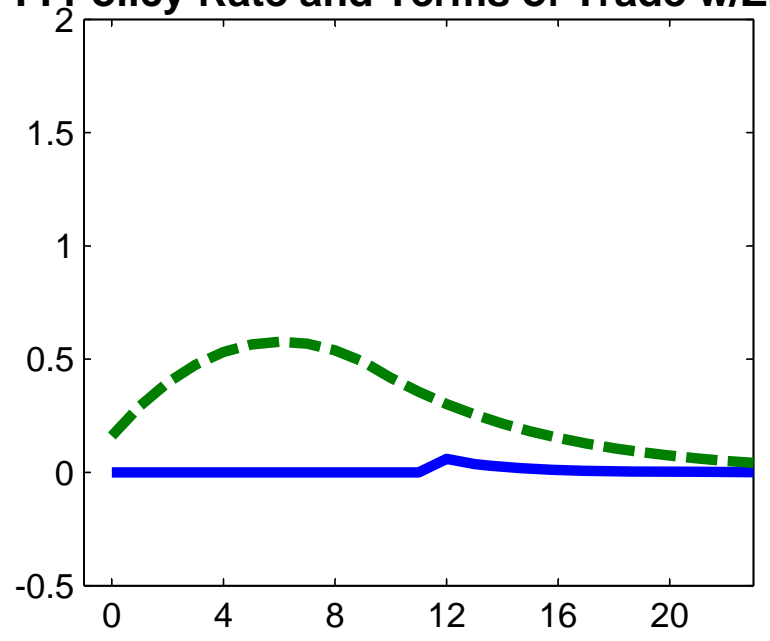


Figure 4: Core Government Spending Hike: Output Responses in Core and Periphery as Function of Liquidity Trap Duration.

Panel A: Benchmark (Slow) vs. Faster Price Adjustment, No Import Content in Core Govt Spending

Periphery Output (Average First Year)

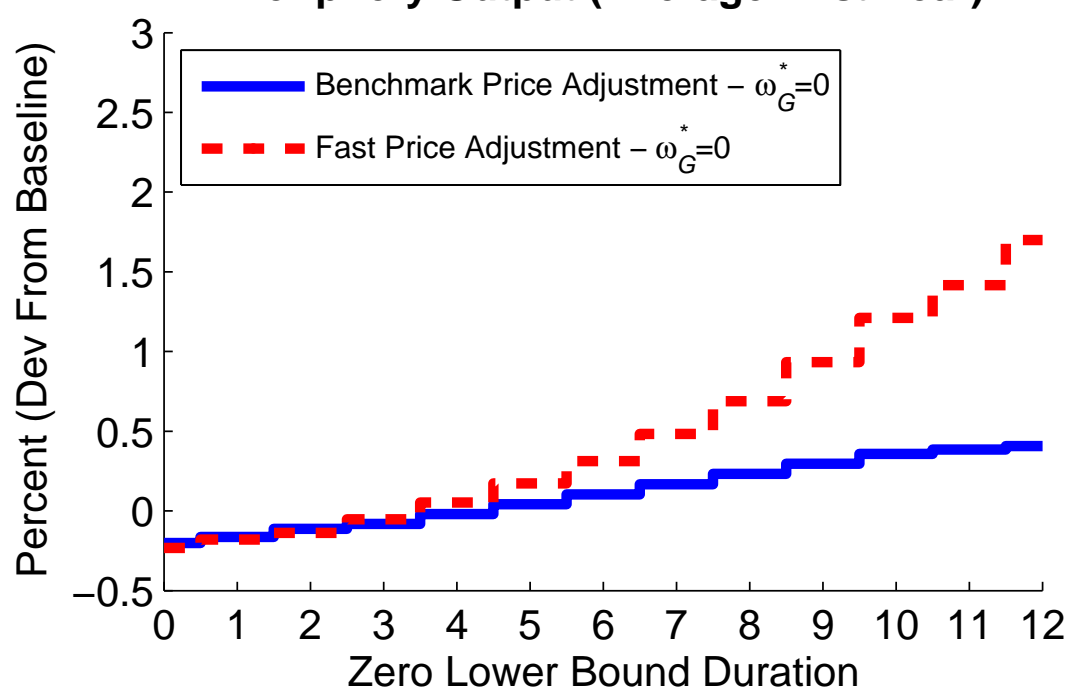

Core Output (Average First Year)

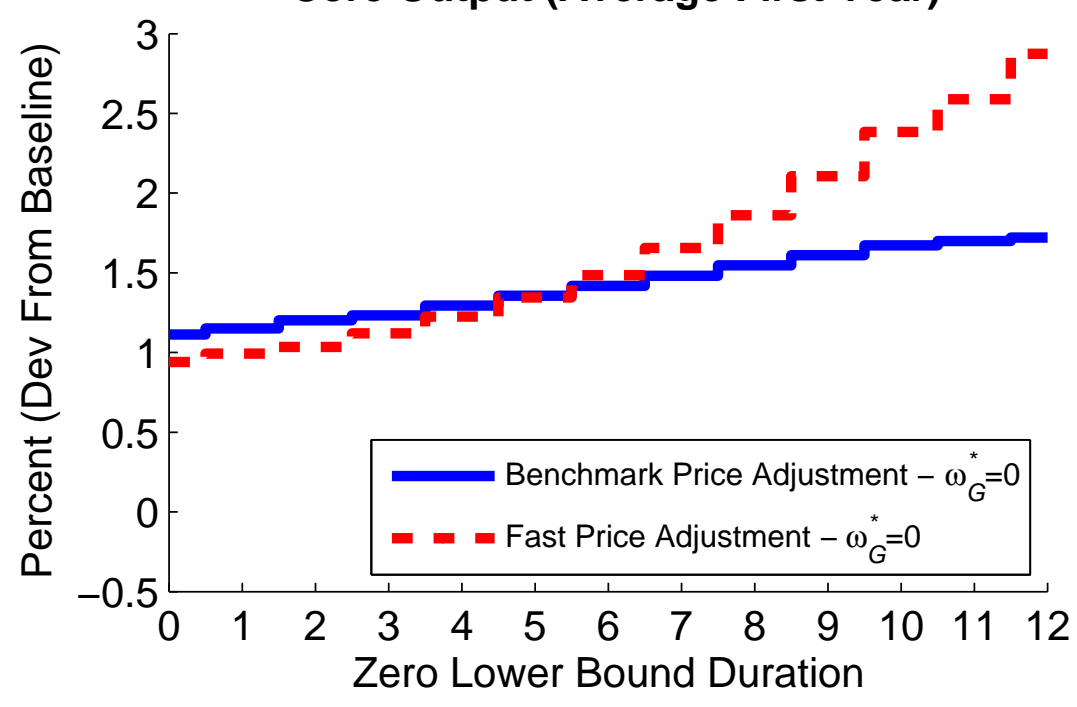

Panel B: Benchmark (Slow) Price Adjustment, Varying the Degree of Import Content in Core Govt Spending

Periphery Output (Average First Year)

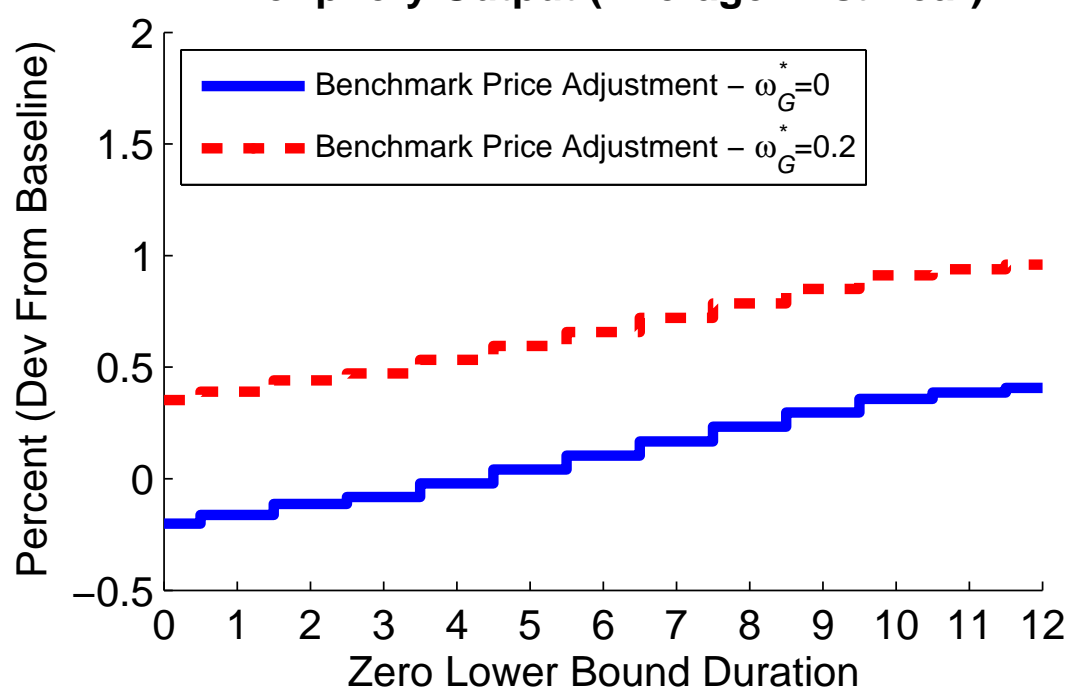

Core Output (Average First Year)

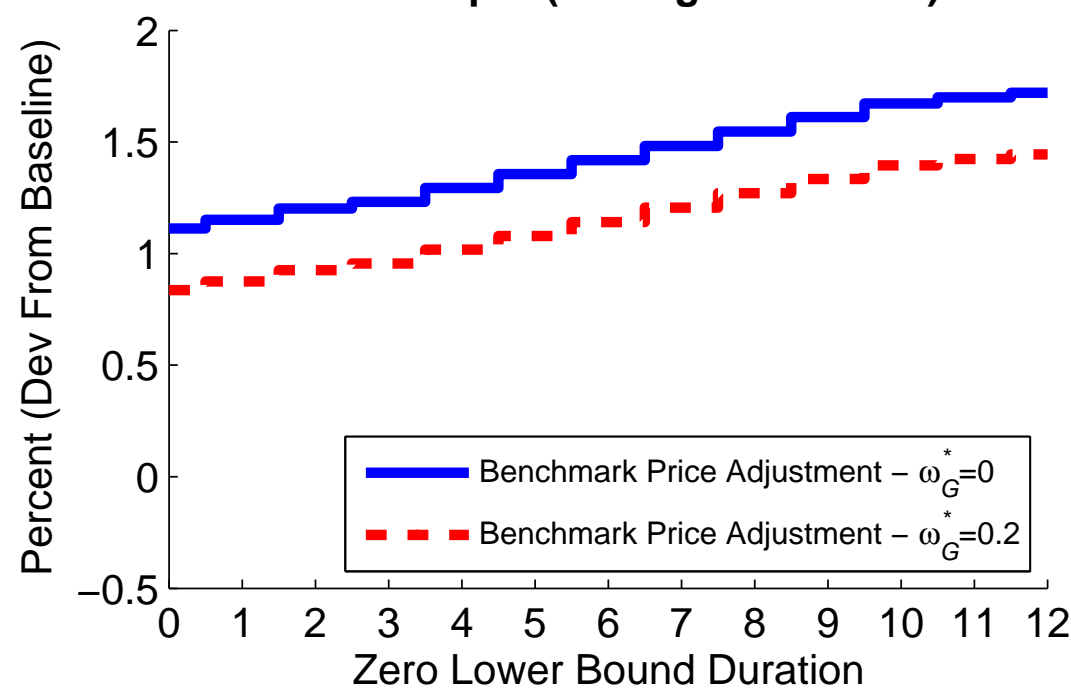


Figure 5: Rise in Core Government Spending: Faster Price Adjustment

No Liquidity Trap

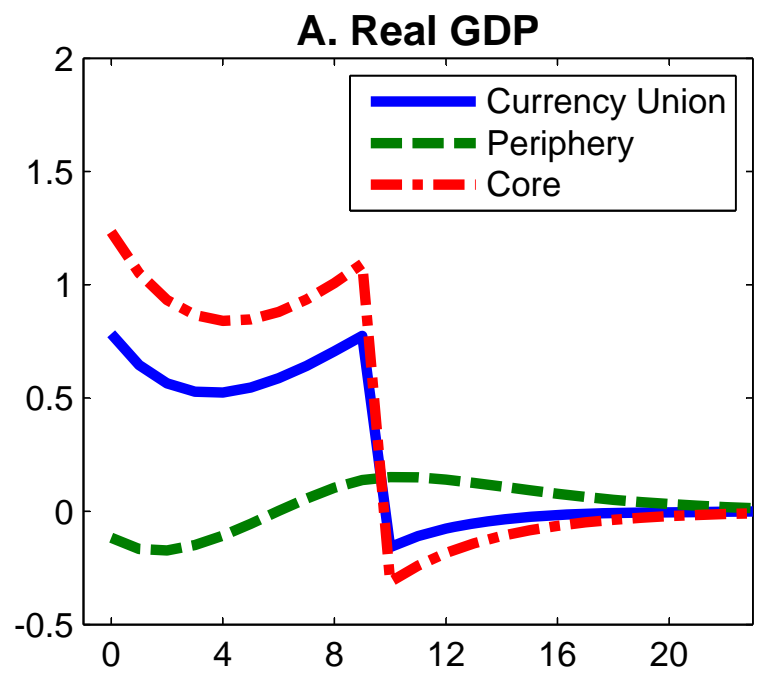

C. Inflation

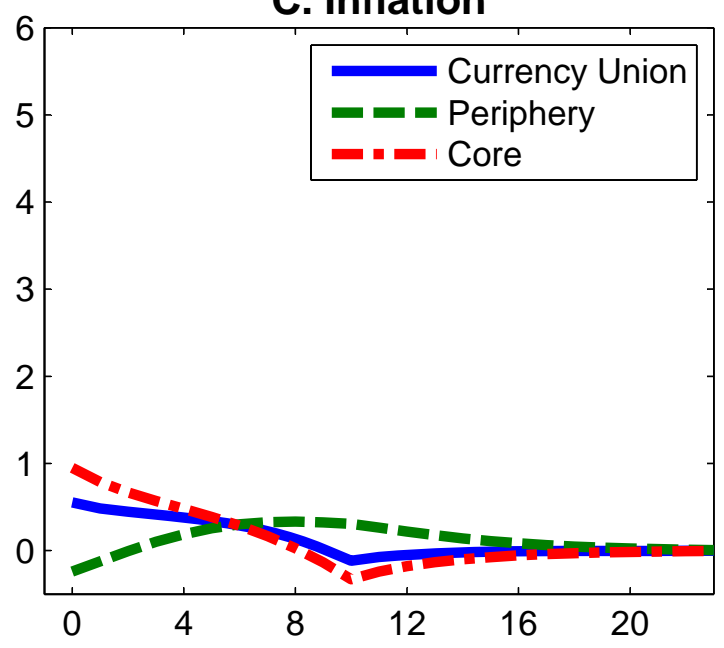

E. Policy Rate and Terms of Trade

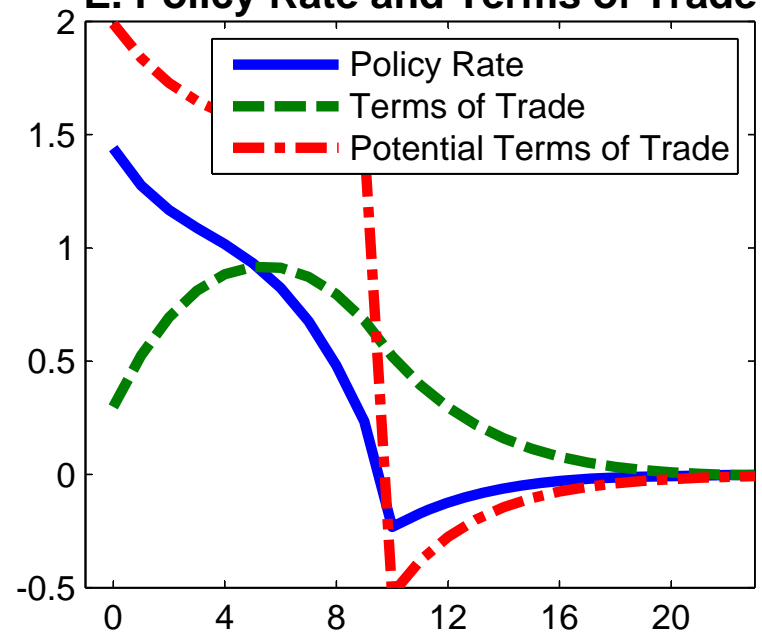

12 Quarter Liquidity Trap

B. Real GDP w/ZLB

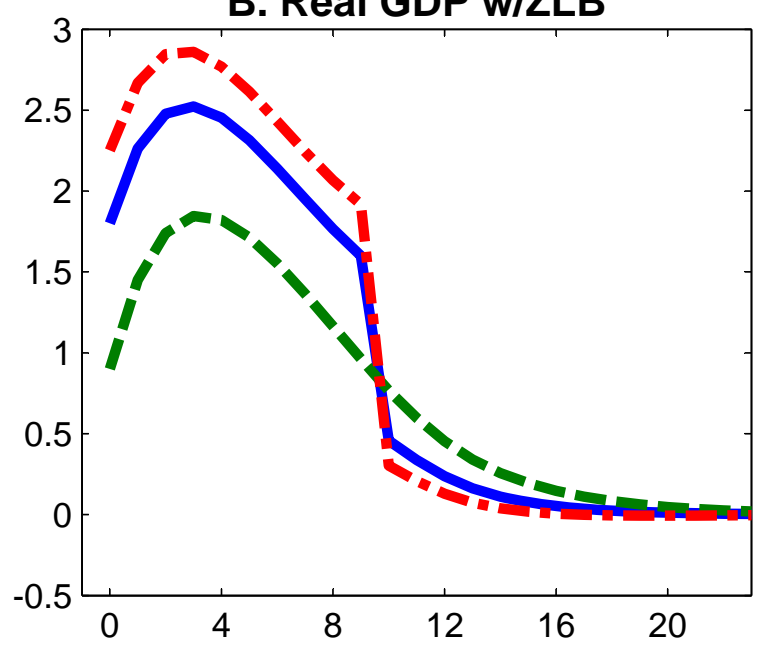

D. Inflation w/ZLB

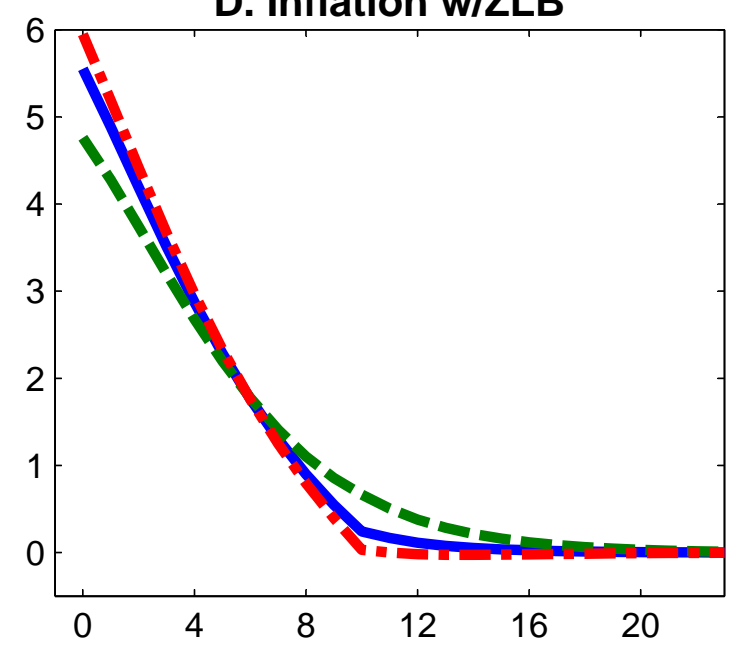

F. Policy Rate and Terms of Trade w/ZLB

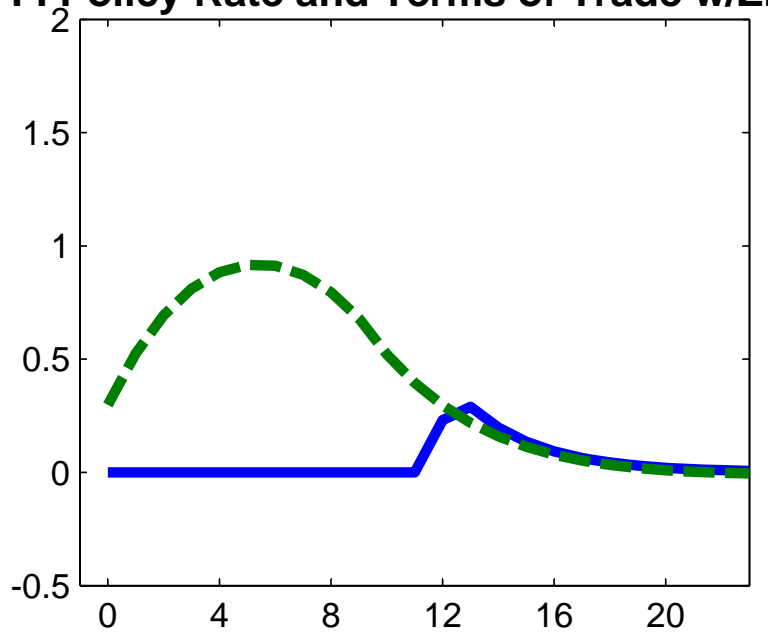


Figure 6: Rise in Core Government Spending: 20 Percent Imported No Liquidity Trap

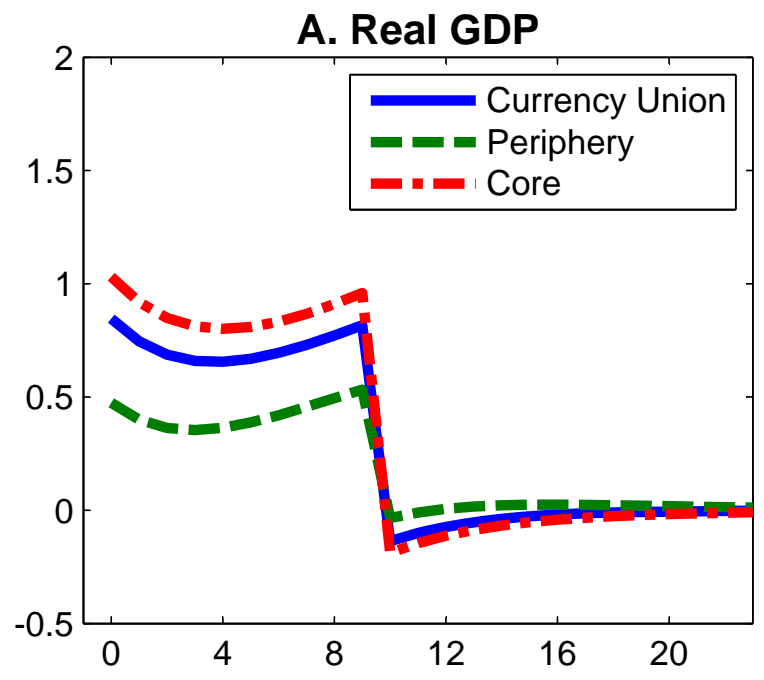

12 Quarter Liquidity Trap
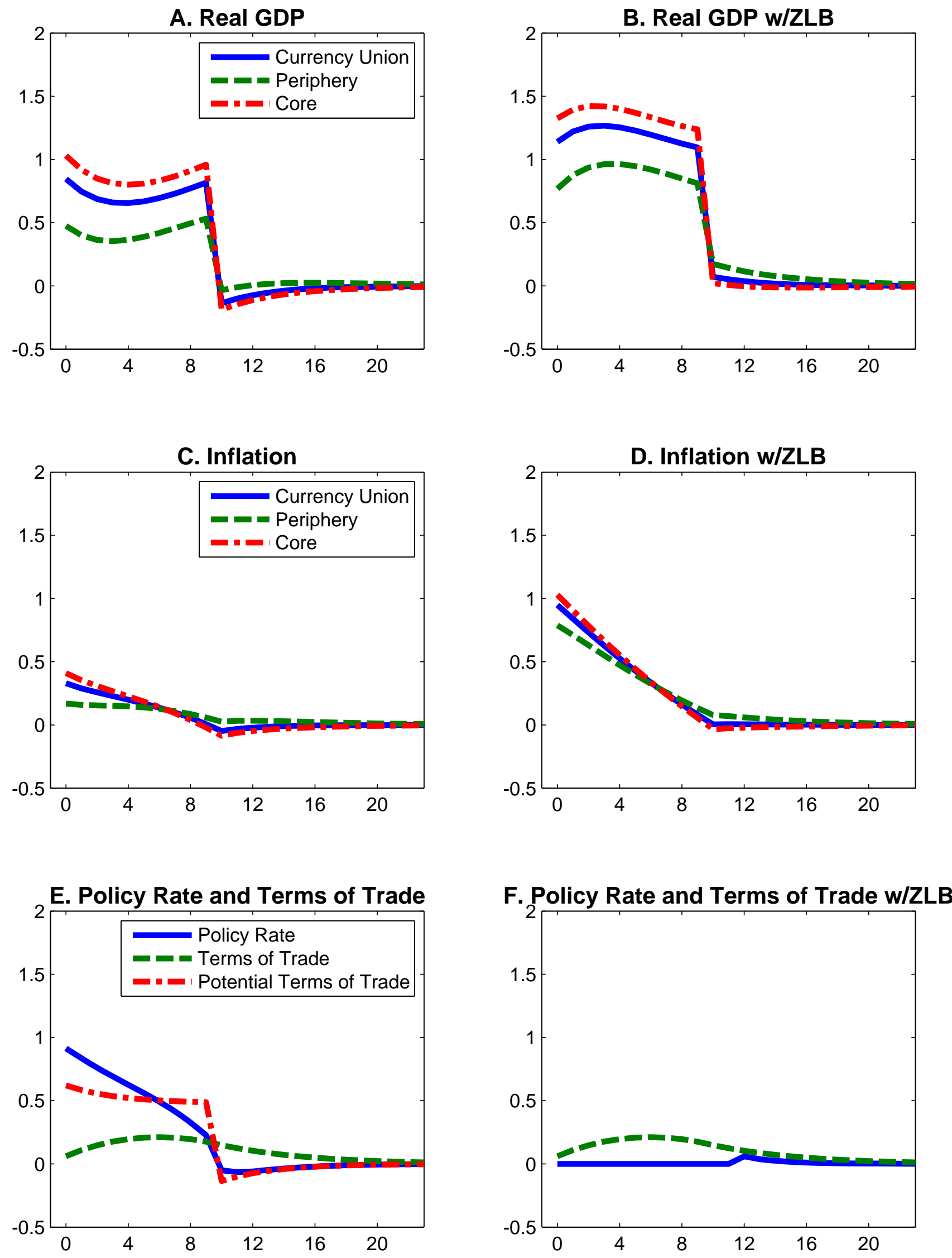
Figure 7: Impact of Fiscal Stimulus When ECB Keeps Exitdate Unchanged.

A. Currency Union Output Gap

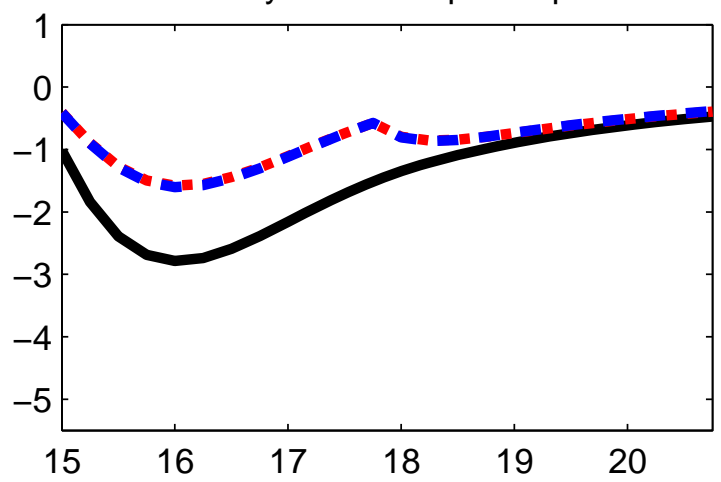

C. Core Output Gap

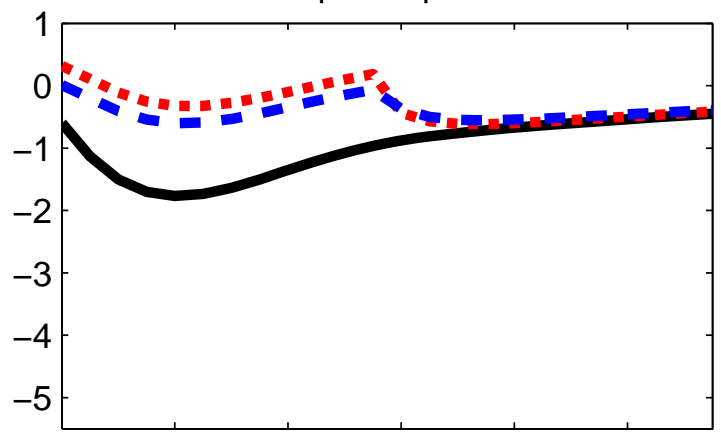

$\begin{array}{llllll}15 & 16 & 17 & 18 & 19 & 20\end{array}$

E. Core Inflation (YoY)

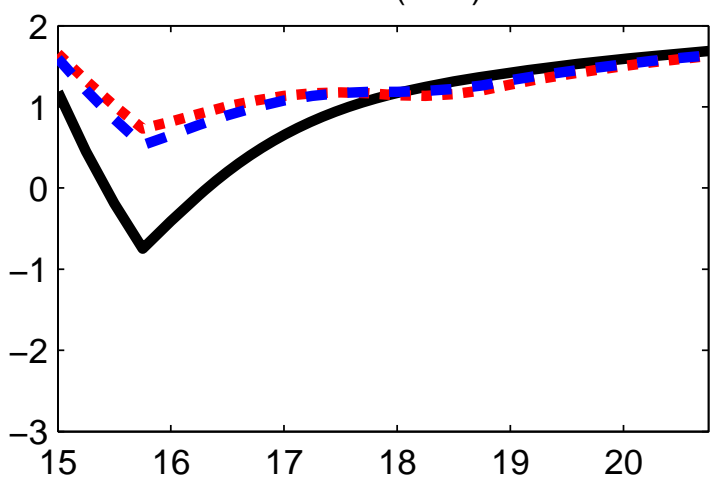

B. Currency Union Inflation (YoY)

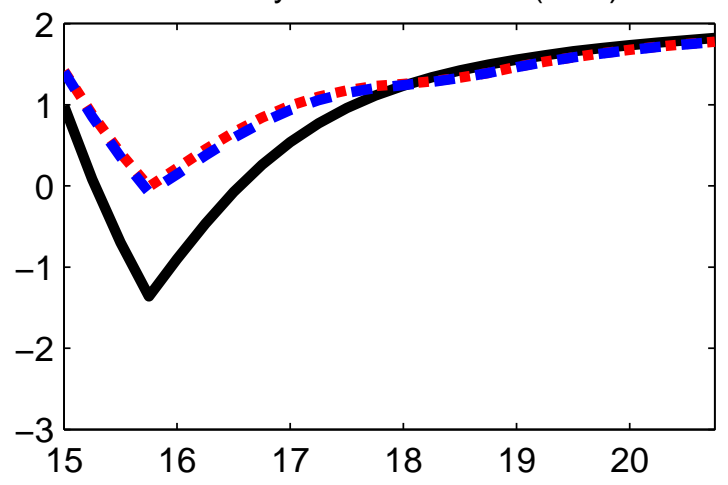

D. Periphery Output Gap

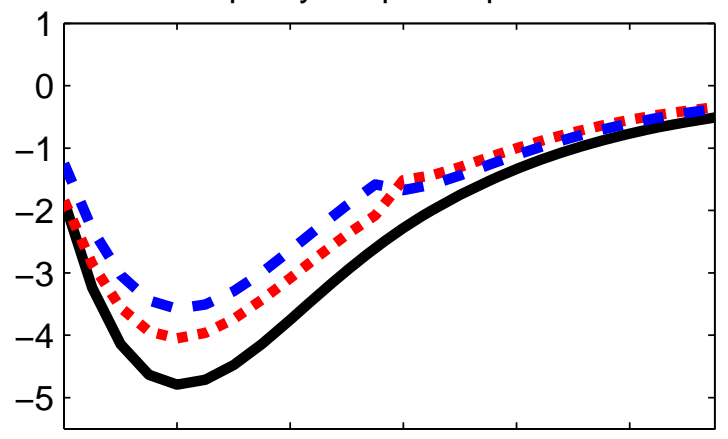

$\begin{array}{llllll}15 & 16 & 17 & 18 & 19 & 20\end{array}$

F. Periphery Inflation (YoY)

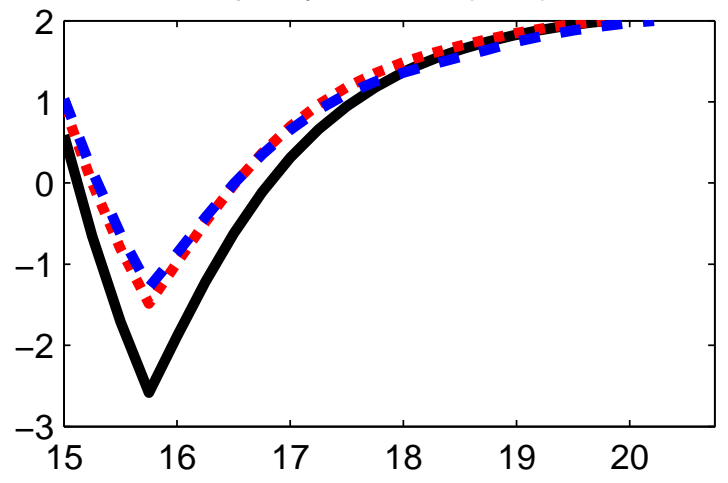

G. ECB Policy Rate (APR)

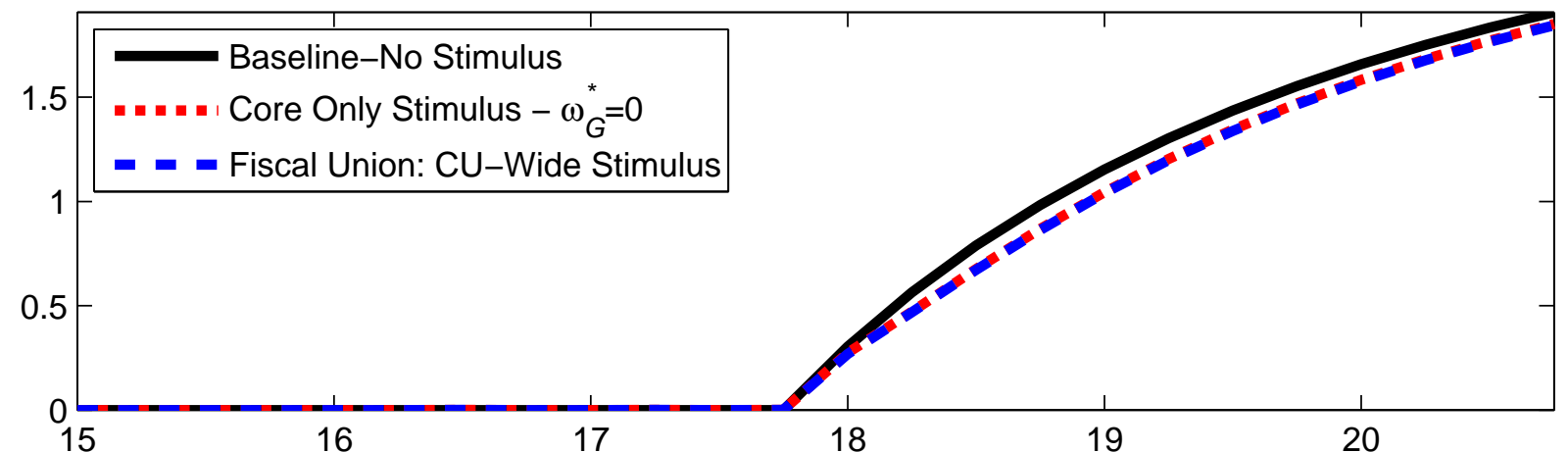


Figure 8: Rise in Core Government Spending in Recession (Deviation From Baseline).

A. Core Consumption

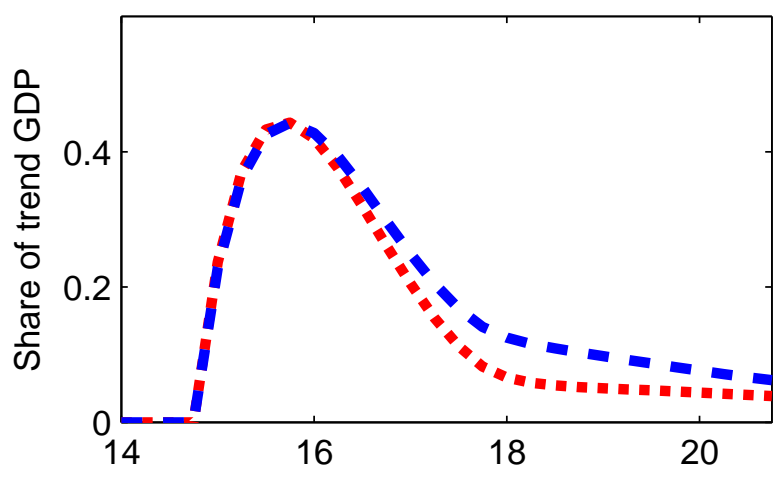

C. Core Hours Worked

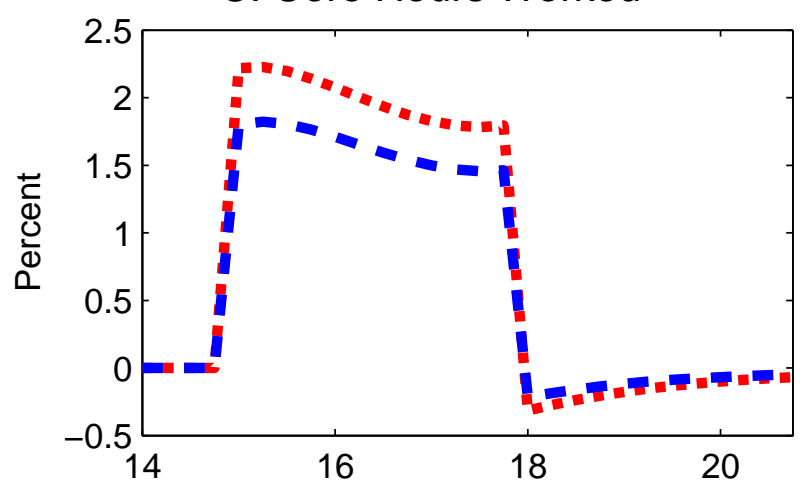

E. Core Net Exports

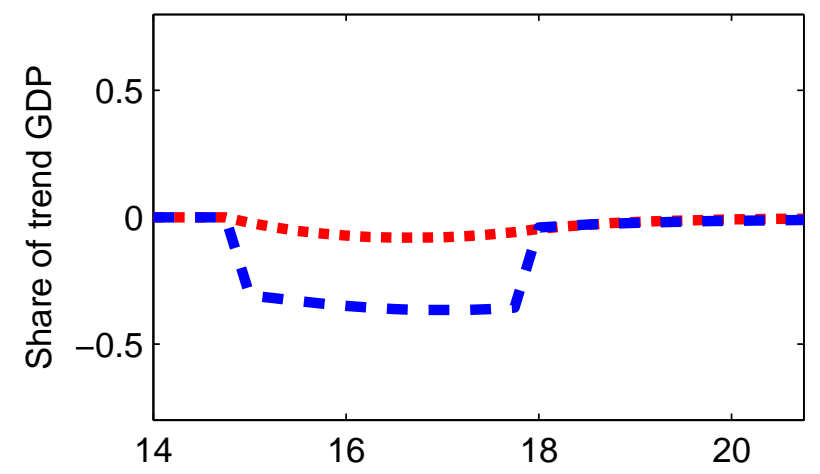

G. Core Period Utility

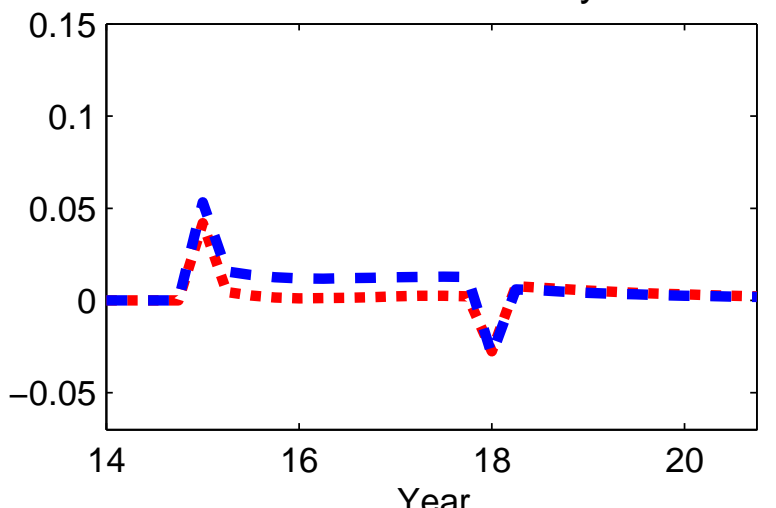

B. Periphery Consumption

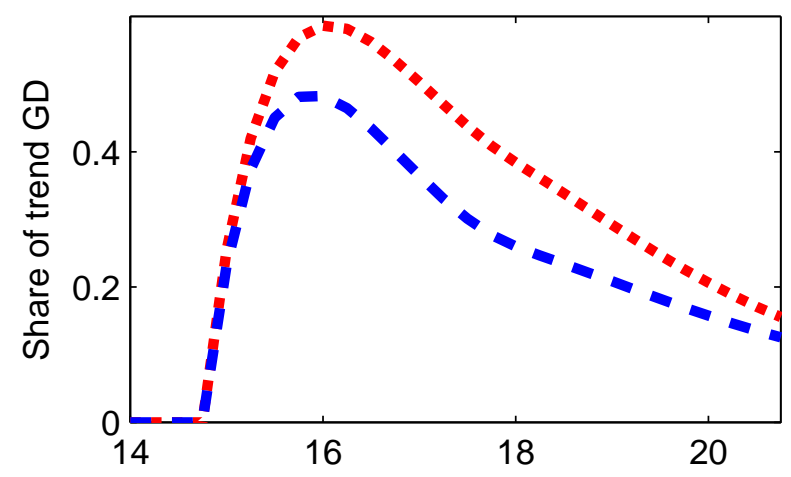

D. Periphery Hours Worked

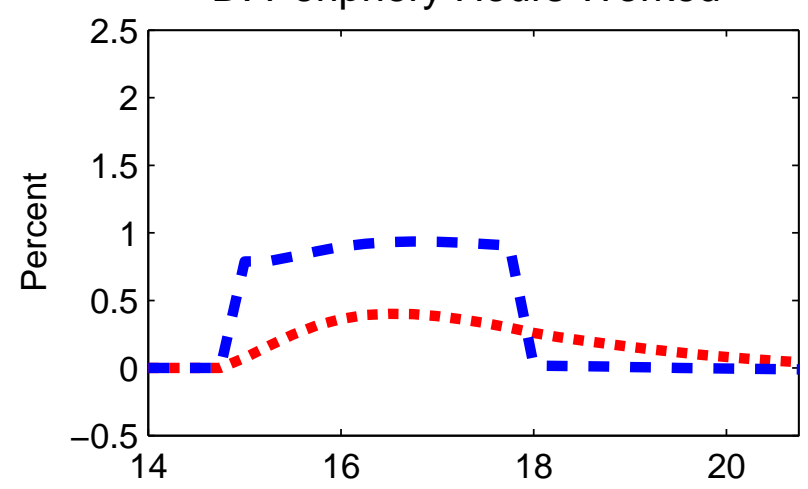

F. Periphery Net Exports

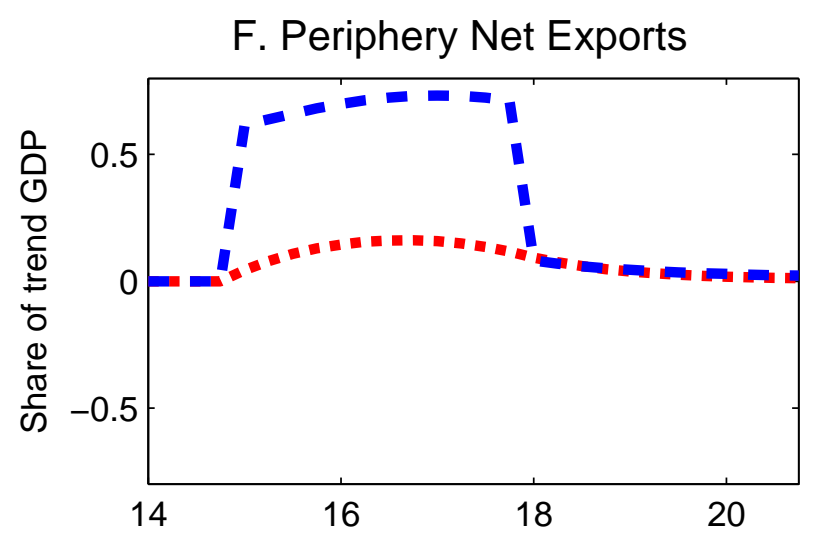

H. Periphery Period Utility
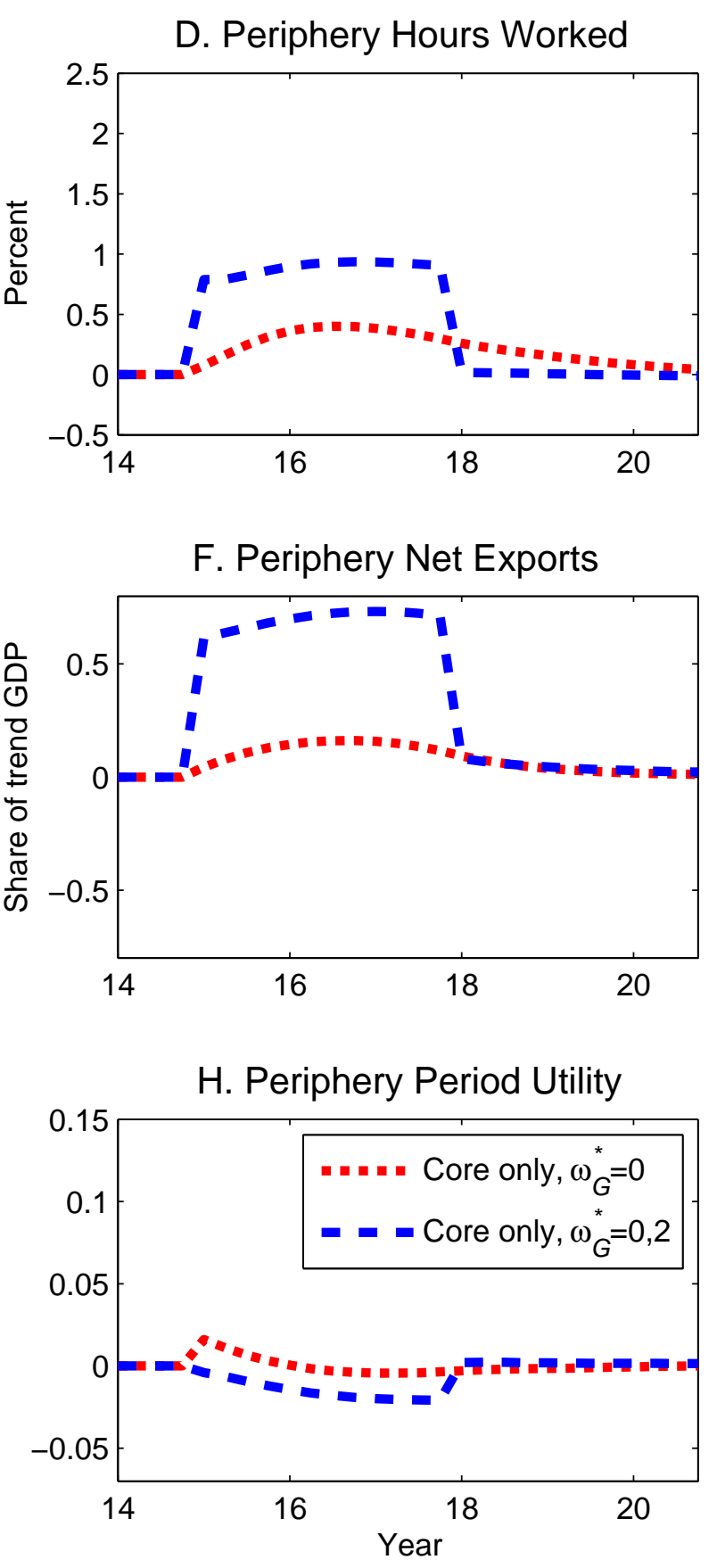
Figure 10: Responses to CU Government Spending Shock (-o- Model, - VAR, Grey Area: $95 \%$ Confidence Interval)

CU Govt Spending (Trend Output Share)
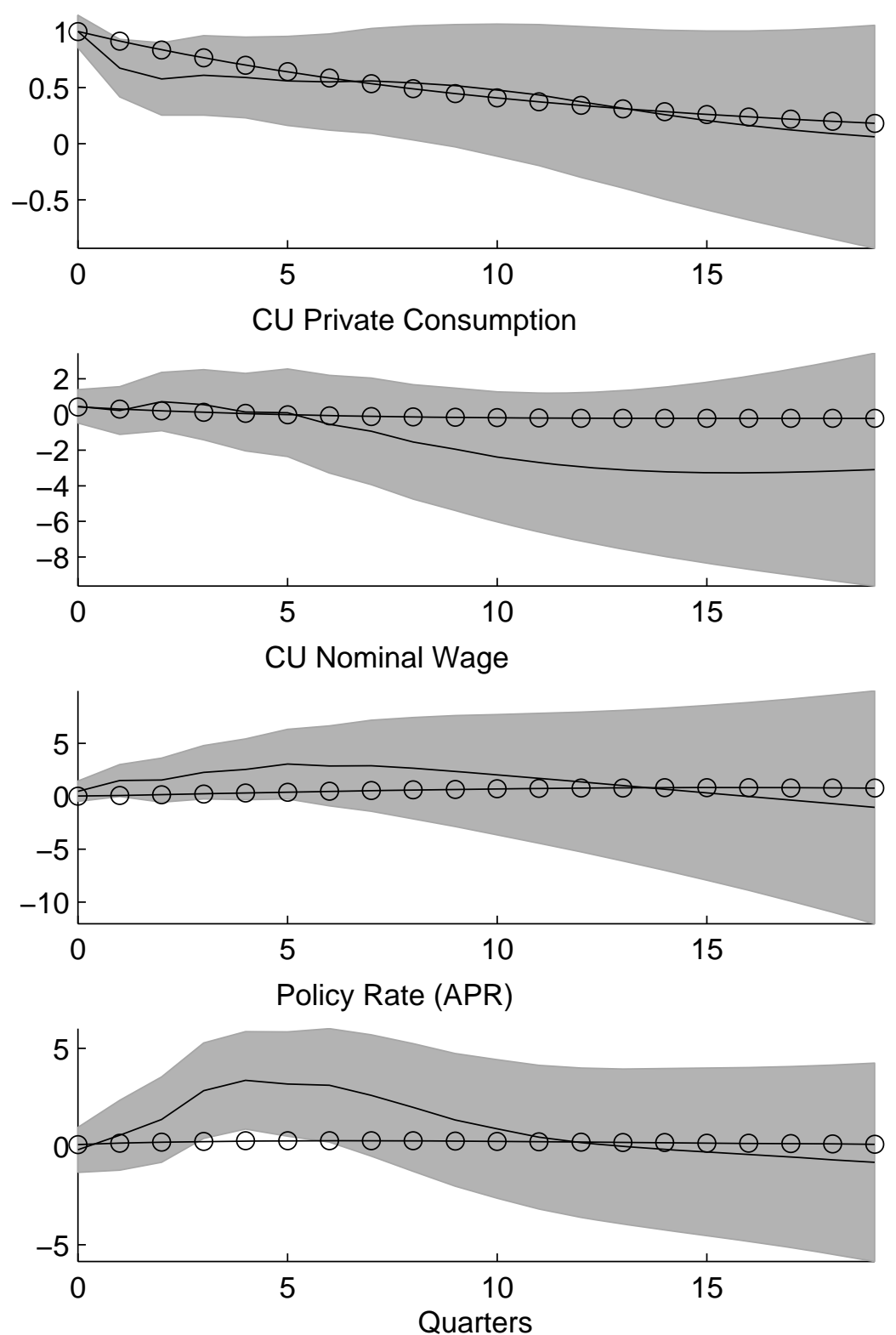

CU Output
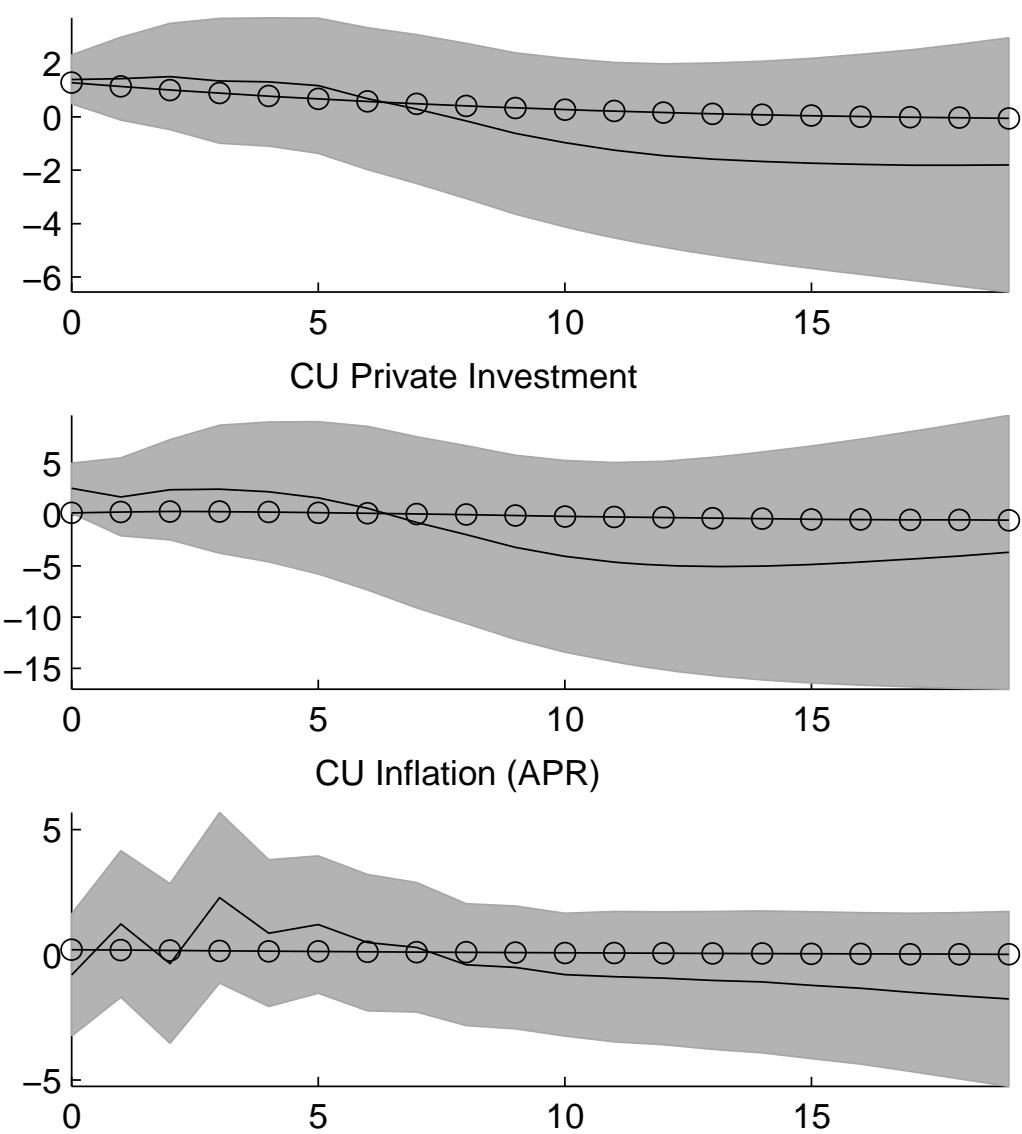

Near-term Effects on CU Private Consumption

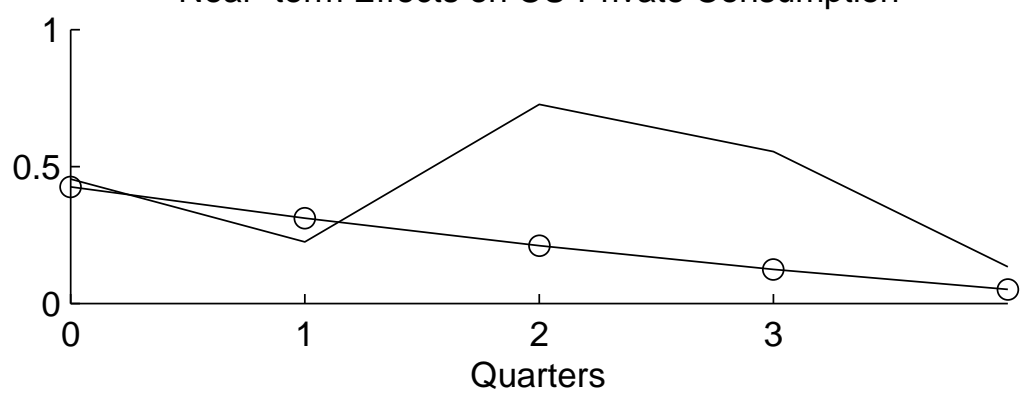


Figure 11: Core Spending Hike in Large-Scale Model in Normal Times.
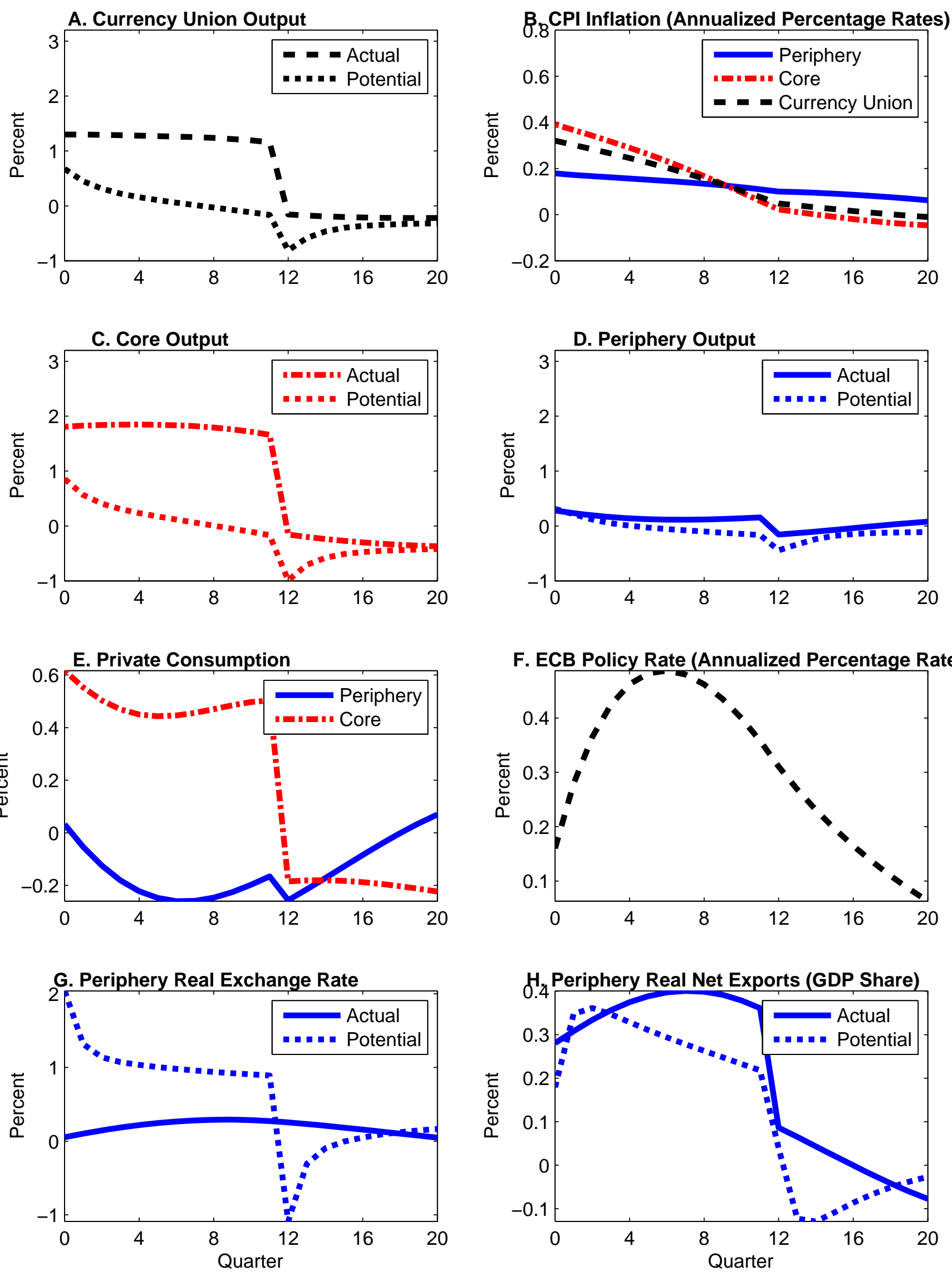
Figure 12: Core Spending Hike in Large-Scale Model in a Long-Lived Liquidity Trap.
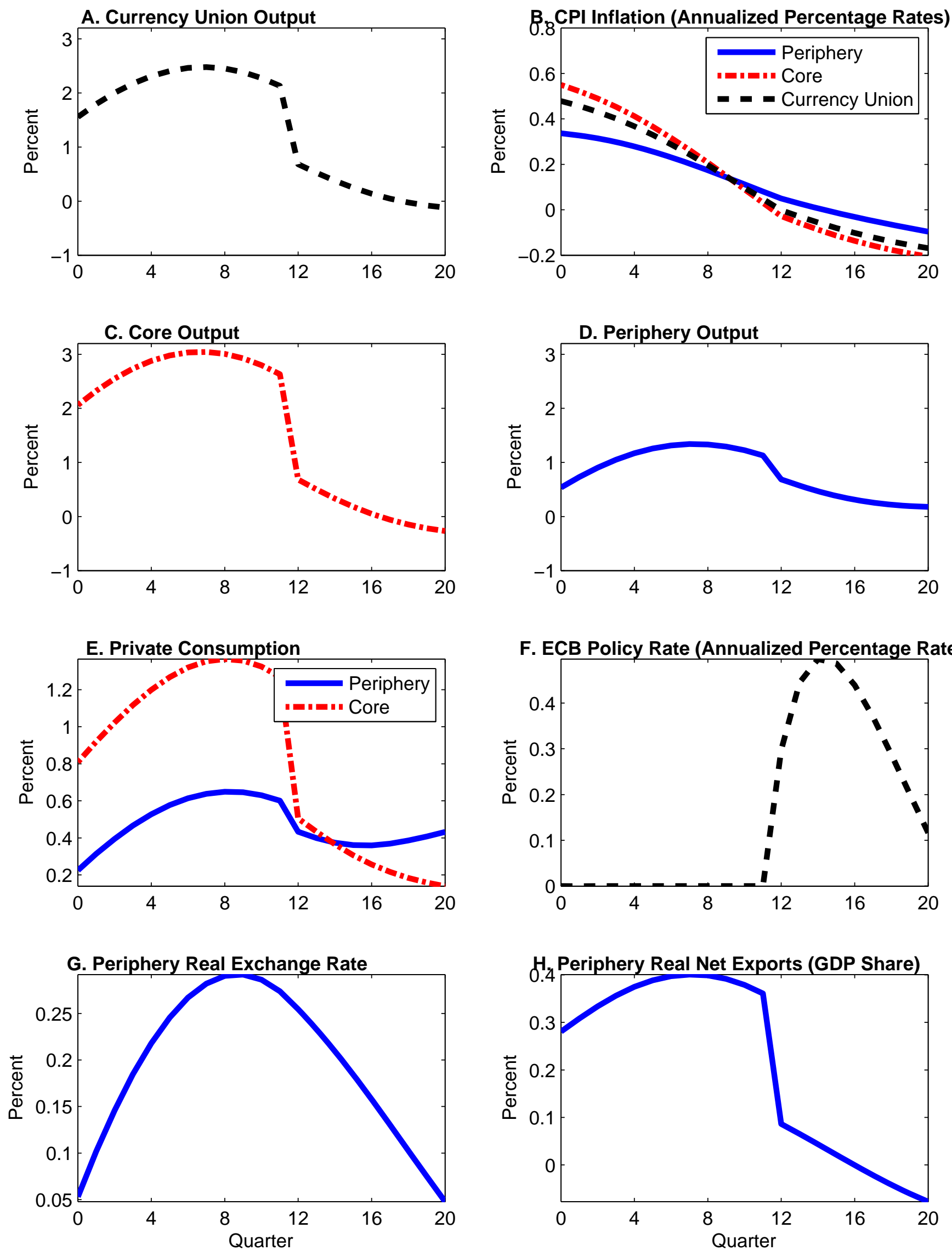


\section{Appendix A. The Benchmark Model}

This Appendix provides a detailed description of the benchmark model from which the log-linearized equations in Section 3 are derived.

\section{A.1. Households}

The utility functional of household $h$ in the home economy is given by:

$$
\mathbb{E}_{t} \sum_{j=0}^{\infty} \beta^{j} \varrho_{t+j}\left\{\begin{array}{c}
\frac{1}{1-\frac{1}{\sigma}}\left(C_{t+j}(h)-\varkappa C_{t+j-1}-C \nu_{t+j}\right)^{1-\frac{1}{\sigma}}-\chi_{0} \frac{\left(N_{t+j}(h)\right)^{1+\chi}}{1+\chi}+\frac{\vartheta_{g}}{1-\frac{1}{\sigma_{g}}} G_{t+j}^{1-\frac{1}{\sigma_{g}}} \\
+\mu_{0} F\left(\frac{M B_{t+j+1}(h)}{P_{C t+j}}\right)
\end{array}\right\}
$$

The preference specification in equation (A.1) implies that household h derives utility from private consumption $C_{t}(h)$, government spending $G_{t}(h)$, and real balances $\frac{M B_{t}(h)}{P_{C t}}$, whereas utility declines in hours worked $N_{t}(h)$. The utility function is assumed to be separable in each of these arguments. The subutility function over consumption incorporates external habit persistence - captured by the presence of lagged aggregate consumption $C_{t-1}$ - with the degree of habit determined by the parameter $\varkappa \in(0,1)$. There are two types of preference shocks, including a consumption taste (demand) shock $\nu_{t}$, and a discount factor shock $\varrho_{t}$. The latter type of shock has been widely used in the ZLB literature (see e.g., Eggertsson, 2011, and Christiano, Eichenbaum and Rebelo, 2011) as a driving force of the "Great Recession." Following Eggertsson and Woodford (2003), the subutility function over real balances, $F\left(\frac{M B_{t+j+1}(h)}{P_{t+j}}\right)$, is assumed to have a satiation point for $\overline{M B} / P$. Hence, the inclusion of money - which is a zero nominal interest asset - provides a rationale for the zero lower bound on nominal interest rates. However, we maintain the assumptions that money is additive and that $\mu_{0}$ is arbitrarily small so that changes in real money balances have negligible implications for government debt and output. Finally, we assume that $0<\beta<1, \sigma>0$, $\sigma_{g}>0, \chi>0, \chi_{0}>0$ and $\vartheta_{g}>0$.

Household $h$ faces a flow budget constraint in period $t$ which states that combined expenditure 
on goods and on the net accumulation of financial assets must equal its disposable income:

$$
\begin{aligned}
P_{C t}\left(1+\tau_{C t}\right) C_{t}(h)+\int_{s} \xi_{t, t+1} B_{t+1}(h)-B_{t}(h)+B_{G, t}(h)= & \left(1-\tau_{N, t}\right) W_{t}(h) N_{t}(h)-T_{t} \quad(\mathrm{~A} .2) \\
& +R_{K t} K+\left(1+i_{t-1}^{C U}\right) B_{G, t-1}(h)+\Gamma_{t}(h) .
\end{aligned}
$$

In (A.2), all variables have been expressed in per capita terms. A household may either spend its income either on consumption goods, which are subject to a sales tax of $\tau_{C t}$, or can save by investing in either government bonds $B_{G, t}(h)$ or contingent claims. The term $\xi_{t, t+1}$ denotes the price of an asset that will pay one unit of domestic currency in a particular state of nature at date $t+1$, and $B_{t+1}(h)$ the quantity of claims purchased. Each household earns per capita labor income net of taxes $\left(1-\tau_{N, t}\right) W_{t}(h) N_{t}(h)$, earns rental income of $R_{K t} K$ on its fixed stock of capital $K$, receives an aliquot share $\Gamma_{t}(h)$ of the firm profits, and pays lump sum taxes of $T_{t}$ to the government. A.1

Each household $h$ maximizes the utility functional (A.1) with respect to its consumption, hours worked, government bonds, and holdings of contingent claims subject to its budget constraint (A.2), taking bond prices, the wage, the rental price of capital $\left(R_{K t}\right)$, and the price of the consumption bundle $\left(P_{C t}\right)$ as given. The first order condition(s) for contingent claims both at home and abroad implies the complete markets condition that the marginal utility of a "euro" is equalized across home and foreign households:

$$
\lambda_{t}=\lambda_{t}^{*}
$$

Because the marginal utility of consumption equals $\Lambda_{C t}=\lambda_{t} P_{C t}$ (and analogously for foreign households), the complete markets condition may be written in the familiar form:

$$
\Lambda_{C t}^{*}=\Lambda_{C t} \frac{P_{C t}^{*}}{P_{C t}}=\Lambda_{C t} Q_{C t} .
$$

\footnotetext{
A.1 While our description of the benchmark model allows for exogenous taxes on consumption and labor income, we abstract from these features in Section 3 (by setting these tax rates equal to zero at all times).
} 
Thus, a depreciation of the home economy's consumption-based real exchange rate ( $Q_{C t}$ rises) boosts the marginal utility of foreign consumption relative to the marginal utility of home consumption.

The first order conditions with respect to $C_{t}, N_{t}$, and $B_{G, t}$ are given by:

$$
\begin{aligned}
\Lambda_{C t} & =\frac{\left(C_{t}-\varkappa C_{t-1}-C \nu_{t}\right)^{-\frac{1}{\sigma}}}{\left(1+\tau_{C, t}\right)}, \\
m r s_{t} & =\frac{\chi_{0} N_{t}^{\chi}}{\Lambda_{C t}}=\left(1-\tau_{N, t}\right) \frac{W_{t}}{P_{C t}} \\
\Lambda_{C t} & =\beta \mathrm{E}_{t} \delta_{t} \frac{\left(1+i_{t}^{C U}\right) P_{C t}}{P_{C t+1}} \Lambda_{C t+1} .
\end{aligned}
$$

The first of these conditions indicates that the marginal utility of consumption decreases in current consumption, but decreases in past consumption due to habit. The second equation is the labor supply curve, which relates the household's marginal cost of working - expressed in terms of the

consumption good, i.e., $m r s_{t}=\frac{\chi_{0} N_{t}^{\chi}}{\Lambda_{C t}}-$ to the after-tax consumption real wage. The final expression is the consumption Euler equation, where $\delta_{t}=\frac{\varrho_{t+1}}{\varrho_{t}}$ is simply a rescaling of the time preference shock.

The problem for the foreign households $h^{*}$ is isomorphic to the problem outlined above for the domestic households.

\section{A.2. Firms and Price-Setting}

Below, we describe the problem for the home producers of both final and intermediate goods.

\section{A.2.1. Production of Final Goods}

We assume that a single final domestic output good $Y_{D t}$ is produced using a continuum of differentiated intermediate goods $Y_{D t}(f)$. The technology for transforming these intermediate goods into 
the final output good is constant returns to scale, and is of the Dixit-Stiglitz form:

$$
Y_{D t}=\left[\int_{0}^{1} Y_{D t}(f)^{\frac{1}{1+\theta_{p}}} d f\right]^{1+\theta_{p}}
$$

where $\theta_{p}>0$.

Firms that produce the final output good are perfectly competitive in both product and factor markets. Thus, final goods producers minimize the cost of producing a given quantity of the output index, $Y_{D t}$, taking as given the price $P_{D t}(f)$ of each intermediate good $Y_{D t}(f)$. Moreover, final

goods producers sell units of the final output good at a price $P_{D t}$ that can be interpreted as the aggregate domestic price index:

$$
P_{D t}=\left[\int_{0}^{1} P_{D t}(f)^{\frac{-1}{\theta_{p}}} d f\right]^{-\theta_{p}}
$$

\section{A.2.2. Production of Domestic Intermediate Goods}

Intermediate good $i$ is produced by a monopolistically competitive firm, whose output $Y_{D t}(i)$ is produced according to a Cobb-Douglas production function:

$$
Y_{D t}(i)=K(i)^{\alpha}\left(Z_{t} L_{t}(i)\right)^{1-\alpha}
$$

where $Z_{t}$ denotes a stationary, country-specific shock to the level of technology. Intermediate goods producers face perfectly competitive factor markets for hiring capital and labor. Thus, each firm chooses $K(i)$ and $L_{t}(i)$, taking as given both the rental price of capital $R_{K t}$ and the aggregate wage rate $W_{t}$. Within a country, labor and the capital stock (albeit fixed in the aggregate) are completely mobile; thus, the standard static first-order conditions for cost minimization imply that all intermediate firms have identical marginal cost per unit of output:

$$
M C_{t}=\left(\frac{W_{t}}{1-\alpha}\right)^{1-\alpha}\left(\frac{R_{K t}}{\alpha}\right)^{\alpha} \frac{1}{Z_{t}^{1-\alpha}}
$$


where the standard static cost minimization problem of the firm implies that

$$
R_{K t}=\frac{\alpha}{1-\alpha} W_{t} \frac{L_{t}}{K}
$$

Intermediate goods-producing firms set prices according to Calvo-style staggered contracts, and set the same price in both the home and foreign market (i.e., the home market price $P_{D t}(i)$ equals the price in the foreign market of $\left.P_{M t}^{*}(i)\right)$. In particular, firm $i$ faces a constant probability, $1-\xi_{p}$, of being able to re-optimize its price, $P_{D t}(i)$. Firms which are not allowed to reoptimize their prices in period $t$ (which is the case with probability $\xi_{p}$ ), update their prices according to the following formula

$$
\tilde{P}_{D t}(i)=\left(1+\pi_{D}\right) P_{D t-1}(i)
$$

where $\pi_{D}$ is the steady-state (net) inflation rate and $\tilde{P}_{D t}$ is the updated price.

Given Calvo-style pricing frictions, firm $i$ that is allowed to reoptimize its price $\left(P_{D t}^{o p t}(i)\right)$ solves the following problem

$$
\max _{P_{D t}^{o p t}(i)} \mathrm{E}_{t} \sum_{j=0}^{\infty} \xi_{p}^{j} \psi_{t, t+j}\left[\left(1+\pi_{D}\right)^{j} P_{D t}^{o p t}(i)-M C_{t+j}\right] Y_{D t+j}(i)
$$

where $\psi_{t, t+j}$ is the stochastic discount factor (the conditional value of future profits in utility units, i.e. $\beta^{j} \mathrm{E}_{t} \varsigma_{t+j} \frac{\lambda_{t+j}}{\lambda_{t}}$, recalling that the household is the owner of the firms), $\theta_{p}$ the net markup and the demand function for firm $i$ has the following general form $Y_{D t+j}(i)=\left[\frac{P_{D t}^{o p t}(i)}{P_{D t}}\right]^{\frac{-\left(1+\theta_{p}\right)}{\theta_{p}}} Y_{D t}$. The first-order condition is given by:

$$
\mathrm{E}_{t} \sum_{j=0}^{\infty} \xi_{p}^{j} \psi_{t, t+j}\left[\frac{\left(1+\pi_{D}\right)^{j} P_{D t}^{o p t}(i)}{1+\theta_{p}}-M C_{t+j}\right] Y_{D t+j}(i)=0
$$

Given that all firms which can re-optimize set the same price, the price index for domesticallyproduced goods evolves according to:

$$
P_{D t}=\left[\left(1-\xi_{p}\right)\left(P_{D t}^{o p t}\right)^{\frac{-1}{\theta_{p}}}+\xi_{p}\left((1+\pi) P_{D t-1}\right)^{\frac{-1}{\theta_{p}}}\right]^{-\theta_{p}}
$$


The productive structure of the foreign economy is isomorphic. Thus, the final good is comprised of a bundle of intermediate goods according to the production function $Y_{D t}^{*}=\left[\int_{0}^{1} Y_{D t}^{*}(f)^{\frac{1}{1+\theta_{p}}} d f\right]^{1+\theta_{p}}$, and the price of this final good is output of the of final goods is denoted by $P_{D t}^{*}=\left[\int_{0}^{1} P_{D t}^{*}(f)^{\frac{-1}{\theta_{p}}} d f\right]^{-\theta_{p}}$.

\section{A.3. Traded Goods}

Household consumption $C_{t}$ in the home economy depends both on its consumption of the domesticallyproduced final output good $C_{D t}$ and on its consumption of the foreign final output good $M_{C t}$ (i.e., consumer goods imports) according to the CES utility function:

$$
C_{t}=\left(\left(1-\omega_{C}\right)^{\frac{\rho_{C}}{1+\rho_{C}}} C_{D t}^{\frac{1}{1+\rho_{C}}}+\omega_{C}^{\frac{\rho_{C}}{1+\rho_{C}}} M_{C t}^{\frac{1}{1+\rho_{C}}}\right)^{1+\rho_{C}} .
$$

The quasi-share parameter $\omega_{C}$ in equation (A.13) may be interpreted as determining household preferences for home relative to foreign goods, or equivalently, the degree of home bias in household consumption expenditure. The domestically-produced final good is purchased at a price of $P_{D t}$, while the foreign imported good is purchased at a price of $P_{M t}$; given the fixed exchange rate and our assumption of producer currency pricing, the law of one price holds, so that $P_{M t}=P_{D t}^{*}$. Households choose $C_{D t}$ and $M_{C t}$ to minimize the cost of producing the consumption good $C_{t}$ taking the prices $P_{D t}$ and $P_{M t}$ as given. This familiar cost-minimization problem implies the following demand schedules for the imported and domestically-produced good:

$$
M_{C t}=\omega_{C}\left(\frac{P_{M t}}{P_{C t}}\right)^{\frac{-\left(1+\rho_{C}\right)}{\rho_{C}}} C_{t} \quad \text { and } \quad C_{D t}=\left(1-\omega_{C}\right)\left(\frac{P_{D t}}{P_{C t}}\right)^{\frac{-\left(1+\rho_{C}\right)}{\rho_{C}}} C_{t},
$$

while the consumer price index $P_{C t}$, is given by:

$$
P_{C t}=\left(\left(1-\omega_{C}\right) P_{D t}^{\frac{1}{1+\rho_{C}}}+\omega_{C} P_{M t}^{\frac{1}{1+\rho_{C}}}\right)^{1+\rho_{C}}
$$

Similarly to households, the home government also produces final government goods (and services) $G_{t}$ using both the domestically-produced final good $G_{D t}$ and imports of the foreign final good $M_{G t}$ according to the CES production function: 


$$
G_{t}=\left(\left(1-\omega_{G}\right)^{\frac{\rho_{G}}{1+\rho_{G}}} G_{D t}^{\frac{1}{1+\rho_{G}}}+\omega_{G}^{\frac{\rho_{G}}{1+\rho_{G}}} M_{G t}^{\frac{1}{1+\rho_{G}}}\right)^{1+\rho_{G}}
$$

The parameter $\omega_{G}$ measures the import share of government consumption; thus, total home imports depend both on the demand of households, and of the government. The government's demand schedules for both the domestically-produced final good and for imported goods are isomorphic to that of households:

$$
M_{G t}=\omega_{G}\left(\frac{P_{M t}}{P_{G t}}\right)^{\frac{-\left(1+\rho_{G}\right)}{\rho_{G}}} G_{t} \quad \text { and } \quad G_{D t}=\left(1-\omega_{G}\right)\left(\frac{P_{D t}}{P_{G t}}\right)^{\frac{-\left(1+\rho_{G}\right)}{\rho_{G}}} G_{t}
$$

although it is important to note that the degree of home bias in government spending $\omega_{G}$ may differ from that in private spending $\omega_{C}$, and that the government's willingness to substitute between home and traded goods $\left(\frac{-\left(1+\rho_{G}\right)}{\rho_{G}}\right)$ may also differ from that of households $\left(\frac{-\left(1+\rho_{C}\right)}{\rho_{C}}\right)$. The price index for government purchases is given by:

$$
P_{G t}=\left(\left(1-\omega_{G}\right) P_{D t}^{\frac{1}{1+\rho_{G}}}+\omega_{G} P_{M t}^{\frac{1}{1+\rho_{G}}}\right)^{1+\rho_{G}}
$$

We define the terms-of-trade as

$$
\tau_{t}=\frac{P_{M t}}{P_{D t}}=\frac{P_{D t}^{*}}{P_{D t}}
$$

so that an increase in $\tau_{t}$ implies that the home economy can buy less imports for any given level of exports.

\section{A.4. Fiscal Policy}

The government finances its nominal spending on goods and services $P_{G t} G_{t}$ through a consumption sales tax, labor tax, and lump-sum tax (we assume that seignorage revenue is de minimis). Thus, evolution of nominal government debt, $B_{G, t}$, is determined by:

$$
B_{G, t}=\left(1+i_{t-1}\right) B_{G, t-1}+P_{G t} G_{t}-\tau_{C, t} P_{C t} C_{t}-\tau_{N, t} W_{t} L_{t}-T_{t}
$$


We assume that the consumption sales tax $\tau_{C, t}$ and labor tax $\tau_{N, t}$ are determined exogenously, so that lump-sum taxes adjust to satisfy the government's intertemporal budget constraint. Thus, the fiscal rule has no effect on macro variables (other than the stock of debt and the lump-sum tax level itself).

\section{A.5. Aggregate Resource Constraints}

The aggregate resource constraint for the domestic economy is given by:

$$
Y_{D t}=C_{D t}+G_{D t}+\frac{\zeta^{*}}{\zeta}\left[M_{C t}^{*}+M_{G t}^{*}\right]
$$

where exports are weighted by the relative population size of the foreign to home country $\frac{\zeta^{*}}{\zeta}$ as the variables are expressed in per capita terms. Similarly, the resource constraint for the foreign economy is given by:

$$
Y_{D t}^{*}=C_{D t}^{*}+G_{D t}^{*}+\frac{\zeta}{\zeta^{*}}\left[M_{C t}+M_{G t}\right]
$$

where exports are weighted by the relative population size of the home to foreign country $\frac{\zeta}{\zeta^{*}}$. The total population is normalized to unity, i.e.,

$$
\zeta+\zeta^{*}=1
$$

We also make the assumption that trade is balanced for both private consumption and government services, which implies that:

$$
\zeta \omega_{C}=\zeta^{*} \omega_{C}^{*}
$$

and

$$
\zeta \omega_{G}=\zeta^{*} \omega_{G}^{*}
$$

Given complete financial markets, the current account and net foreign assets are always equal 
to zero. The nominal trade balance (in absolute levels) is given by

$$
T B_{t} \equiv \frac{\zeta^{*}}{\zeta} P_{D t}\left[M_{C t}^{*}+M_{G t}^{*}\right]-P_{M t}\left[M_{C t}+M_{G t}\right]
$$

\section{A.6. Monetary Policy}

The currency union central bank is assumed to adhere to a Taylor-type policy rule subject to the ZLB. Given that we start out with a log-linearized version of the model, it is convenient to simply specify the reaction function as a linear relation (aside from the zero lower bound), expressing variables in deviation from baseline form:

$$
i_{t}^{C U}=\max \left(-i, \psi_{\pi} \pi_{t}^{C U}+\psi_{x} x_{t}^{C U}\right)
$$

Here $i$ denotes the steady-state (net) nominal interest rate (equal to $r+\pi$ where $r \equiv 1 / \beta-1$ ), $\pi_{t}^{C U}$ is currency union inflation, and $x_{t}^{C U}$ is the currency union output gap. Currency union inflation $\pi_{t}^{C U}$ is itself a population-weighted average of the inflation rate $\pi_{C t}$ in both the home and foreign country:

$$
\pi_{t}^{C U}=\zeta \pi_{C t}+\zeta^{*} \pi_{C t}^{*}
$$

where each country inflation rate is simply the log percentage change in the respective consumption price index (i.e., $\left.\pi_{C t}=\ln \left(P_{C t} / P_{C t-1}\right)\right)$. The CU output gap $x_{t}^{C U}$ is the difference between currency union output $y_{t}^{C U}$ and its potential level $y_{t}^{C U, p o t}$, with both variables again simply populationweighted averages of the respective country variables:

$$
y_{t}^{C U}=\zeta y_{D t}+\zeta^{*} y_{D t}^{*},
$$

and:

$$
y_{t}^{C U, p o t}=\zeta y_{D t}^{p o t}+\zeta^{*} y_{D t}^{*, p o t}
$$




\section{Appendix B. The Large-Scale Open Economy Model}

The large-scale model closely follows Erceg and Lindé (2013) aside from some features of the fiscal policy specification. As in the benchmark model described in Appendix A, the model consists of two countries - home and foreign - that share a common currency. The larger-scale model extends the benchmark model on a number of dimensions, including allowing for endogenous investment, handto-mouth (HM) or "Keynesian" households, sticky wages as well as sticky prices, trade adjustment costs, and incomplete financial markets across the two countries. Although the model we focus on in Section 6 abstracts from a financial accelerator, the appendix concludes with a brief description of how the model may be modified to include a financial accelerator (Section B.6).

\section{B.1. Firms and Price Setting}

\section{B.1.1. Production of Domestic Intermediate Goods}

As in the simple model, there is a continuum of differentiated intermediate goods (indexed by $i \in[0,1])$ in the home country, each of which is produced by a single monopolistically competitive firm. In the domestic market, firm $i$ faces a demand function that varies inversely with its output price $P_{D t}(i)$ and directly with aggregate demand at home $Y_{D t}$ :

$$
Y_{D t}(i)=\left[\frac{P_{D t}(i)}{P_{D t}}\right]^{\frac{-\left(1+\theta_{p}\right)}{\theta_{p}}} Y_{D t}
$$

where $\theta_{p}>0$, and $P_{D t}$ is an aggregate price index defined below.

Each producer utilizes capital services $K_{t}(i)$ and a labor index $L_{t}(i)$ (defined below) to produce its respective output good. The production function is assumed to have a constant-elasticity of substitution (CES) form:

$$
Y_{D t}(i)=\left(\omega_{K}^{\frac{\rho}{1+\rho}} K_{t}(i)^{\frac{1}{1+\rho}}+\omega_{L}^{\frac{\rho}{1+\rho}}\left(Z_{t} L_{t}(i)\right)^{\frac{1}{1+\rho}}\right)^{1+\rho}
$$


The production function exhibits constant-returns-to-scale in both inputs, and $Z_{t}$ is a countryspecific shock to the level of technology. Firms face perfectly competitive factor markets for hiring capital and labor. Thus, each firm chooses $K_{t}(i)$ and $L_{t}(i)$, taking as given both the rental price of capital $R_{K t}$ and the aggregate wage index $W_{t}$ (defined below). Firms can costlessly adjust either factor of production, which implies that each firm has an identical marginal cost per unit of output, $M C_{t}$. The (log-linearized) technology shock is assumed to follow an $\operatorname{AR}(1)$ process:

$$
z_{t}=\rho_{z} z_{t-1}+\varepsilon_{z, t}
$$

We assume that purchasing power parity holds, so that each intermediate goods producer $i$ sets the same price $P_{D t}(i)$ in both blocks of the currency union, implying that the foreign import price $P_{M t}^{*}(i)=P_{D t}(i)$ and that $P_{M t}^{*}=P_{D t}$. The prices of the intermediate goods are determined by Calvo-style staggered contracts (see Calvo, 1983). In each period, a firm faces a constant probability, $1-\xi_{p}$, of being able to re-optimize its price $\left(P_{D t}(i)\right)$. This probability of receiving a signal to reoptimize is independent across firms and time. If a firm is not allowed to optimize its prices, we follow Christiano, Eichenbaum and Evans (2005) and Smets and Wouters (2003), and assume that the firm must reset its home price as a weighted combination of the lagged and steady state rate of inflation $P_{D t}(i)=\widetilde{\pi_{D t-1}} P_{D t-1}(i)=\pi_{D t-1}^{\iota_{p}} \pi^{1-\iota_{p}} P_{D t-1}(i)$ for the non-optimizing firms. This formulation allows for structural persistence in price-setting if $\iota_{p}$ exceeds zero.

When a firm $i$ is allowed to reoptimize its price in period $t$, the firm maximizes:

$$
\max _{P_{D t}(i)} \mathbb{E}_{t} \sum_{j=0}^{\infty} \psi_{t, t+j} \xi_{p}^{j}\left[\prod_{h=1}^{j} \widetilde{\pi_{D t+h-1}}\left(P_{D t}(i)-M C_{t+j}\right) Y_{D t+j}(i)\right] .
$$

The operator $\mathbb{E}_{t}$ represents the conditional expectation based on the information available to agents at period $t$. The firm discounts profits received at date $t+j$ by the state-contingent discount factor $\psi_{t, t+j}$; for notational simplicity, we have suppressed all of the state indices. ${ }^{\text {B.2 }}$ The first-order

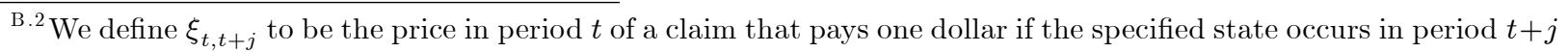


condition for setting the contract price of good $i$ is:

$$
\mathbb{E}_{t} \sum_{j=0}^{\infty} \psi_{t, t+j} \xi_{p}^{j}\left(\frac{\prod_{h=1}^{j} \pi_{D t+h-1} P_{D t}(i)}{\left(1+\theta_{p}\right)}-M C_{t+j}\right) Y_{D t+j}(i)=0
$$

\section{B.1.2. Production of the Domestic Output Index}

Because households have identical Dixit-Stiglitz preferences, it is convenient to assume that a representative aggregator combines the differentiated intermediate products into a composite homeproduced good $Y_{D t}$ :

$$
Y_{D t}=\left[\int_{0}^{1} Y_{D t}(i)^{\frac{1}{1+\theta_{p}}} d i\right]^{1+\theta_{p}}
$$

The aggregator chooses the bundle of goods that minimizes the cost of producing $Y_{D t}$, taking the price $P_{D t}(i)$ of each intermediate good $Y_{D t}(i)$ as given. The aggregator sells units of each sectoral output index at its unit cost $P_{D t}$ :

$$
P_{D t}=\left[\int_{0}^{1} P_{D t}(i)^{\frac{-1}{\theta_{p}}} d i\right]^{-\theta_{p}}
$$

\section{B.1.3. Production of Consumption and Investment Goods}

Final consumption goods are produced by a representative consumption goods distributor. This firm combines purchases of domestically-produced goods with imported goods to produce a final consumption good $\left(C_{A t}\right)$ according to a constant-returns-to-scale CES production function:

$$
C_{A t}=\left(\omega_{C}^{\frac{\rho_{C}}{1+\rho_{C}}} C_{D t}^{\frac{1}{1+\rho_{C}}}+\left(1-\omega_{C}\right)^{\frac{\rho_{C}}{1+\rho_{C}}}\left(\varphi_{C t} M_{C t}\right)^{\frac{1}{1+\rho_{C}}}\right)^{1+\rho_{C}}
$$

where $C_{D t}$ denotes the consumption good distributor's demand for the index of domesticallyproduced goods, $M_{C t}$ denotes the distributor's demand for the index of foreign-produced goods, (see the household problem below); then the corresponding element of $\psi_{t, t+j}$ equals $\xi_{t, t+j}$ divided by the probability that the specified state will occur. 
and $\varphi_{C t}$ reflects costs of adjusting consumption imports. The final consumption good is used by both households and by the government. ${ }^{\text {B. } 3}$ The form of the production function mirrors the preferences of households and the government sector over consumption of domestically-produced goods and imports. Accordingly, the quasi-share parameter $\omega_{C}$ may be interpreted as determining the preferences of both the private and public sector for domestic relative to foreign consumption goods, or equivalently, the degree of home bias in consumption expenditure. Finally, the adjustment cost term $\varphi_{C t}$ is assumed to take the quadratic form:

$$
\varphi_{C t}=\left[1-\frac{\varphi_{M_{C}}}{2}\left(\frac{\frac{M_{C t}}{C_{D t}}}{\frac{M_{C t-1}{ }^{a}}{C_{D t-1}}-1}\right)^{2}\right] .
$$

This specification implies that it is costly to change the proportion of domestic and foreign goods in the aggregate consumption bundle, even though the level of imports may jump costlessly in response to changes in overall consumption demand. We assume that the adjustment costs for each distributor depend on distributor's current import ratio $\frac{M_{C t}}{C_{D t}}$ relative to the economy-wide ratio in the previous period ${\frac{M_{C t-1}}{C_{D t-1}}}^{a}$, so that adjustment costs are external to individual distributors.

Given the presence of adjustment costs, the representative consumption goods distributor chooses (a contingency plan for) $C_{D t}$ and $M_{C t}$ to minimize its discounted expected costs of producing the aggregate consumption good:

$$
\begin{aligned}
& \min _{C_{D t+k}, M_{C t+k}} \mathbb{E}_{t} \sum_{k=0}^{\infty} \psi_{t, t+k}\left\{\left(P_{D t+k} C_{D t+k}+P_{M t+k} M_{C t+k}\right)\right. \\
& \left.+P_{C t+k}\left[C_{A, t+k}-\left(\omega_{C}^{\frac{\rho_{C}}{1+\rho_{C}}} C_{D t+k}^{\frac{1}{1+\rho_{C}}}+\left(1-\omega_{C}\right)^{\frac{\rho_{C}}{1+\rho_{C}}}\left(\varphi_{C t+k} M_{C t+k}\right)^{\frac{1}{1+\rho_{C}}}\right)^{1+\rho_{C}}\right]\right\} .
\end{aligned}
$$

The distributor sells the final consumption good to households and the government at a price $P_{C t}$, which may be interpreted as the consumption price index (or equivalently, as the shadow cost of producing an additional unit of the consumption good).

\footnotetext{
B.3 Thus, the larger-scale model constrains the import share of government consumption to equal that of private consumption.
} 
We model the production of final investment goods in an analogous manner, although we allow the weight $\omega_{I}$ in the investment index to differ from that of the weight $\omega_{C}$ in the consumption goods index. ${ }^{\text {B.4 }}$

\section{B.2. Households and Wage Setting}

We assume a continuum of monopolistically competitive households (indexed on the unit interval), each of which supplies a differentiated labor service to the intermediate goods-producing sector (the only producers demanding labor services in our framework) following Erceg, Henderson and Levin (2000). A representative labor aggregator (or "employment agency") combines households' labor hours in the same proportions as firms would choose. Thus, the aggregator's demand for each household's labor is equal to the sum of firms' demands. The aggregate labor index $L_{t}$ has the Dixit-Stiglitz form:

$$
L_{t}=\left[\int_{0}^{1}\left(\zeta N_{t}(h)\right)^{\frac{1}{1+\theta_{w}}} d h\right]^{1+\theta_{w}},
$$

where $\theta_{w}>0$ and $N_{t}(h)$ is hours worked by a typical member of household $h$. The parameter $\zeta$ is the size of a household of type $h$, and effectively determines the size of the population in the home country. The aggregator minimizes the cost of producing a given amount of the aggregate labor index, taking each household's wage rate $W_{t}(h)$ as given, and then sells units of the labor index to the production sector at their unit cost $W_{t}$ :

$$
W_{t}=\left[\int_{0}^{1} W_{t}(h)^{\frac{-1}{\theta_{w}}} d h\right]^{-\theta_{w}} .
$$

The aggregator's demand for the labor services of a typical member of household $h$ is given by

$$
N_{t}(h)=\left[\frac{W_{t}(h)}{W_{t}}\right]^{-\frac{1+\theta_{w}}{\theta_{w}}} L_{t} / \zeta .
$$

We assume that there are two types of households: households that make intertemporal consumption, labor supply, and capital accumulation decisions in a forward-looking manner by maxi-

\footnotetext{
B.4 Government spending is assumed to fall exclusively on consumption, so that all investment is private investment.
} 
mizing utility subject to an intertemporal budget constraint (FL households, for "forward-looking"); and the remainder that simply consume their after-tax disposable income (HM households, for "hand-to-mouth" households). The latter type receive no capital rental income or profits, and choose to set their wage to be the average wage of optimizing households. We denote the share of

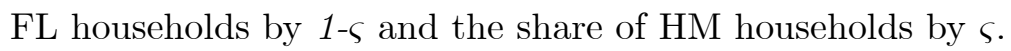

We consider first the problem faced by FL households. The utility functional for an optimizing representative member of household $h$ is

$$
\begin{aligned}
& \mathbb{E}_{t} \sum_{j=0}^{\infty} \beta^{j}\left\{\frac{1}{1-\sigma}\left(C_{t+j}^{O}(h)-\varkappa C_{t+j-1}^{O}-C \nu_{c t+j}\right)^{1-\sigma}+\right. \\
& \left.\frac{\chi_{0} Z_{t+j}^{1-\sigma}}{1-\chi}\left(1-N_{t+j}(h)\right)^{1-\chi}+\mu_{0} F\left(\frac{M B_{t+j+1}(h)}{P_{C t+j}}\right)\right\},
\end{aligned}
$$

where the discount factor $\beta$ satisfies $0<\beta<1$. As in Smets and Wouters (2003, 2007), we allow for the possibility of external habit formation in preferences, so that each household member cares about its consumption relative to lagged aggregate consumption per capita of forward-looking agents $C_{t-1}^{O}$. The period utility function depends on an each member's current leisure $1-N_{t}(h)$, his end-of-period real money balances, $\frac{M B_{t+1}(h)}{P_{C t}}$, and a preference shock, $\nu_{c t}$. The subutility function $F($.$) over real balances is assumed to have a satiation point to account for the possibility of a$ zero nominal interest rate; see Eggertsson and Woodford (2003) for further discussion. B.5 The (log-linearized) consumption demand shock $\nu_{c t}$ is assumed to follow an $\operatorname{AR}(1)$ process:

$$
\nu_{c t}=\rho_{\nu} \nu_{c t-1}+\varepsilon_{\nu_{c}, t}
$$

Forward-looking household $h$ faces a flow budget constraint in period $t$ which states that its combined expenditure on goods and on the net accumulation of financial assets must equal its

\footnotetext{
B.5 For simplicity, we assume that $\mu_{0}$ is sufficiently small that changes in the monetary base have a negligible impact on equilibrium allocations, at least to the first-order approximation we consider.
} 
disposable income:

$$
\begin{gathered}
P_{C t}\left(1+\tau_{C t}\right) C_{t}^{O}(h)+P_{I t} I_{t}(h)+M B_{t+1}(h)-M B_{t}(h)+\int_{s} \xi_{t, t+1} B_{D t+1}(h) \\
-B_{D t}(h)+P_{B t} B_{G t+1}-B_{G t}+\frac{P_{B t}^{*} B_{F t+1}(h)}{\phi_{b t}}-B_{F t}(h) \\
=\left(1-\tau_{N t}\right) W_{t}(h) N_{t}(h)+\Gamma_{t}(h)+T R_{t}(h)+\left(1-\tau_{K t}\right) R_{K t} K_{t}(h)+ \\
P_{I t} \tau_{K t} \delta K_{t}(h)-P_{D t} \phi_{I t}(h) .
\end{gathered}
$$

Consumption purchases are subject to a sales tax of $\tau_{C t}$. Investment in physical capital augments the per capita capital stock $K_{t+1}(h)$ according to a linear transition law of the form:

$$
K_{t+1}(h)=(1-\delta) K_{t}(h)+I_{t}(h)
$$

where $\delta$ is the depreciation rate of capital.

Financial asset accumulation of a typical member of FL household $h$ consists of increases in nominal money holdings $\left(M B_{t+1}(h)-M B_{t}(h)\right)$ and the net acquisition of bonds. While the domestic financial market is complete through the existence of state-contingent bonds $B_{D t+1}$, crossborder asset trade is restricted to a single non-state contingent bond issued by the government of the foreign economy. ${ }^{\text {B. } 6}$

The terms $B_{G t+1}$ and $B_{F t+1}$ represents each household member's net purchases of the government bonds issued by the home and foreign governments, respectively. Each type of bond pays one currency unit (e.g., euro) in the subsequent period, and is sold at price (discount) of $P_{B t}$ and $P_{B t}^{*}$, respectively. To ensure the stationarity of foreign asset positions, we follow Turnovsky (1985) by assuming that domestic households must pay a transaction cost when trading in the foreign bond. The intermediation cost depends on the ratio of economy-wide holdings of net foreign assets to nominal GDP, $P_{D t} Y_{D t}$, and are given by:

$$
\phi_{b t}=\exp \left(-\phi_{b}\left(\frac{B_{F t+1}}{P_{D t} Y_{D t}}\right)\right) .
$$

If the home country is an overall net lender position internationally, then a household will earn a lower return on any holdings of foreign bonds; conversely, if the home country is a net debtor

\footnotetext{
B.6 The domestic contingent claims $B_{D t+1}$ are in zero net supply from the standpoint of home economy as a whole.
} 
position, home households pay a higher return on their foreign liabilities. Given that the domestic government bond in the home economy and foreign bond have the same payoff, the price faced by home residents net of the transaction cost is identical, so that $P_{B t}=\frac{P_{B t}^{*}}{\phi_{b t}}$. The effective nominal interest rate on domestic bonds (and similarly for foreign bonds) hence equals $i_{t}=1 / P_{B t}-1$.

Each member of FL household $h$ earns after-tax labor income, $\left(1-\tau_{N t}\right) W_{t}(h) N_{t}(h)$, where $\tau_{N t}$ is a stochastic tax on labor income. The household leases capital at the after-tax rental rate $\left(1-\tau_{K t}\right) R_{K t}$, where $\tau_{K t}$ is a stochastic tax on capital income. The household receives a depreciation write-off of $P_{I t} \tau_{K t} \delta$ per unit of capital. Each member also receives an aliquot share $\Gamma_{t}(h)$ of the profits of all firms and a lump-sum government transfer, $T R_{t}(h)$ (which is negative in the case of a tax). Following Christiano, Eichenbaum and Evans (2005), we assume that it is costly to change the level of gross investment from the previous period, so that the acceleration in the capital stock is penalized:

$$
\phi_{I t}(h)=\frac{1}{2} \phi_{I} \frac{\left(I_{t}(h)-I_{t-1}\right)^{2}}{I_{t-1}} .
$$

In every period $t$, each member of FL household $h$ maximizes the utility functional (B.44) with respect to its consumption, investment, (end-of-period) capital stock, money balances, holdings of contingent claims, and holdings of domestic and foreign bonds, subject to its labor demand function (B.43), budget constraint (B.46), and transition equation for capital (B.47). In doing so, a household takes as given prices, taxes and transfers, and aggregate quantities such as lagged aggregate consumption and the aggregate net foreign asset position.

Forward-looking (FL) households set nominal wages in staggered contracts that are analogous to the price contracts described above. In particular, with probability $1-\xi_{w}$, each member of a household is allowed to reoptimize its wage contract. If a household is not allowed to optimize its wage rate, we assume each household member resets its wage according to:

$$
W_{t}(h)=\omega_{t-1}^{\iota w} \omega^{1-\iota_{w}} W_{t-1}(h),
$$


where $\omega_{t-1}$ is the gross nominal wage inflation rate in period $t-1$, i.e. $W_{t} / W_{t-1}$, and $\omega=\pi$ is the steady state rate of change in the nominal wage (equal to gross price inflation since steady state gross productivity growth is assumed to be unity). Dynamic indexation of this form introduces some element of structural persistence into the wage-setting process. Each member of household $h$ chooses the value of $W_{t}(h)$ to maximize its utility functional (B.44) subject to these constraints.

Finally, we consider the determination of consumption and labor supply of the hand-to-mouth (HM) households. A typical member of a HM household simply equates his nominal consumption

spending, $P_{C t}\left(1+\tau_{C t}\right) C_{t}^{H M}(h)$, to his current after-tax disposable income, which consists of labor income plus lump-sum transfers from the government:

$$
P_{C t}\left(1+\tau_{C t}\right) C_{t}^{H M}(h)=\left(1-\tau_{N t}\right) W_{t}(h) N_{t}(h)+T R_{t}(h) .
$$

The HM households are assumed to set their wage equal to the average wage of the forwardlooking households. Since HM households face the same labor demand schedule as the forwardlooking households, this assumption implies that each HM household works the same number of hours as the average for forward-looking households.

\section{B.3. Monetary Policy}

As in the simple benchmark model, the currency union central bank is assumed to adhere to a Taylor-type policy rule although we allow here for some inertia in the interest rate reaction function that is captured by the term $\gamma_{i} i_{t-1}^{C U}$ :

$$
i_{t}^{C U}=\left(1-\gamma_{i}\right)\left(\psi_{\pi} \pi_{t}^{C U}+\psi_{x} x_{t}^{C U}+\gamma_{i} i_{t-1}^{C U}+\varepsilon_{M, t} .\right.
$$

The monetary policy shock, $\varepsilon_{M, t}$, which we use when we estimate some of the model parameters in Section 6.2 , is assumed to be normally and idependently estimated with zero mean and standard deviation $\sigma_{M}$. 
When monetary policy is subject to the ZLB, the policy rule is modified as follows:

$$
i_{t}^{C U}=\max \left(-i,\left(1-\gamma_{i}\right)\left(\psi_{\pi} \pi_{t}^{C U}+\psi_{x} x_{t}^{C U}+\gamma_{i} i_{t-1}^{C U}\right)\right.
$$

where $i$ is the steady state nominal interest rate: as before, $i_{t}^{C U}$ measures the currency union policy rate as a deviation from steady state, so that $i_{t}^{C U}=-i$ implies that the policy rate is zero when expressed in levels.

\section{B.4. Fiscal Policy}

The government does not need to balance its budget each period, and issues nominal debt $B_{G t+1}$ at the end of period $t$ to finance its deficits according to:

$$
\begin{gathered}
P_{B t} B_{G t+1}-B_{G t}=P_{C t} G_{t}+T R_{t}-\tau_{N t} W_{t} L_{t}-\tau_{C t} P_{C t} C_{t}-\tau_{K t}\left(R_{K t}-\delta P_{I t}\right) K_{t} \\
-\left(M B_{t+1}-M B_{t}\right)
\end{gathered}
$$

where $C_{t}$ is total private consumption. Equation (B.54) aggregates the capital stock, money and bond holdings, and transfers and taxes over all households so that, for example, $T R_{t}=\int_{0}^{1} T R_{t}(h) d h$. The taxes on capital $\tau_{K t}$ and consumption $\tau_{C t}$ are assumed to be fixed, and the ratio of real transfers to (trend) GDP, $t r_{t}=\frac{T R_{t}}{P_{t} Y}$, is also fixed. ${ }^{\text {B.7 }}$ Check footnote for comment! Government purchases have no direct effect on the utility of households, nor do they affect the production function of the private sector.

When we estimate the model, the process for the (log of) government spending is given by an $\operatorname{AR}(1)$ process:

$$
\left(g_{t}-g\right)=\rho_{G}\left(g_{t-1}-g\right)+\varepsilon_{g, t}
$$

where $\varepsilon_{g, t}$ is independently normally distributed with zero mean and standard deviation $\sigma_{G} \cdot{ }^{\text {B. } 8}$

\footnotetext{
B.7 Given that the central bank uses the nominal interest rate as its policy instrument, the level of seigniorage is determined by nominal money demand.

B.8 When we simulate the effects of higher spending in Sections 6.3 and 6.4, we instead assume that spending follows an $\mathrm{MA}(12)$ process, i.e. $g_{t}-g=\Sigma_{s=0}^{11} \varepsilon_{g, t-s}$.
} 
We assume that policymakers in the core and periphery adjust labor income taxes to stabilize the debt/GDP ratio and the deficit. Specifically, the labor tax rate evolves according to:

$$
\tau_{N t}-\tau_{N}=\nu_{1}\left(\tau_{N t-1}-\tau_{N}\right)+\left(1-\nu_{1}\right)\left[\nu_{2}\left(b_{G t}-b_{G}\right)+\nu_{3}\left(\Delta b_{G t+1}-\Delta b_{G}\right)\right]
$$

\section{B.5. Resource Constraint and Net Foreign Assets}

The home economy's aggregate resource constraint can be written as:

$$
Y_{D t}=C_{D t}+I_{D t}+\phi_{I t}+\frac{\zeta^{*}}{\zeta} M_{t}^{*}
$$

where $\phi_{I t}$ is the adjustment cost on investment aggregated across all households. The final consumption good is allocated between households and the government:

$$
C_{A t}=C_{t}+G_{t}
$$

where $C_{t}$ is (per capita) private consumption of FL (optimizing) and HM households:

$$
C_{t}=(1-\varsigma) C_{t}^{O}+\varsigma C_{t}^{H M}
$$

Total exports may be allocated to either the consumption or the investment sector abroad:

$$
M_{t}^{*}=M_{C t}^{*}+M_{I t}^{*}
$$

The evolution of net foreign assets can be expressed as:

$$
\frac{P_{B, t}^{*} B_{F, t+1}}{\phi_{b t}}=B_{F, t}+P_{M t}^{*} \frac{\zeta^{*}}{\zeta} M_{t}^{*}-P_{M t} M_{t} .
$$

This expression can be derived from the budget constraint of the FL households after imposing the government budget constraint, the consumption rule of the HM households, the definition of firm profits, and the condition that domestic state-contingent non-government bonds $\left(B_{D t+1}\right)$ are in zero net supply

Finally, we assume that the structure of the foreign country is isomorphic to that of the home country. 


\section{B.6. Production of capital services}

In an augmented variant of the model, we incorporated a financial accelerator mechanism into both country blocks of our benchmark model following the basic approach of Bernanke, Gertler and Gilchrist (1999). Thus, the intermediate goods producers rent capital services from entrepreneurs (at the price $R_{K t}$ ) rather than directly from households. Entrepreneurs purchase physical capital from competitive capital goods producers (and resell it back at the end of each period), with the latter employing the same technology to transform investment goods into finished capital goods as described by equations B.47) and B.49). To finance the acquisition of physical capital, each entrepreneur combines his net worth with a loan from a bank, for which the entrepreneur must pay an external finance premium (over the risk-free interest rate set by the central bank) due to an agency problem. Banks obtain funds to lend to the entrepreneurs by issuing deposits to households at the interest rate set by the central bank, with households bearing no credit risk (reflecting assumptions about free competition in banking and the ability of banks to diversify their portfolios). In equilibrium, shocks that affect entrepeneurial net worth - i.e., the leverage of the corporate sector - induce fluctuations in the corporate finance premium. ${ }^{\text {B.9 }}$

\section{B.7. Solution Method and Calibration}

To analyze the behavior of the model, we log-linearize the model's equations around the nonstochastic steady state. Nominal variables are rendered stationary by suitable transformations. To solve the unconstrained version of the model, we compute the reduced-form solution of the model for a given set of parameters using the numerical algorithm of Anderson and Moore (1985), which provides an efficient implementation of the solution method proposed by Blanchard and

\footnotetext{
B.9 We follow Christiano, Motto and Rostagno (2008) by assuming that the debt contract between entrepreneurs and banks is written in nominal terms (rather than real terms as in Bernanke, Gertler and Gilchrist, 1999). For further details about the setup, see Bernanke, Gertler and Gilchrist (1999), and Christiano, Motto and Rostagno (2008). An excellent exposition is also provided in Christiano, Trabandt and Walentin (2007).
} 
Kahn (1980). When we solve the model subject to the non-linear monetary policy rule (??), we use the techniques described in Hebden, Lindé and Svensson (2009). An important feature of the Hebden, Lindé and Svensson algorithm is that the duration of the liquidity trap is endogenously determined. ${ }^{\text {B.10 }}$

The model is calibrated at a quarterly frequency. As in the simple benchmark model, the country size parameter $\zeta=1 / 3$, so that the periphery (the home country) constitutes $1 / 3$ of euro area output. The trade share of the periphery is set to 15 percent of periphery GDP. This pins down the trade share parameters $\omega_{C}$ and $\omega_{I}$ for the home country under the additional assumption that the import intensity of consumption is equal to $3 / 4$ that of investment. The trade share of the foreign economy is thus 7.5 percent. We assume that $\rho_{C}=\rho_{I}=2$, consistent with a long-run price elasticity of demand for imported consumption and investment goods of 1.1. The adjustment cost parameters are set so that $\varphi_{M_{C}}=\varphi_{M_{I}}=1$, which slightly damps the near-term relative price sensitivity. The financial intermediation parameter $\phi_{b}$ is set to a very small value (0.00001), which is sufficient to ensure the model has a unique steady state.

The utility functional parameter $\sigma$ is set equal to 1 to ensure that the model exhibit balanced growth, while the parameter determining the degree of habit persistence in consumption is estimated to be $\varkappa=0.877$ (as discussed in the text). The Frisch elasticity of labor supply is set to 0.4 (so $\chi=2.5)$. The utility parameter $\chi_{0}$ is set so that employment comprises one-third of the household's time endowment, while the parameter $\mu_{0}$ on the subutility function for real balances is set at an arbitrarily low value (so that variation in real balances do not affect equilibrium allocations). We set the share of HM agents $\varsigma=0.65$, implying that these agents account for about one third of aggregate private consumption spending (the latter is much smaller than the population share of HM agents because the latter own no capital).

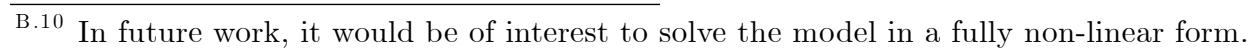


The parameter determining investment adjustment costs is estimated to be $\phi_{I}=1.941$. The depreciation rate of capital $\delta$ is set at 0.03 (consistent with an annual depreciation rate of 12 percent). The parameter $\rho$ in the CES production function of the intermediate goods producers is set to -2 , implying an elasticity of substitution between capital and labor $(1+\rho) / \rho$, of $1 / 2$. The quasi-capital share parameter $\omega_{K}$ - together with the price markup parameter of $\theta_{P}=0.20$ - is chosen to imply a steady state investment to output ratio of 15 percent. In the augmented version of the model with a financial accelerator, our calibration of parameters follows Bernanke, Gertler and Gilchrist (1999). In particular, the monitoring cost, $\mu$, expressed as a proportion of entrepreneurs' total gross revenue, is set to 0.12 . The default rate of entrepreneurs is 3 percent per year, and the variance of the idiosyncratic productivity shocks to entrepreneurs is 0.28 .

As discussed in the text, the Calvo price contract duration parameter is estimated to be $\xi_{p}=$ 0.944 , while the wage contract duration parameter is estimated to be $\xi_{w}=0.871$. We set the degree of price indexation $\iota_{p}=0.65$ and wage indexation indexation $\iota_{w}=0.65$, while the wage markup $\theta_{W}$ $=1 / 3{ }^{\mathrm{B} .11}$ The parameters of the monetary rule are set such that $\gamma_{\pi}=2.5, \gamma_{x}=0$, and $\gamma_{i}=0.7$. With the discount factor set at $\beta=0.99875$ and the inflation target at 2 percent, the steady state nominal interest rate is 2.5 percent.

The parameters pertaining to fiscal policy are intended to roughly capture the revenue and spending sides of euro area government budgets. The share of government spending on goods and services is set equal to 23 percent of steady state output. The government debt to GDP ratio, $b_{G}$, is set to 0.75 , roughly equal to the average level of debt in euro area countries at end-2008. The ratio of transfers to GDP is set to 20 percent. The steady state sales (i.e., VAT) tax rate $\tau_{C}$ is set to 0.2 , while the capital tax $\tau_{K}$ is set to 0.30 . Given the annualized steady state real interest

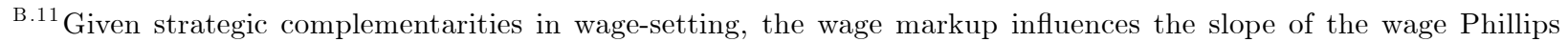
Curve. 
rate (of 0.5 percent), the government's intertemporal budget constraint then implies that the labor income tax rate $\tau_{N}$ equals 0.42 in steady state. We assume an unaggressive tax adjustment rule in (B.56) by setting $\nu_{1}=0.985$ and $\nu_{2}=\nu_{3}=.1$.

Finally, the first order autoregressive coefficient $\rho_{g}$ on the government spending shock is estimated to be 0.92 , while the persistence of the consumption demand shock is set to 0.9 , and the technology shock 0.975 (noting that we assume that government spending follows a moving average when simulating the effects of a core government spending hike). 